\title{
Money and Exchange
}

Whether a theoretical system is realistic or not has been a major concern in economics, particularly in monetary theory, over the past century. Following John R. Hicks's proposal that a realistic monetary theory could be constructed along an evolutionary path, starting with the workings of a real market, this volume considers whether we can look to the medieval economy as the point of departure.

Money and Exchange draws upon the work of Aristotle, scholastic economists, Adam Smith, Karl Marx, William Stanly Jevons, and Léon Walras, as well as some modern monetary theorists, to provide a critical analysis of some basic theories that form the starting point of monetary analysis. It concentrates primarily on certain interrelated and fundamental building blocks of monetary theory, such as the difficulties of barter as the origin of money, the concept of exchange as an equation, the notion of the exchange relation as a relation of equality, the distinction between barter and monetary relations, and money and non-money commodities.

This groundbreaking study dispels some of the old myths and conjectures concerning money and exchange and opens up the way for the development of new approaches to monetary theory-approaches that are both realistic and evolutionary. It will be of particular interest to researchers and students of monetary theory and history and of the history of economic thought.

Sasan Fayazmanesh is Associate Professor of Economics at California State University, Fresno. His current areas of research include monetary history and theory, money and banking, the history, methodology, and philosophy of economics, and the political economy of the Middle East. 


\section{Routledge Studies in the History of Economics}

1 Economics as Literature Willie Henderson

2 Socialism and Marginalism in Economics 1870-1930

Edited by Ian Steedman

3 Hayek's Political Economy The socio-economics of order Steve Fleetwood

4 On the Origins of Classical Economics

Distribution and value from William Petty to Adam Smith

Tony Aspromourgos

5 The Economics of Joan Robinson

Edited by Maria Cristina Marcuzzo, Luigi Pasinetti, and Alesandro Roncaglia

6 The Evolutionist Economics of Léon Walras

Albert Jolink

7 Keynes and the 'Classics'

A study in language,

epistemology and mistaken identities

Michel Verdon
8 The History of Game Theory, Volume 1 From the beginnings to 1945 Robert W. Dimand and Mary Ann Dimand

9 The Economics of W. S. Jevons Sandra Peart

10 Gandhi's Economic Thought Ajit K. Dasgupta

11 Equilibrium and Economic Theory Edited by Giovanni Caravale

12 Austrian Economics in Debate Edited by Willem Keizer, Bert Tieben, and Rudy van Zijp

13 Ancient Economic Thought Edited by B. B. Price

14 The Political Economy of Social Credit and Guild Socialism

Frances Hutchinson and Brian Burkitt

15 Economic Careers Economics and economists in Britain 1930-1970

Keith Tribe 
16 Understanding 'Classical' Economics

Studies in the long-period theory

Heinz Kurz and Neri Salvadori

17 History of Environmental Economic Thought

E. Kula

18 Economic Thought in Communist and PostCommunist Europe Edited by Hans-Jürgen Wagener

19 Studies in the History of French Political Economy From Bodin to Walras Edited by Gilbert Faccarello

20 The Economics of John Rae Edited by O. F. Hamouda, C. Lee, and D. Mair

21 Keynes and the Neoclassical Synthesis

Einsteinian versus Newtonian macroeconomics

Teodoro Dario Togati

22 Historical Perspectives on Macroeconomics

Sixty years after the 'General Theory'

Edited by Philippe Fontaine and Albert Jolink

23 The Founding of Institutional Economics

The leisure class and sovereignty Edited by Warren J. Samuels

24 Evolution of Austrian Economics

From Menger to Lachmann Sandye Gloria
25 Marx's Concept of Money: the God of Commodities Anitra Nelson

26 The Economics of James Steuart Edited by Ramón Tortajada

27 The Development of Economics in Europe since 1945 Edited by A. W. Bob Coats

28 The Canon in the History of Economics

Critical essays

Edited by Michalis

Psalidopoulos

29 Money and Growth Selected papers of Allyn Abbott Young Edited by Perry G. Mehrling and Roger J. Sandilands

30 The Social Economics of Jean-Baptiste Say Markets and virtue Evelyn L. Forget

31 The Foundations of Laissez-Faire

The economics of Pierre de Boisguilbert Gilbert Faccarello

32 John Ruskin's Political Economy Willie Henderson

33 Contributions to the History of Economic Thought Essays in honour of RDC Black Edited by Antoin E. Murphy and Renee Prendergast 
34 Towards an Unknown Marx A commentary on the manuscripts of 1861-63

Enrique Dussel

35 Economics and Interdisciplinary Exchange Edited by Guido Erreygers

36 Economics as the Art of Thought

Essays in memory of

G L S Shackle

Edited by Stephen F. Frowen

and Peter Earl

37 The Decline of Ricardian Economics

Politics and economics in PostRicardian theory

Susan Pashkoff

38 Piero Sraffa

His life, thought and cultural heritage

Alessandro Roncaglia

39 Equilibrium and Disequilibrium in Economic Theory

The Marshall-Walras divide Michel de Vroey

40 The German Historical School The historical and ethical approach to economics Edited by Yuichi Shionoya

41 Reflections on the Classical Canon in Economics Essays in honor of Samuel Hollander

Edited by Sandra Peart and Evelyn Forget
42 Piero Sraffa's Political Economy A centenary estimate Edited by Terenzio Cozzi and Roberto Marchionatti

43 The Contribution of Joseph Schumpeter to Economics Economic development and institutional change Richard Arena and Cecile Dangel

44 On the Development of Long-run Neo-Classical Theory Tom Kompas

45 F. A. Hayek as a Political Economist

Economic analysis and values Edited by Jack Birner, Pierre Garrouste, and Thierry Aimar

46 Pareto, Economics and Society

The mechanical analogy Michael McLure

47 The Cambridge Controversies in Capital Theory

A study in the logic of theory development

Jack Birner

48 Economics Broadly Considered

Essays in honor of Warren

J Samuels

Edited by Steven G. Medema, Jeff Biddle, and John B. Davis

49 Physicians and Political Economy

Six studies of the work of doctor-economists Edited by Peter Groenewegen 
50 The Spread of Political

Economy and the

Professionalisation of

Economists

Economic societies in Europe,

America and Japan in the

nineteenth century

Massimo Augello and

Marco Guidi

51 Historians of Economics and

Economic Thought

The construction of disciplinary

memory

Steven G. Medema and

Warren J. Samuels

52 Competing Economic Theories

Essays in memory of

Giovanni Caravale

Sergio Nisticò and

Domenico Tosato

53 Economic Thought and Policy in Less Developed Europe The $19^{\text {th }}$ century

Edited by Michalis Psalidopoulos and Maria-Eugenia Almedia Mata

54 Family Fictions and Family Facts

Harriet Martineau, Adolphe Quetelet and the population question in England 1798-1859

Brian Cooper

55 Eighteeth-Century Economics Peter Groenewegen

56 The Rise of Political Economy in the Scottish Enlightenment

Edited by Tatsuya Sakamoto and Hideo Tanaka
57 Classics and Moderns in Economics Volume I

Essays on nineteenth and twentieth century economic thought

Peter Groenewegen

58 Classics and Moderns in Economics Volume II

Essays on nineteenth and twentieth century economic thought

Peter Groenewegen

59 Marshall's Evolutionary

Economics

Tiziano Raffaelli

60 Money, Time and Rationality in Max Weber

Austrian connections

Stephen D. Parsons

61 Classical Macroeconomics

Some modern variations and distortions

James C. W. Ahiakpor

62 The Historical School of Economics in England and Japan

Tamotsu Nishizawa

63 Classical Economics and Modern Theory

Studies in long-period analysis

Heinz D. Kurz and

Neri Salvadori

64 A Bibliography of Female Economic Thought

to 1940

Kirsten K. Madden, Janet A. Sietz, and Michele Pujol 
65 Economics, Economists and Expectations

From microfoundations to macroeconomics

Warren Young, Robert Leeson, and William Darity $\mathrm{Jr}$

66 The Political Economy of Public Finance in Britain, 1767-1873

Takuo Dome

67 Essays in the History of Economics

Warren J. Samuels, Willie

Henderson, Kirk D. Johnson, and

Marianne Johnson

68 History and Political Economy

Essays in Honour of

P. D. Groenewegen

Edited by Tony Aspromourgos and

John Lodewijks

69 The Tradition of Free Trade

Lars Magnusson

70 Evolution of the Market Process

Austrian and Swedish economics Edited by Michel Bellet, Sandye Gloria-Palermo, and Abdallah

Zouache

71 Consumption as an Investment The fear of goods from Hesiod to Adam Smith

Cosimo Perrotta
72 Jean-Baptiste Say and the Classical Canon in Economics The British connection in French classicism

Samuel Hollander

73 Knut Wicksell on Poverty

No place is too exalted

Knut Wicksell

74 Economists in Cambridge

A study through their correspondence 1907-1946

Edited by M. C. Marcuzzo and

A. Rosselli

75 The Experiment in the History of Economics

Edited by Philippe Fontaine and

Robert Leonard

76 At the Origins of Mathematical Economics

The economics of A.N. Isnard

(1748-1803)

Richard van den Berg

77 Money and Exchange

Folktales and reality

Sasan Fayazmanesh 


\section{Money and Exchange}

Folktales and reality

\section{Sasan Fayazmanesh}

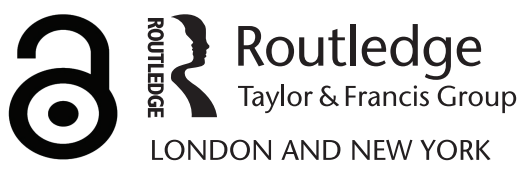


First published 2006 by Routledge

Published 2017 by Routledge

2 Park Square, Milton Park, Abingdon, Oxon OX14 4RN

711 Third Avenue, New York, NY 10017, USA

Routledge is an imprint of the Taylor \& Francis Group, an informa business

Copyright (C 2006 Sasan Fayazmanesh

Typeset in Times New Roman by

Newgen Imaging Systems (P) Ltd, Chennai, India

The Open Access version of this book, available at www.tandfebooks.com, has been made available under a Creative Commons Attribution-Non Commercial-No Derivatives 4.0 license.

Library of Congress Cataloging in Publication Data

A catalog record for this book has been requested

British Library Cataloguing in Publication Data

A catalogue record for this book is available

from the British Library

ISBN 978-0-415-29974-9 (hbk) 


\section{Contents}

Acknowledgments $\quad$ xi

1 Introduction 1

2 The first community and the equation of exchange 9

The origin of money and the nature of exchange 10

Making sense of Aristotle 12

The "primitivist-modernist" controversy 14

The exchange relation 17

Conclusion 23

3 The sons of Adam, justice in exchange, and the medieval economy

Equality and justice in exchange 28

The "abacus manuscripts" 31

The "Rules of Barter" 32

Formalization of the "Rules of Barter" 36

The "difficulties of barter" revisited 39

"Just price" and equality of exchange revisited 41

Conclusion 43

4 The bartering savage and the equation of exchange

The inconvenience of barter and emergence of money 47

Exchange and the meanings of "value" 50

Solving the equation of exchange in the "rude state of society" 56

"Civilized nations" and the solution to the equation of exchange 59

Conclusion 62 
x Contents

5 Primitive communities, the equation of exchange, and proper point of departure

The origin of exchange and money 66

Aristotle and the relation of exchange 69

The relation of exchange and exchange-value 71

Monetary theory and history: the second point of departure 75

Monetary theory and history: the first point of departure 79

Conclusion 82

6 Mademoiselle Zélie and the "scientific" theory of exchange

The difficulties of barter 85

Turning economics into a "science" 89

Jevons's "scientific" theory of exchange 93

Walras and the "scientific" theory of exchange 97

Buying and selling in a moneyless Walrasian world 102

Conclusion 105

7 Neo-Walrasianism, the matrix of exchange, and beyond

Realistic or unrealistic? 109

Neo-Walrasianism and the "matrix of exchange" 112

The "matrix of exchange" and the real economy 117

Post-Clower matrices of exchange 121

Conclusion 126

8 Conclusion

Notes

References

Index 


\section{Acknowledgments}

This book is the culmination of a series of essays written over the years dealing mostly with money and exchange. Some of the essays are published and some remain unpublished. Specifically, Chapter 2 draws from "Barter, Money and Commercial Arithmetic," Journal of the History of Economic Thought (2001) 23, 1: 77-98 (Routledge Journals, Taylor \& Francis). Chapters 4 and 6 incorporate the results of some research appearing in "The Magical, Mystical Paradox of Value," Research in the History of Economic Thought and Methodology (1998) 16: 123-153 (JAI Press). Chapter 5 includes some ideas expressed in "Marx's Semantics and the Logic of the Derivation of Value," Research in the History of Economic Thought and Methodology (1994) 12: 65-91 (JAI Press). Even though the book draws from these earlier essays, every chapter has been written anew in order to present a unified whole.

Since some of the chapters were presented at various meetings of the History of Economics Society, I am grateful to many discussants and participants who made valuable comments. In particular, I would like to thank Professor Robert Clower for reading and commenting on my "Matrix of Exchange and the Real World," presented at the annual meeting of the History of Economics Society, Wake Forest University, Winston-Salem, North Carolina, June 30, 2001. His kind and generous review of that essay encouraged me not only to revise it and incorporate it as Chapter 7 of this book, but also to preface this chapter with some earlier arguments. He, of course, bears no responsibility for any errors of mine.

Above all, I am indebted to Professor Vida Samiian, my friend and partner in life. Even though inundated with heavy academic and administrative responsibilities, she cheerfully read every chapter a number of times for syntax and style. To her, I dedicate this work. 



\section{Introduction}

Whether a theoretical system is realistic or not has been a concern in economics, particularly in the twentieth century. The concern is nowhere more apparent than in monetary theory where the distinction between barter and monetary exchange has often been at the heart of many discussions. For example, in his well-known "A Monetary Theory of Production," John Maynard Keynes distinguished between Alfred Marshall's "real exchange" or "barter economy," where money is "neutral," and the real world "monetary economy," where money matters (Keynes 1933: 408). With regard to the former he wrote:

The distinction which is normally made between a barter economy and a monetary economy depends upon employment of money as a convenient means of effecting exchanges - as an instrument of great convenience, but transitory and neutral in its effect. It is regarded as a mere link between cloth and wheat, or between the day's labor spent on building the canoe and the day's labor spent harvesting the crop. It is not supposed to affect the essential nature of the transaction from being, in the minds of those making it, one between real things, or to modify the motives and decisions of the parties to it. Money, that is to say, is employed, but is treated in some sense as neutral.

(Keynes 1933: 408, emphasis in the original)

With regard to the latter he argued that this is

an economy in which money plays a part of its own and affects motives and decisions and is, in short, one of the operative factors in the situation, so that the course of events cannot be predicted, either in the long or in the short, without a knowledge of the behavior of money between the first state and the last. And it is this which we ought to mean when we speak of a monetary economy.

(Keynes 1933: 408-409, emphasis in the original)

This monetary economy, Keynes went on to argue, corresponds to the "real world" in which "we actually live" (Keynes 1933: 410).

Similar concerns have been raised repeatedly by the Keynesian economists who have referred to the literature on monetary theory, particularly those based 


\section{Introduction}

on the Walrasian general equilibrium, as "unrealistic" and then attempted to construct a theory of money based on the real world. ${ }^{1}$ The Keynesian economists, however, are not alone in arguing for a realistic theory of money. Various monetary theorists, even some Walrasians and neo-Walrasians, have argued the same, as we will see in this book.

One economist who has consistently and elegantly expressed concerns about why monetary theory should be realistic is John R. Hicks. Hicks articulated such sentiments in his early writings when he spoke of the exclusion of money as a medium of exchange in the Walrasian general equilibrium theory and, therefore, the unrealistic nature of the theory. He also expressed the same feelings in his more mature writings. For example, in his "Monetary Theory and History," Hicks states: "Monetary theory is less abstract than most economic theory; it cannot avoid a relation to reality, which in other economic theory is sometimes missing" (Hicks 1967: 156). Hicks's reasoning for his contention appears to be twofold. First, he argues that monetary theory is "topical," often prompted by "particular episodes, by particular experiences of the writer's own time" (Hicks 1967: 156). ${ }^{2}$ For instance, Hicks contrasts Keynes's monetary theory during the Great Depression to the "ossified" monetary theory "in the neoclassical phase," particularly the "dull" question paper "that was set to Marshall by his monetary facts" (Hicks 1967: 157). He also speaks of David Ricardo's monetary writings that "cover a period of War Inflation, in the last stages of British war against Napoleon, a period of reconstruction, and attempted stabilization, after Peace" (Hicks 1967: 157). Ricardo's work, Hicks goes on to say, "like Keynes's, was the result of a challenge - a challenge from contemporary experience" (Hicks 1967: 157). Second, Hicks argues that "money itself has been evolving" and this evolution at times calls for a "radical revision of monetary theory" (Hicks 1967: 157-158). He mentions, for example, the "obvious change in the money medium," from "coins to notes and bank deposits" (Hicks 1967: 158).

The same sentiment is articulated by Hicks in "The Two Triads" lecture where he writes:

One of the chief things which monetary theory ought to explain is the evolution of money. If we can reduce the main lines of that evolution to a logical pattern, we shall not only have thrown light upon history, we shall have deepened our understanding of money, even modern money, itself.

(Hicks 1967: 2)

Along the same lines, in criticizing Léon Walras for excluding the most important function of money in his general equilibrium theory and chiding Don Patinkin for trying to solve the problem by merely cutting the knot, Hicks writes:

I shall begin by constructing a model to which, in other respects, the Walras theory ought to apply exactly. I shall then ask how that model is to be developed, in order that a money, which is to be no more than a means of payment, is to be fitted in. 
We should thus consider what would be the working of a market on which a number of traders meet to exchange a variety of goods: a market which is open on a particular "day," so that it can be studied (as Walras studies in his theory of exchange) in complete isolation from what went before and what is to come after.

If we want to visualize it, we can think of it as one of those great fairs, which played so important a part in the organization of trade in the Middle Ages; or indeed (except in so far as a scale is matter of importance) as the kind of weekly or monthly market which survives in country places all over the world. There are in fact several ways in which a market could be conducted; and from the point of view of monetary theory (though not essentially, as we shall see, from the point of view with which Walras was concerned) it is essential to distinguish them.

(Hicks 1967: 3-4, emphasis in the original)

Setting aside Walras's theory of exchange, which will be discussed later in this book, what Hicks seems to be proposing in the earlier passage is to construct a monetary theory based on the workings of a real market, such as those that were existing in the medieval era. This would be, indeed, an ideal market for "visualization," since it is not as complicated as the modern market and, at the same time, embraces both barter and monetary relations. The distinction between these relations, as well as that between money and non-money commodities, is at the heart of the monetary theory, and Hicks realizes this. Actually, immediately after the earlier discussion, Hicks tries to develop these distinctions.

Unfortunately, in Hicks's attempt to distinguish between direct and indirect exchange and money and non-money commodities, and in his further attempt to align monetary theory with the evolution of money, there is nothing about those "great fairs" of the Middle Ages that was supposed to help us visualize what goes on in a particular market day. Actually, the grand work that Hicks suggests never really materializes and all his attempts to reconstruct monetary theory along an evolutionary path appear to get caught up in the Walrasian problematic.

Could what Hicks envisions, but never delivers, be done? In other words, assuming that monetary theory must be realistic, or evolutionary, could we look at the medieval economy as the point of departure for a theoretical construct? I believe that such a project is not only desirable but also actually possible. But before any reconstruction begins some demolition and removal of old debris must take place.

The demolition, I contend, should start with Aristotle's folktales and conjectures concerning money and exchange. Also included in this demolition should be Aristotle's method of analysis. The method consists of abstract theorizing about the nature of exchange, a kind of theorizing that is completely indifferent to what goes on in the real marketplace. The method also consists of rational reconstruction of monetary history, a reconstruction that is at odds with real monetary history. But the demolition should not stop with Aristotle. Many monetary thinkers who followed in the wake of Aristotle accepted, with some minor modifications, his 


\section{Introduction}

conjectures and adopted his method of analysis. Those works, too, must be considered as nothing more than rational reconstructions and must be set aside. It is only after demolishing the old conjectures and discarding the rationalist method of analysis that a serious reconstruction of monetary theory can begin.

To contribute to the aforementioned aim, in this study I attempt to refute some old folktales and unrealistic theories concerning money and exchange that have dominated monetary theory to this day. Some alternatives are also suggested. The focus of the book, however, is narrow. It concentrates primarily on certain interrelated and fundamental building blocks of monetary theory, such as the theory of the difficulties of barter as the origin of money, the concept of exchange as an equation, the notion of the exchange relation as a relation of equality, and the distinction between barter and monetary relations and money and non-money commodities.

The range of individuals included in this study is also narrow. It surveys, after Aristotle, some scholastics - such as Nicholas Oresme and Thomas AquinasAdam Smith, Karl Marx, William Stanley Jevons, Léon Walras, and some of his followers, as well as a few modern monetary theorists. But this range, I believe, is quite representative of all those who have dealt with the issues raised earlier. Given the focus of the study and individuals chosen, the book is not meant to be a generalized history of monetary theory. ${ }^{3}$ Instead, it is intended to be a critical analysis of some basic and elemental, but dominant, theories that form the starting point of monetary analysis. It is hoped that the study would lead to rethinking some of the old myths and conjectures concerning money and exchange and help open up a way for the development of new approaches to monetary theory, approaches that are realistic and that follow the evolutionary path as suggested by Hicks. The outline of the chapters is as follows.

Chapter 2, as it is apparent from the earlier discussion, deals with Aristotle's influential conjectures concerning the difficulties of barter and the origin of money. After reviewing what he has to say on such issues, various attempts by commentators to make sense of Aristotle's enigmatic writings, particularly those dealing with his equation of exchange, are presented. Subsequently, the so-called primitivist-modernist controversy is visited briefly. This will lead to a discussion of what is missing in such controversies, namely, a critical analysis of Aristotle's concept of exchange as a relation of equality. In this discussion I analyze the properties of barter and monetary relations as conveyed by the language of the marketplace. It is concluded that Aristotle's conjectures concerning money and exchange are incompatible with the history and reality of markets in general.

Chapter 3 plays a pivotal role in this book. It lays the conceptual framework for the analysis of exchange. This is where the kind of economy that Hicks had in mind - the medieval economy - is discussed. If one is looking for a primordial economy in which barter and monetary relations exist side by side, this is the one. But there is another issue that makes the medieval economy a perfect source for visualizing exchange. Unlike the ancient economy, about which we know very 
little, there is plenty of information about markets in the medieval period. The evidence is particularly strong in a number of unique manuscripts left by medieval and renaissance merchants about their market practices. The medieval economy could therefore be used as a case study to distinguish between the properties of barter and monetary relations. It could also be used to test the accuracy of what is usually said about direct and indirect exchange. But before looking at such an economy and developing a formal model of exchange, the scholastic notions of the difficulties of barter, the equation of exchange, and the theory of just price are briefly reviewed. Subsequently, in light of the actual market practices, as documented in the aforementioned manuscripts, it is contended that the scholastic notions, which are mostly Aristotelian in nature, are contrary to the reality of the medieval markets.

Chapter 4 deals with the role of the "savage" in Adam Smith's theory of value. I show how the image of North American Indians replaces that of the divided first family and the barbarians in Aristotle's writings, or the sons of Adam in the scholastic narratives. The savage engages in barter, runs into difficulties, and develops money. Also, the savage solves the equation of exchange by means of his labor bestowed or commanded, a solution that appears to be hard to come by in the age of the scholastics, and even harder in the ancient economy. But this solution, according to Smith, only holds for the first stage of history, that is, the age of hunters. In the age of commerce the labor-bestowed or labor-commanded solution is no longer viable, and Smith reverts to Aristotle's solution to the equation of exchange. It is concluded that nearly 2,000 years after Aristotle, neither the method of rational reconstruction of exchange and money nor the concept of exchange itself has changed in any significant way.

Chapter 5 looks at Karl Marx's theory of the origin of exchange, the difficulties of barter, and the development of money. Unlike many other economists, Marx is familiar with history and puts forward monetary theories that are at times different from others. Nevertheless, some of his conjectures, which are strongly influenced by Aristotle's historiography, cannot be substantiated. The chapter also examines how Marx perfects Aristotle's equation of exchange and reduces the exchange relation to the mathematical relation of equality. In this reduction the role of the concept of exchange-value is also examined. Moreover, since the controversy surrounding Marx's point of departure in Capital and the theoretical exposition of money involves the issue of the existence of a simple commodity production or barter economy, this chapter deals with the controversy and tries to resolve it. Finally, the negative influence of Aristotle on Marx's unique and innovative contributions to monetary theory is discussed.

Chapter 6 begins with William Stanley Jevons's theory of the difficulties of barter and the emergence of money, a theory in which the image of direct exchange between a Parisian singer, Mademoiselle Zélie, and the Society Islanders replaces earlier images of exchange. The theory is more systematic than any other theory presented before. As such, it is very influential and appears in 


\section{Introduction}

modern monetary models. It also appears in many books dealing with money, particularly textbooks. But how does it stand up against reality? More importantly, how does the story fit the utility theory of exchange put forward by Jevons and other marginalist theorists, especially Walras? This chapter tries to answer these questions. In so doing, the chapter looks at Jevons's concepts of the science of economics and scientific exchange, as well as those of Walras. It is contended that given their concepts of science, there is actually no need for the theory of the difficulties of barter and emergence of money. Indeed, it will be shown that money must and will vanish from Jevons and Walras's theories. In the end, Mademoiselle Zélie is completely irrelevant to the "scientific" theory of exchange, a theory that is meant to resemble the physico-mathematical sciences.

Chapter 7 extends the discussion of the topics mentioned earlier to the modern period. In the early part of the twentieth century a controversy arose over whether the Walrasian general equilibrium theory is realistic in the sense of not being based on a hypothetical pure barter economy and being able to incorporate money as a medium of exchange in an essential way. As mentioned earlier, Hicks was one of the main participants in the controversy. But even though the controversy is mostly settled among monetary economists, it still continues among some historians of economic thought. This chapter reviews the controversy and proceeds to look at the unsuccessful neo-Walrasian attempts to incorporate money in the general equilibrium theory. Subsequently, the chapter examines Robert Clower's seminal response to the neo-Walrasians, a response in which he put forward his concept of the matrix of exchange. Even though the concept got lost in the marginalist discussions, the matrix of exchange was a revolutionary concept, since it tried to distinguish between barter and monetary relations and money and nonmoney commodities in a unique fashion. To what extent these distinctions conform to the medieval economy will be examined next. Afterward, the direction that monetary theory took following Clower's matrix of exchange will be reviewed briefly. This will include the decentralized exchange theory and a unique attempt to reformulate Marx's theory of exchange and money. It will be concluded that even though the neo-Walrasian foundation of monetary theory was destroyed in the latter half of the twentieth century there was little to replace it with.

Concluding remarks appear in Chapter 8. But before embarking on the journey, a cautionary note about terminology is in order.

Economists, particularly monetary theorists, often use such words as "real" and "realism." But they do not necessarily employ these expressions with the same care or concern shown by philosophers, especially philosophers of science. In

philosophy, the word "real" is used often in an ontological sense, emphasizing that something exists. Similarly, "realism," as contrasted with "idealism," is a philosophical position that emphasizes the existence of entities. ${ }^{4}$ This, of course, might be called "ontological realism." Besides this, one might also recognize "semantic" and "epistemological" realism (Mäki 1998a: 404). The first pertains to the "view concerning such things as references and truth," and the second 
has to do with whether that which is said to exist is also "knowable" (Mäki 1998a: 406-407).

Within the earlier classification one might also recognize "scientific realism" as a particular philosophical trend. Scientific realism and its close associates, "critical" and "transcendental realism"-which have become influential in some economic circles mainly due to the writings of Bhaskar $(1978,1983)$ and Lawson (1997, 1998) - generally hold that objects of scientific enquiry are themselves structured and nonreducible to the events that they generate. This is, of course, very much in accord with Marx's belief that "all science would be superfluous if the form of appearance of things directly coincided with their essence" (Marx 1981: 956). Similar to Marx, scientific realists generally believe that neither nature nor a capitalist economy could be understood at the level of sense perception. Instead, one must locate the deeper structures, or the "internal framework" in Marx's terminology, that generate what appears to the senses or, to use Marx's expression again, the "apparent framework" (Marx 1977: 174-175).

But most economists and, particularly, monetary theorists are not concerned with the different classifications of realism or the schools of thought within the realist project. When, in reference to such entities as assumptions, statements, or theories, they talk about "real" or "realism" they often mean whether these entities are or are not realistic. ${ }^{5}$

There is also a second problem with the economists' cursory use of the earlier expressions. When economists imply or say that something is or is not "realistic," it is often not clear what is meant exactly by "realistic." As Nagel points out, an economist might refer to a statement as "unrealistic" in at least three senses: (1) the statement "does not give 'exhaustive' description of some object"; (2) the statement is "believed to be either false or highly improbable on the available evidence"; (3) the statement holds only under highly "purified" or "idealized" conditions and "is not intended to designate anything actual" (Nagel 1963: 214-215).

The list, of course, is not comprehensive and one can find other senses in which the expression "realistic" is used in economics. ${ }^{6}$ But the list is representative and the three senses do, indeed, appear in the literature dealing with monetary matters. For example, as it was mentioned earlier and will be seen later, when Hicks contends that the Walrasian general equilibrium theory is not "realistic," he often means that it is not exhaustive in the sense that an important component of the real monetary world, namely money as a medium of exchange, is missing from the theory. Or when he pleads for a more realistic theory of money by arguing that we should look at the workings of the great fairs of Europe, he implies that the Walrasian general equilibrium theory does not refer to any actual market. The same, of course, holds for his argument that monetary theory should be evolutionary to reflect the development of money in the real world. The third sense of being unrealistic also appears in the literature dealing with monetary matters. When, for example, some monetary historians or theorists argue against the prevalent concept of pure barter economy they basically contend that the 


\section{Introduction}

concept is false or highly improbable since we have no evidence for the existence of such an economy.

With this caveat concerning the usage of the expressions "real," "realism," and "realistic" the work at hand can begin. As we shall see, much of the theories of exchange and money that are challenged in this work are simply untrue or extremely unlikely, since they are basically no more than folktales. Others are mostly idealized theories and do not refer to anything actual. 


\section{The first community and the equation of exchange}

Aristotle's writings on money and exchange have exerted a powerful influence on monetary theory. This influence has been noted by a number of historians of economic thought and scholars of classical writings. Schumpeter, for example, wrote with regard to Aristotle's theory of money: "Whatever its shortcoming, this theory, though never unchallenged, prevailed substantially to the end of the nineteenth century and even beyond. It is the basis of the bulk of all analytical work in the field of money" (Schumpeter 1954: 63). Similarly, in a recent study of the so-called primitivist and modernist controversy, Meikle observes that

Aristotle's theory of money substantially informed treatments of the subject into the twentieth century, and most schools of modern economic thought have had claims of Aristotelian paternity made on their behalf, including Jevonsian utility theory, mathematical economics, neoclassical economics and Marxism.

(Meikle 1995: 1)

The influence of Aristotle on monetary theory is puzzling. His writings on exchange and money, relative to those on nature, are rather sporadic and meager. More importantly, following the Scientific Revolution, the natural sciences dispensed with Aristotle's conjectures altogether on various grounds, including not conforming to the facts of the natural world. Yet, when it comes to the theories of money and exchange there is no sign of weakening of the Aristotelian hold, as we will see in this book.

What accounts for the longevity of Aristotle's influence on monetary theory? Is this enduring influence due to the compatibility of the facts of the monetary world with his writings? In this chapter I search for some answers to these questions. Specifically, in the first section, I review Aristotle's scanty but highly influential commentaries on the nature and origin of money and exchange. The second section deals with various interpretations of Aristotle's monetary writings. Here, numerous attempts to make sense of his enigmatic comments concerning exchange and equality, as well as his possible intentions for making such comments, are reviewed. In the third section I look at the so-called primitivist-modernist controversy. Different perspectives about the nature and 
extent of markets in the ancient world are presented in this section. The fourth section deals with what is missing from the controversies surrounding Aristotle's monetary writings: a critical analysis of his concept of the relation of exchange and the reduction of this relation to the relation of equality. By analyzing the properties of simple monetary expressions in any marketplace, it is argued that Aristotle's concept of equality of exchange is faulty and contrary to the facts of the real monetary world. This section also sets the stage for the analysis of the exchange relation in the forthcoming chapters. Concluding remarks concerning the primitivist-modernist controversy and continued Aristotelian influence on monetary theory appear in the last section.

\section{The origin of money and the nature of exchange}

Aristotle's famous passages concerning monetary matters are found primarily in two of his works: Politica and Ethica Nicomachea. In the former he traces the origin of money, and in the latter he discusses his theory of exchange. But before looking at the relevant passages in these works, it should be noted that when it comes to exchange many historians of economic thought rightfully start with the distinction in Politics between the two uses of an object:

Of everything which we possess there are two uses: both belong to the thing as such, but not in the same manner, for one is the proper, and the other the improper or secondary use of it. For example, a shoe is used for wear, and is used for exchange; both are uses of the shoe. He who gives a shoe in exchange for money or food to him who wants one, does indeed use the shoe as a shoe, but this is not its proper or primary purpose, for a shoe is not made to be an object of barter.

(Aristotle 1946, Book I, Part IX: 1257ª-10)

Setting aside the concept of "proper" and "improper" use, this important distinction, of course, would appear later in the writings of many generations of economic thinkers and would play an important role in the construction of models of exchange.

Another issue that is often mentioned as Aristotle's contribution to monetary theory is his recognition of the functions of money as a medium of exchange and as a unit of account. Schumpeter's reference to the long-lasting influence of the Aristotelian thought in the field of money primarily refers to this contribution.

Aristotle, however, set forth other important theories that have had a long-lasting impact on monetary thinking, namely, those that are concerned with the issue of the origin of money and the nature of exchange. His account of the origin of money appears shortly after the earlier passage in the context of his discussion of retail trade and the "art of getting wealth":

In the first community, indeed, which is the family, this art is obviously of no use, but it begins to be useful when the society increases. For the members of the family originally had all things in common; later, when the family 
divided into parts, the parts shared in many things, and different parts in different things, which they had to give in exchange for what they wanted, a kind of barter which is still practiced among barbarous nations who exchange with one another the necessaries of life and nothing more; giving and receiving wine, for example, in exchange for corn, and the like. This sort of barter is not part of the wealth-getting art and is not contrary to nature, but is needed for the satisfaction of men's natural wants. The other or more complex form of exchange grew, as might have been inferred, out of the simpler. When the inhabitants of one country became more dependent on those of another, and they imported what they needed, and exported what they had too much of, money necessarily came into use. For the various necessaries of life are not easily carried about, and hence men agreed to employ in their dealings with each other something which was intrinsically useful and easily applicable to the purposes of life, for example, iron, silver, and the like. Of this the value was at first measured simply by size and weight, but in process of time they put a stamp upon it, to save the trouble of weighing and to mark the value.

(Aristotle 1946, Book I, Part IX: 1257ª15-40)

The aforementioned account of the origin of money is somewhat different from that given by Plato. Plato traces the origin of money to the "origin of the city" and the "fact that we are not, any of us self-sufficient; we have all sorts of need... Different individuals, then, form associations with one person to meet one need, and with another person to meet a different need" (Plato 2000: 51). This division of labor and attempt to satisfy different needs would, according to Plato, bring about trade, and this, in turn, would "give rise to a market-place and a currency, a unit of exchange for transactions" (Plato 2000: 53). Even though this account of the origin of money is less fanciful than that of Aristotle's, it is actually the latter's account that is favored by most economists. In one form or another, Aristotle's story has been repeated by many generations of economists up to the present time. The explanation is indeed the backbone of monetary theory to this day, and it is difficult to find a modern textbook that does not repeat some version of it. Yet, in spite of its importance and influence, Aristotle's passage has attracted relatively little scrutiny. ${ }^{1}$ I return to Aristotle's account of the origin of money after dealing with his concept of exchange.

Equally powerful and influential are Aristotle's concepts of the relation and substance of exchange. These concepts appear in a famous passage in Ethica Nicomachea in the context of the discussion of justice. Given the importance of the passage and the fact that it raises many questions, it is best to quote it in its entirety:

Now proportionate return is secured by cross-conjunction. Let A be a builder, $\mathrm{B}$ a shoemaker, $\mathrm{C}$ a house, $\mathrm{D}$ a shoe. The builder, then, must get from the shoemaker the latter's work, and must himself give him in return his own. If, then, first there is proportionate equality of goods, and then reciprocal 


\section{The first community and the equation of exchange}

action takes place, the result we mention will be effected. If not, the bargain is not equal, and does not hold; for there is nothing to prevent the work of the one being better than that of the other; they must therefore be equated. (And this is true of the other arts also; for they would have been destroyed if what the patient suffered had not been just what the agent did, and of the same amount and kind.) For it is not two doctors that associate for exchange, but a doctor and a farmer, or in general people who are different and unequal; but these must be equated. This is why all things that are exchanged must be somehow comparable. It is for this end that money has been introduced, and it becomes in a sense an intermediate; for it measures all things, and therefore the excess and the defect - how many shoes are equal to a house or to a given amount of food. The number of shoes exchanged for a house (or for a given amount of food) must therefore correspond to the ratio of builder to shoemaker. For if this be not so, there will be no exchange and no intercourse. And this proportion will not be effected unless the goods are somehow equal. All goods must therefore be measured by some one thing, as we said before. Now this unit is in truth demand, which holds all things together (for if men did not need one another's goods at all, or did not need them equally, there would be either no exchange or not the same exchange); but money has become by convention a sort of representative of demand; and this is why it has the name "money" (nomisma) - because it exists not by nature but by law (nomos) and it is in our power to change it and make it useless. There will, then, be reciprocity when the terms have been equated so that as farmer is to shoemaker, the amount of the shoemaker's work is to that of the farmer's work for which it exchanges. But we must not bring them into a figure of proportion when they have already exchanged (otherwise one extreme will have both excesses), but when they still have their own goods... Let $\mathrm{A}$ be a house, $\mathrm{B}$ ten minae, $\mathrm{C}$ a bed. $\mathrm{A}$ is half of $\mathrm{B}$, if the house is worth five minae or equal to them; the bed, $\mathrm{C}$, is a tenth of $\mathrm{B}$; it is plain, then, how many beds are equal to a house, viz. five.

(Aristotle 1949, Book V, Part V: 1133a 5-30 and 1133 25 )

Unlike the passage concerning the origin of money, various aspects of the above narrative have been the subject of endless interpretations in the twentieth century alone. Let us briefly examine some of the most popular and well-known interpretations.

\section{Making sense of Aristotle}

Historically, the most controversial part of the above passage appears to be the enigmatic statement that the "number of shoes exchanged for a house... must therefore correspond to the ratio of builder to shoemaker." At least since the medieval era, individuals have tried to make sense of the argument. This is, for example, evident in the complex, but even more puzzling, scholastic representation of the argument as a rectangular figure. Such attempts to find a highly sophisticated mathematical argument in Aristotle's statement have continued well 
into modern times (see, for example, Soudek 1952; Lowery 1979, 1987). These attempts, however, have often been challenged by others as fanciful. For example, Meikle has argued recently that there is no "wonderful mathematics" involved in the sentence at all (Meikle 1995: 142). Instead, he contends that "the ratio of the shoemaker to the builder must equal to $1(\mathrm{~A}: \mathrm{B}=1)$, and in order to correspond with it, the ratio of shoes to houses must equal to 1 also $(x D: C=1)$ " (Meikle 1995: 142). ${ }^{2}$ But a more common reaction to Aristotle's statement is an expression of bewilderment. Schumpeter, for example, after arguing that Aristotle must be trying to compare the labor of different individuals, wrote: "At least, I cannot get any other sense out of this passage" (Schumpeter 1954: 61). An even sharper reaction was that of Finley who had argued that if the statement was meant to be a theory of price, it is a complete "nonsense" (Finley 1977: 149).

There is another aspect of the aforementioned passage that is often hotly debated: If exchange is characterized by equality, which is contended by Aristotle, what makes the goods exchanged commensurable or, to put it differently, what is the substance of exchange? One usual answer to the question is that of Schumpeter's who, after expressing the above-discussed bewilderment, wrote: It seems "Aristotle was groping for some labor-cost theory of price which he was unable to state explicitly" (Schumpeter 1954: 61). The interpretation that the substance of exchange has something to do with labor is, of course, an old and persistent one. As we shall see later on, Marx, for example, restated Aristotle's concept of exchange in the mathematical form of " 5 beds $=1$ house" and contended that Aristotle could not come up with the concept of abstract labor as the common substance of exchange because of the "historical limitation inherent in the society in which he lived" (Marx 1977: 151). ${ }^{3}$ Similar arguments have been made by more recent writers. ${ }^{4}$

There are also some marginalist interpretations of Aristotle's substance of exchange as well. According to these interpretations, Aristotle was groping for some subjective utility theory as the explanation of exchange. Soudek, for example, contends that Aristotle "anticipated by more than 2,000 years Jevons' theory of exchange" (Soudek 1952: 12). This interpretation stems partly from the translation of the Greek word cheria in the passage, which has often been mistranslated as "demand" rather than "need" (Meikle 1995: 29-31; Kaye 1998: 68). A third and more recent interpretation is that Aristotle could not and did not come up with a solution to the puzzle of the substance of exchange, and he, himself, basically admitted it (Meikle 1995).

More importantly, however, it is the general intention of the passage that has been the subject of numerous debates. Even though the passage clearly appears in the context of the discussion of ethics and justice, it is not clear what the purpose of the passage is. Is it meant to be a theory of exchange and price in the actual marketplace? It seems that those who believe that Aristotle anticipated Jevons by some 2,000 years imply that it was. Even those who argue that Aristotle's theory is the anticipation of the labor theory of value seem to argue that the theory was indeed about real exchange and actual market price. Schumpeter, for example, contended that Aristotle's preoccupation with the ethical problem of justice in 


\section{The first community and the equation of exchange}

pricing, that is, "commutative justice," does not mean that he was uninterested in the "analytical problem of actual pricing" or the analysis of "actual market mechanism" (Schumpeter 1954: 60).

The majority of commentators, however, seems to hold that the passage is not a theory of actual market exchange and price. One line of argument is that Aristotle merely tried to set certain criteria for fairness in exchange. Lowery, for example, contends that "Aristotle's analysis of exchange in the Ethics was an attempt to determine the criteria for fairness from the point of view of the Athenian legal process, whether in arbitration or the courts, and it was not an explanation of market forces" (Lowery 1987: 185). But even though Lowery maintains that the passage is not an analysis of the actual market, he still holds that the discussion is in the context of "isolated exchange" or "barter" and that it "served as the foundation not only for Gossen's work but also for Edgeworth's 'contract curve" " (Lowery 1987: 186, 191). But, given that such works ultimately meant to explain actual market prices, it is not quite clear how Aristotle's theory, which was "not an explanation of market forces," is the foundation of these works.

\section{The "primitivist-modernist" controversy}

Another controversy surrounding Aristotle's famous passage revolves around whether it was even possible for Aristotle to write a theory of actual exchange and market price, given the stage of economic development of the Greek society. Here the arguments fall along what the classicists usually refer to as the "modernist" and "primitivist" views. The former view, as stated succinctly by Meikle, is that "the ancient economy is to be understood as an early and restricted version of what we are familiar with today, not as something different in kind, and that it is to be studied by bringing to bear the same economic concepts we use to study the economy of our own time" (Meikle 1995: 2). The latter view, on the other hand, is that the ancient economy is "different in kind, and that the use of modern economic concepts is fatal to our attempt to understand it" (Meikle 1995: 2). Here the definition of economics often enters the controversy as well. If "economics" is to be understood in the "neoclassical" sense of the "study of choice and scarcity," then the tools of the trade are universal and applicable to any form of economic system. But if by "economics" we mean the study of the capitalist economic system, then it might have little relevance to the ancient economy. In the latter case, more substantive issues arise: Were the markets in the ancient economy fundamentally the same as those existing today? If so, how extensive was the reach of these markets?

We get different answers to the aforementioned questions. Some economic historians draw a picture of a vibrant and flourishing market economy at the time of Aristotle that is similar, if not substantially identical, to what we see today. Heichelheim, for example, writes:

The retail markets of Athens proper and the emporium of Piraeus were a gay sight with their varied arrays of booths, tents, and tables, where a kapeloi displayed their wares. There were autopolai too, peasants from neighboring 
lands, fishermen, and craftsmen who sought to sell their own produce, and here and there emporoi could be seen concerned with a little retail trade in their import cargoes. There were similarly varied throngs of peddlers in the streets of Athens ... The principal market-day in Athens was the first of each month when all market-places and streets were packed with people.

(Heichelheim 1964: 65)

Heichelheim's description of the ancient economy is often so vivid, and his account of the market exchanges and the types of goods traded so precise that one gets the feeling that it all happened only yesterday (Heichelheim 1964: 67). His description also gives one the impression that the ancient economy was substantially a capitalist economy - an economy not very different from our own. Indeed, he speaks of fifth-century BC "capitalist promoters who engaged in banking business of every kind and related capitalistic enterprises" (Heichelheim 1964: 74).

Similar views are expressed by Jean-Philippe Levy who writes: "Athenian economics gives one the impression somewhat similar to that of Europe in the nineteenth century, making all the necessary allowances for the different eras. The difference, considerable of course, is nevertheless quantitative rather than qualitative" (Levy 1964: 22-23). Levy, too, goes on to write with great precision and certainty about the market exchanges and the types of goods exchanged. He also speaks of the "movement of capital," the existence of "banks" and "bankers" in a modern sense, and of "even small stock exchanges, which differed from ours only in an absence of regulations" (Levy 1964: 23-27).

A more recent study actually looks at the ancient economy and society from a "banking perspective" and concentrates exclusively on the Athenian "banking reality" (Cohen 1992: 4). Cohen defines a bank as a "business having obligation to repay funds ('deposits') received from multitude of sources, but with the interim right to make loans and investments for its own account" (Cohen 1992: 9). Given this definition, we are told that the Greek "trapeza is undeniably a 'bank'" and that the Athenian economy was a market economy (Cohen 1992: 9). Cohen, however, does not produce any statistical evidence for his claims. Indeed, he writes: "Although it deals with money and finance, this book does not rely on statistics" (Cohen 1992: 26). Instead, all the contentions concerning ancient economy and its modern banking systems are based on a "close reading of texts" (Cohen 1992: 26).

As opposed to this "modernist" view, we have the "primitivist" position exemplified by the likes of Karl Polanyi, who, in analyzing Aristotle's work, wrote:

To go to the root of our approach, classical antiquity was altogether wrongly placed by economic historians along the time scale which led to the market trade. In spite of intensive trading activities and fairly advanced money uses, Greek business life as a whole, was still in the very first beginnings of market trade in Aristotle's time.

(Polanyi 1968: 80) 
Finley seconds this view by stating that the "inapplicability to the ancient world of market-centered analysis was powerfully argued by Max Weber and by his most important disciple among ancient historians, Johannes Hasebroek; in our own day by Karl Polanyi” (Finley 1973: 26).

Finley not only plays down the existence of vibrant markets but also raises doubt as to whether it is actually possible to have a detailed and precise knowledge of the ancient economy. For example, he repeatedly refers to the "absence of statistics, and hence of our difficulty in trying to quantify ancient economic data" (Finley 1973: 23). ${ }^{5} \mathrm{He}$ states: "It is frustrating to try to analyze landholding in classical Athens from precisely five figures for individual estates... Our lack of precise knowledge about Roman holding is no less frustrating" (Finley 1973: 24). Similarly, he contends that we do not even know the "number of slaves in Greece or Italy at any given time, not even the number in any particular community or in any particular possession, save exceptions" (Finley 1973: 71). Moreover, he argues that when we do know some economic facts, they generally do not reveal the existence of markets as we know them today. With reference to the Roman world, he writes that the

typical "peasant market" was a place where peasants (and no doubt village craftsmen) met from a radius of 5 or 6 miles in order to fill gaps in necessities by exchange with each other; there were only a few things a peasant could not produce himself... The paucity of coin finds in genuinely rural areas is no accident.

(Finley 1973: 107)

With regard to such things as investment in antiquity, he contends that there "was no clear conception of the distinction between capital costs and labor costs, no planned ploughing back of profits, no long term loans for productive purposes" (Finley 1973: 117). On the issue of manufacturing in the ancient economy, Finley writes that "David Hume was not seriously mistaken when he could 'not remember a passage in any ancient author where the growth of the city is ascribed to the establishment of a manufacture" "(Finley 1973: 137). Similarly, he writes that the excavation of ancient districts has never shown "Guildhalls and Bourses which, next to the cathedrals, are to this day the architectural glories of the great medieval cities of Italy, France, Flanders, the Hansa towns, or England" (Finley 1973: 137). In general, Finley contends that given the "household self-sufficiency" of the ancient medieval economy, there was little need for the market:

The local peasantry remained a constant: men with the small holdings we have examined, even free citizen-peasants, represent the lowest and most inelastic possible market for urban production. That is why "in most peasant societies, markets are periodic rather than permanent and continuous... the per capita demand for goods sold in the market is small, the market area is limited by primitive transport technologies, and the aggregate demand is therefore insufficient to support permanent shops." $"$

(Finely 1973: 138) 
In sum, the controversies surrounding Aristotle's comments concerning exchange and money are mostly confined to (1) the nature and extent of markets in the ancient world; (2) whether Aristotle was groping for a theory of exchange and price or merely the criteria for fairness in exchange; (3) what Aristotle could or could not have possibly meant by the "number of shoes exchanged for a house... must therefore correspond to the ratio of builder to shoemaker"; and (4) Aristotle's concept of the substance of exchange.

Absent from these controversies are any critical analysis of Aristotle's undifferentiated concept of exchange, his reduction of the relation of exchange to the concept of equality, the compatibility of such a reduction with real market practices, and some possible reasons for such a reduction. Also, absent from most debates is Aristotle's concept of the origin of money that seems to tie closely with his concept of exchange. Given that such absences have had a profound effect on the development of monetary theory, I attempt in the following section to provide a critical analysis of Aristotle's concept of the relation of exchange and the origin of money.

\section{The exchange relation}

Aristotle, similar to many generations of economists that would follow him, hardly drew a clear line of demarcation between the relation of barter and monetary relation. This is evident in many of his statements. For example, as we saw earlier, in the context of proper and improper use of objects he states: "He who gives a shoe in exchange for money or food to him who wants one, does indeed use the shoe as a shoe" (Aristotle 1946, Book I, Part IX: 1257¹0). Here, by "exchange" Aristotle clearly means both barter and monetary transaction. This is even clearer in the Ethica Nicomachea when he states: "That exchange took place thus before there was money is plain; for it makes no difference whether it is five beds that exchange for a house, or the money value of five beds" (Aristotle 1949, Book V, Part V: 1133²5).

Moreover, Aristotle views the relation of exchange as a relation of equality in a mathematical sense. Whether this is only ideal or real it makes very little difference for monetary theory, since, as we see in the forthcoming chapters, from here onward the relation of exchange will be viewed as a relation of equality. But is the relation of barter identical to monetary relation and, moreover, can either of these be conceptualized as a mathematical relation of equality? I answer these questions at length in Chapter 3 by examining direct and indirect exchange in the medieval economy, an economy about which we have plenty of information, unlike the ancient economy. But for the time being, we can analyze certain properties of the relation of exchange that one finds in any real market. These relations, such as "exchanges for," "buys," and "sells," not only are found in the ancient markets but are also expressed in the writings of Aristotle as well. Yet, he does not and, perhaps, given the stage of economic development, could not analyze the mathematical properties of these expressions. Examining such properties, however, is not difficult and, indeed, in some sense Aristotle himself paves the way for such an analysis. 


\section{The first community and the equation of exchange}

Let us start with Aristotle's concept of the "proper" use of an object or what the classical economists later called "value in use." One can rethink this concept more concisely as a set of classes of useful objects designated by $U$. For example, Aristotle's "shoes" and "houses" constitute two sets of classes of objects. On such sets one can define certain binary relations that are encountered in any real market. The relations are "purchase(s)"or "buy(s)" represented by $P$, "sell(s) for" symbolized by $S$, and "barter(s) for" designated by $B$. In addition to these relations, we can define a "monetary relation" symbolized by $M$ and an "exchange relation" represented by $E$. Each of these relations requires its own analysis both from a qualitative and a quantitative perspective. I first concentrate on the former aspect.

The qualitative relation "barter(s) for," or $B \subset U \times U$, can be viewed as deus ex machina that either does or does not allow direct exchange. We can graphically depict such a procedure by the following figure, where "+" indicates the occurrence of direct exchange and "-" designates the opposite. ${ }^{7}$

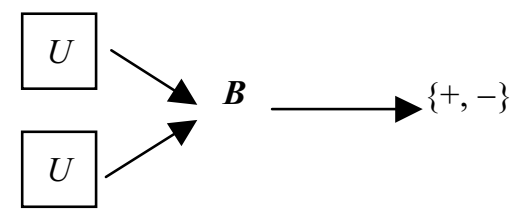

Looking at any actual market, one can say that such a relation is not reflexive, since a useful object never "barters for" itself. The relation, however, is clearly symmetric, since $U_{i} B U_{j}$ implies $U_{j} B U_{i}$, for all $i, j=1, \ldots, n$. It is, however, difficult to say whether the relation is transitive or intransitive without specific information about market practices in the ancient economy. We return to this issue in the analysis of the medieval market in Chapter 3 , but we can assume here, without any loss of generality, that the relation $B$ is transitive, that is, $U_{i} B U_{j}$ and $U_{j}$ $B U_{k}$ imply $U_{i} B U_{k}$, for all $i, j, k=1, \ldots, n$.

Given this formulation, one could give a more precise meaning to Aristotle's concept of "object of barter" or what a classical economist might call "value in exchange." We can define the set of classes of objects of barter, $V$, as any class of useful objects that "barters for" another, that is, $V=\left\{U: U_{i} B U_{j}\right.$, for all $i, j=1, \ldots, n$, and $i \neq j\}$. Obviously, in the ancient economy many useful objects were excluded from such a set.

The qualitative relation "purchase(s)," or $P$, however, is very different from "barter(s) for." It consists of the binary relation $P \subset U_{\mathrm{m}} \times U$ :

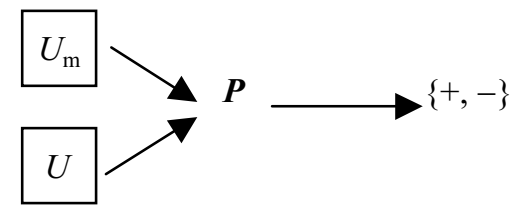


where $U_{\mathrm{m}}$ is the class of "money-objects" or, to use a more modern expression, the class of "money commodities." $U_{\mathrm{m}}$, as in Aristotle's time, consists of coins that have a specific use, that is, they circulate other useful objects.

Looking at the properties of $P$, we can say that such a relation is clearly not reflexive, since no class of useful objects "purchases itself." Also, unlike $B$, the relation $P$ is not symmetric, since $U_{\mathrm{m}} P U_{i}$ does not imply $U_{i} P U_{\mathrm{m}}$. And, since the relation is not symmetric, it is also not transitive.

The third qualitative relation "sell(s) for," $S \subset U \times U_{\mathrm{m}}$, can be viewed as the exact opposite of the relation $P$.

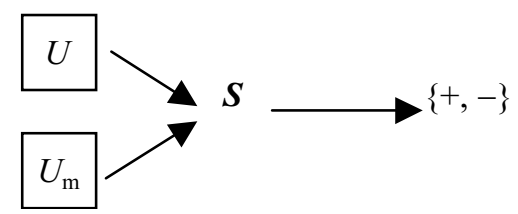

Similar to $P$, the relation $S$ is neither reflexive nor symmetric nor transitive.

Given the relations "purchase(s)" and "sell(s) for," we can define the qualitative monetary relation, $M \subset U \times U$, as the union of the two relations, "purchase(s)" and "sell(s) for," that is, $M=P \cup S$.

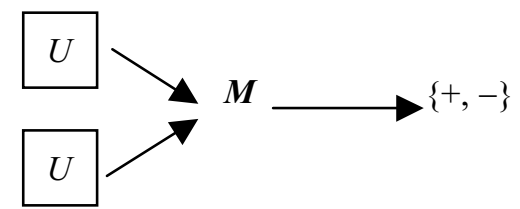

The relation $M$ is not reflexive. But it is symmetric, since $U_{i} M U_{\mathrm{m}}$ implies that $U_{\mathrm{m}} M U_{i}$. The relation, however, is not transitive, since $U_{i} M U_{\mathrm{m}}$ and $U_{\mathrm{m}} M U_{j}$ do not imply $U_{i} M U_{j}$.

The ancient economy, however, similar to the medieval economy that will be examined in Chapter 3, seems to embrace both barter and monetary relations. One can therefore view the exchange relation, to which Aristotle refers, as the union of direct and indirect exchanges and define the qualitative relation "exchange(s) for," $E$, as $E=B \cup M$. This relation, $E \subset U \times U$, is not reflexive. But it is symmetric since $U_{i} E U_{j}$ implies that $U_{j} E U_{i}$, for all $i, j=1, \ldots n$. Assuming that barter relation is transitive, $E$ is also transitive, since $U_{i} E U_{j}$, $U_{j} E U_{k}$ implies $U_{i} E U_{k}$, for all $i, j=1, \ldots, n$.

This analysis concentrates on the qualitative aspect of exchange. But Aristotle, contrary to many later economic thinkers who became mostly concerned with the qualitative aspect of exchange, appears to have been more interested in the quantitative aspect, since he refers to such things as " $a$ shoe," "five beds," or " $a$ house." This requires examining the relations from a quantitative perspective as well. 


\section{The first community and the equation of exchange}

One can start with the quantitative relation of barter, or "barter(s) for." This relation must now be redefined on the set of units of classes of useful objects $U$, which will be designated by $u$. Let $\beta$ be such a relation, and let $b_{i j}$ stand for a certain quantity of $U_{j}$ that barters for a unit of $U_{i}$. We can say that $b_{i j} u_{j}$ is the $U_{j}$-barter-value of $u_{i}$. This concept, as will be discussed in later chapters, is reminiscent of the classical and Marxian notion of "exchange-value of something," but it avoids the usual ambiguities associated with the expression (see Fayazmanesh 1998a, 1994). Now, if a class of useful objects $U_{i}$ does not barter for $U_{j}$, we can assume that it has no $U_{j}$-barter-value. In that case, we can let $\mathrm{b}_{i j}=0$.

As far as reflexivity and symmetry are concerned, the relation $\beta$ is similar to $B$. But is it necessarily true that if $B$ is transitive, $\beta$ is also transitive? That is, can we say that if $U_{i} B U_{j}$ and $U_{j} B U_{k}$ imply $U_{j} B U_{k}$, then $b_{i j} u_{i} \beta u_{j}$ and $u_{j} \beta b_{j k} u_{k}$ imply that $b_{i j} u_{i} \beta b_{j k} u_{k}$ ? $^{8}$ The answer is negative. As we see in Chapter $3, \beta$ is transitive only if the kinds of cheating that one encounters in the medieval markets, such as barter values not reflecting prices, do not occur. However, in all probability the ancient markets, similar to those that came after it, particularly in the medieval era, were characterized not by fairness and equality but by swindle and inequality. Indeed, as Meikle points out, Herodotus gives a glimpse of actual ancient market practices when he tells us that Cyrus the Great refers to the Greek merchants as the "men who, in the middle of their cities, set up places where they gather to cheat each other with oath" (Meikle 1995: 86). ${ }^{9}$ If this is the case, then $\beta$ is for the most part non-transitive.

The quantitative counterparts of "purchase(s)," "sell(s) for," and "monetary relation" can similarly be defined, as will be done in the later chapters when it becomes necessary. The properties of these quantitative relations are identical to those of the qualitative relations and, therefore, there is no need for elaboration. However, even though the quantitative counterpart of the relation "exchange(s) for" is symmetric and non-reflexive, it might be intransitive if barter is fraught with deceit.

Let us now return to Aristotle. In light of what was said earlier, his assertion that it "makes no difference whether it is five beds that exchange for a house, or the money value of five beds" is absolutely wrong. As the earlier analysis shows, the relation of barter is very different from a monetary relation. A house might "barter for" five beds. But a house does not "buy" five beds. Moreover, 5 minae do not "barter for" a house, but they "buy" a house. Similarly, a house does not "buy" five minae. To put it more succinctly, and to use Patinkin's aphorism, to which we return in Chapter 7: "Money buys goods, and goods do not buy money" (Patinkin 1965: xxiii). ${ }^{10}$ But Aristotle has no such understandings. He does not analyze the properties of the relation of barter and monetary relation in a real market. He, therefore, does not see that direct exchange and indirect exchange are fundamentally different, and that in the real world money plays a unique role.

Aristotle's concept of equality of exchange is also flawed and incompatible with the facts of the real monetary world. Under no condition can either the 
relation of barter or monetary relation be viewed as a relation of equality in a mathematical sense. In mathematics, the relation of equality, which for the first time was symbolized by "=" in the writings of the renaissance mathematician Robert Recorde (1557), is defined on the set of numbers. Moreover, this relation is reflexive, symmetric, and transitive. "Barter(s) for," on the other hand, either as a qualitative or as a quantitative relation involves heterogeneous objects. Furthermore, as a qualitative relation, "barter(s) for" is not an equivalence relation, since it is not reflexive. In addition to being non-reflexive, its quantitative counterpart is non-transitive, if cheating occurs.

The same can be said, even more strongly, about the monetary relation. Such a relation is never an equivalence relation, since it is neither reflexive nor transitive. Thus Aristotle's mathematical relation of equality cannot signify the monetary relation either. Finally, even if we combine all the relations, as Aristotle unconsciously does under the rubric of "exchange(s) for," the resulting relation of exchange will still not be an equivalence relation, since it is surely non-reflexive and, if cheating takes place, it is also non-transitive.

The above argument rules out attempts to justify Aristotle's reduction of the exchange relation to equality by contending that such a reduction takes place only in an ideal state. To begin with, the nature of Aristotle's ideal state is not at all clear. Just before the famous passage, quoted earlier, Aristotle wrote:

These names, both loss and gain, have come from voluntary exchange; for to have more than one's own is called gaining, and to have less than one's original share is called losing, e.g. in buying and selling and in all other matters in which the law has left people free to make their own terms; but when they get neither more nor less but just what belongs to themselves, they say that they have their own and they neither lose nor gain.

Therefore the just is intermediate between a sort of gain and a sort of loss, viz. those which are involuntary; it consists in having an equal amount before and after the transaction.

(Aristotle 1949, Ethica Nicomachea, Volume IX, Book V, Part V: 1132 ${ }^{\mathrm{b}} 11-20$ )

Does this "intermediate between a sort of gain and a sort of loss" mean that no profit is made in exchange? Or could it mean that in exchange no one is swindled? In the latter case, what does it mean to be swindled? Could it mean selling a good above its usual or normal price? Or does it mean that the price of a good does not reflect the correct amount of some substance embodied in the good? There are no answers to such questions in the Ethica Nicomachea. But, however one tries to answer these questions and interpret the ideal state, there is still no justification for reducing the relation of exchange to the mathematical relation of equality, since the former, unlike the latter, is never an equivalence relation.

But what led Aristotle, as well as many generations of economic thinkers who followed him, to think of the exchange relation in terms of the mathematical relation of equality? The explanation lies partly in semantic ambiguity. Consider 


\section{The first community and the equation of exchange}

Aristotle's example of exchange between a house, " $A$," a shoe, " $C$," and the money of account, " $B$." Technically speaking, one can say that $C$ and $A$ "sell for" 1 and 5 units of the money of account, " $B$," respectively. One could also say that $A$ might "barter for" five $C$ s. What Aristotle does, however, is to say that " $A$ is half of $B$ " and " $C$ is a tenth of $B$ " (Aristotle 1949, Book V, Part V: 1133b25, emphasis added). In this loose language, "is" or "is worth" becomes "equal" or, to put it mathematically, $A=B / 2$ and $C=B / 10$. From this simple semantic ambiguity it follows that "five beds are equal to a house," or $A=5 C$. We will see, in the forthcoming chapters, the same ambiguities and conclusions in the writings of many generations of economic thinkers that followed Aristotle.

In reaching the conclusion that $A=5 C$, Aristotle's concept of "substance" of exchange also plays a role. True to his search for finding the substance of all natural phenomena, Aristotle was trying to find the material of exchange as well. This is clearly evident when he states that the just exchange "consists in having an equal amount before and after the transaction" (Aristotle 1949, Ethica Nicomachea, Volume IX, Book V, Part V: 1132b20). But an "equal amount" of what? Aristotle is clearly groping for some substance that makes exchange equal but, as Meikle (1995) points out, he cannot find it. In the absence of such a known substance, Aristotle settles for money as a proxy:

Thus they are equals and associates just because this equality can be affected in their case. Let A be a farmer, C food, B a shoemaker, D his product equated to C. If it had not been possible for reciprocity to be thus effected, there would have been no association of the parties. That demand holds things together as a single unit is shown by the fact that when men do not need one another, i.e. when neither needs the other or one does not need the other, they do not exchange, as we do when some one wants what one has oneself, e.g. when people permit the exportation of corn in exchange for wine. This equation [in exchange] therefore must be established. And for the future exchange - that if we do not need a thing now we shall have it if ever we do need it - money is as it were our surety; for it must be possible for us to get what we want by bringing the money. Now the same thing happens to money itself as to goods-it is not always worth the same; yet it tends to be steadier. This is why all goods must have a price set on them; for then there will always be exchange, and if so, association of man with man. Money, then, acting as a measure, makes goods commensurate and equates them; or neither would there have been association if there were not exchange, nor exchange if there were not equality, nor equality if there were not commensurability. Now in truth it is impossible that things differing so much should become commensurate, but with reference to demand they may become so sufficiently. There must, then, be a unit, and that fixed by agreement (for which reason it is called money); for

it is this that makes all things commensurate, since all things are measured by money.

(Aristotle 1949, Book V, Part V: 1133 5 5-20) 
The above narrative reinforces the concept of exchange as an equation, since it implies that hidden behind " $A=5 C$ " - which mathematically makes no sense-is another equation: "certain units of demand = certain units of demand." demand or, more correctly, need does not have any known units of measurement, one can look at another equation: "certain units of money = certain units of money" or " $B / 2=5(B / 10) . " 12$ However, since money itself "is not always worth the same," according to Aristotle, it is not a perfect measure.

The narrative also contains a number of points concerning the concept of price that are worth noting. When he contends that in the absence of any known measurable substance money acts as an equalizer in exchange, Aristotle also adds that "all goods must have a price set on them." But this argument defies his concept of primordial exchange or bartering economy when, presumably, there is no price. Furthermore, the narrative seems to imply that price itself acts as an equalizing force in exchange. But this is a meaningless contention as well, since the price of a good tells us nothing more about the equality of exchange than does its barter values. The issue can be illuminated in terms of the previous analysis by letting $\lambda$ and $\beta$ to represent, respectively, the relations "sell(s) for" and "barter(s) for" defined on the set $u$. If barter and monetary exchanges are both feasible and no cheating takes place and if $u_{i}$ and $u_{j}$, respectively, sell for $p_{i \mathrm{~m}}$ and $p_{j \mathrm{~m}}$ amounts of a unit of money commodity, $u_{\mathrm{m}}$, then $u_{i} \lambda p_{i \mathrm{~m}} u_{\mathrm{m}}, u_{j} \lambda p_{j \mathrm{~m}} u_{\mathrm{m}}$, and $\left(u_{i} / p_{i \mathrm{~m}}\right) \beta$ $\left(u_{j} / p_{j \mathrm{~m}}\right)$. Here, we can say that $p_{i \mathrm{~m}} u_{\mathrm{m}}$ and $p_{j \mathrm{~m}} u_{\mathrm{m}}$ are, respectively, prices of $u_{i}$ and $u_{j}$. We can also say that $\left(p_{i \mathrm{~m}} / p_{j \mathrm{~m}}\right) u_{j}$ is the $U_{j}$-barter-value of $u_{i}$. However, the concept of price of $u_{i}$, or $p_{i \mathrm{~m}} u_{\mathrm{m}}$, expresses no more equality in exchange than does the concept of $U_{j}$-barter-value of $u_{i}$, or $\left(p_{i \mathrm{~m}} / p_{j \mathrm{~m}}\right) u_{j}$.

\section{Conclusion}

The "modernist/primitivist" debate, as mentioned earlier, mostly revolves around the issue of whether, given the stage of economic development in the ancient world, Aristotle could or could not write a theory of money and exchange, whether he was actually searching for such a theory or merely looking for criteria for fairness in exchange, whether his geometry of exchange was a profound mathematical idea or merely nonsense, and whether his concept of substance of exchange was this or that. In light of what was said earlier, many aspects of these debates appear to be less significant.

Whether the markets in the ancient economy were or were not well developed, for instance, is not that crucial for evaluating Aristotle's theory of exchange and money because the theory has very little to offer in the first place and has no relevance to any actual market whatsoever. In this theory there is no distinction between direct and indirect exchange, no analysis of the properties of barter and monetary relations, and no concept of money commodity as distinct from non-money commodity. Furthermore, Aristotle's semantic confusions and the concept of the substance of exchange result in his reduction of the relation of exchange, which is a non-equivalence relation in reality, to the mathematical relation of equality, which is an equivalence relation. Here it does not matter what 


\section{The first community and the equation of exchange}

the substance of exchange is or whether the exchange is fair or unfair. Whatever the substance and the context in which exchange takes place, the relation of exchange is not a relation of equality. Finally, if there is nothing mathematically profound about Aristotle's concept of the relation of exchange, then it is hard to imagine that his more complicated, and even less clear, geometry of exchange represents any profound mathematical concept.

One can also say that Aristotle's theory of the origin of money, similar to his concept of exchange, has nothing to do with reality. Even though his primordial theory of how money came into being sounds simple and rational, it is nevertheless fictitious. The first community or family, its lack of exchange, its division into parts, the subsequent barter of such things as wine for corn, the development of more complex forms of exchange, the difficulties associated with carrying the necessities of life, the agreement among men to employ useful objects, the stamping of these objects, etc., are all figments of Aristotle's imagination and have no historical support. Even his reference to the exchange among "barbarians" is imaginary, since we have no evidence of any systematic exchange among these "barbarians" without the use of money.

Setting aside the fictitious nature of Aristotle's theory of the origin of money, one can also say that the story does not even square with his concept of exchange as equality. If systematic exchange is possible without the use of money, as in the case of the primordial exchange or the exchange among "barbarians," then it is not necessary for money to act as the equalizing substance of exchange; nor is it necessary, as mentioned earlier, for price to act as the equalizing force.

In sum, Aristotle's theories of money and exchange help us understand the monetary world no more than his theories of nature enhance our understanding of the natural world. The latter theories, of course, were successfully challenged and purged from the natural sciences centuries ago for being internally inconsistent and incompatible with the facts of the world. Galileo, for example, in his Dialogue Concerning the Two Chief World Systems (1632) and Two New Sciences (1638) effectively demolished the Aristotelian model of the physical world by using a combination of logical arguments and references to nature. In his famous challenge to Aristotle's concept of velocity, for instance, Galileo wrote:

Aristotle says that "an iron ball of one hundred pounds falling from a height of one hundred cubits reaches the ground before a one-pound ball has fallen a single cubit." I say that they arrive at the same time. You find, on making the experiment, that the larger outstrips the smaller by two finger-breadths.

(Galileo 1638: 68)

In monetary theory, however, we cannot resort to experimentation to prove that Aristotle was wrong. Nevertheless, we can still resort to monetary history, monetary practices, and, as did Galileo, logic to show that Aristotle's ideas were both incompatible with the real world and internally inconsistent. Yet many generations of economists have refused to do that. Indeed, as mentioned earlier, not only do various schools of monetary theory continue to claim Aristotelian 
paternity proudly, but they also keep alive and disseminate, one way or the other, his theories of money and exchange. Why that is the case is hard to say. But it seems that many economists have been, and remain to this day, perfectly content with Aristotle's method of analysis, a method that consists of abstract, speculative, and rational reconstruction with no direct reference to the real world. As we see in Chapter 3, it is this method of analysis that the scholastics adopted in constructing their theories of money and exchange, including the just price theory, at a time when merchants were engaged in all sorts of swindling in the market. It is also this same method of analysis that many generations of monetary thinkers have adopted afterward, as will be shown in the following chapters. 


\section{The sons of Adam, justice in exchange, and the medieval economy}

In the first paragraph of the first chapter of the De Moneta, and under the heading "Why Money was invented," Nicholas Oresme writes:

"When the Most High divided to the nations their inheritance, when $\mathrm{He}$ separated the sons of Adam, He set the bounds of the people."1 Next, men were multiplied on the earth, and possessions were divided to the best advantage. The result of this was that one man had more than he needed of one commodity, while another had little or none of it, and of another commodity the converse was true... Men therefore began to trade by barter: one man gave another a sheep for corn, another gave his labor for bread or wool, and so with other things... But as this exchange and transport of commodities gave rise to many inconveniences, men were subtle enough to devise the use of money to be the instrument for exchanging the natural riches which of themselves minister to human need. For money is called "artificial riches" seeing that a man who abounds in it may die of hunger; as appears from Aristotle's example of the greedy king.

(Oresme 1956: 4)

Even though written in the fourteenth century, the above account of the origin of money is essentially the same as that of Aristotle: in the first community or family there was no exchange, but once the family was divided, exchange began, and, subsequently, the difficulties of barter led to the invention of money. There are, of course, some differences between the two narratives. One obvious difference is the biblical flavor of the narrative. But there is something else. Not only men exchanged goods for goods, writes Oresme, but they also exchanged labor for goods. To this, Oresme adds in the sixth chapter of the De Moneta: "For if a man gives bread or bodily labor in exchange for money, the money he receives is as much his as the bread or bodily labor of which he (unless he were slave) was free to dispose" (Oresme 1956: 10).

The concept of exchanging labor for goods or money, which cannot be found in Aristotle, is quite telling. It indicates the spread of markets in the age of scholasticism and its influence on monetary theory. Let me briefly touch upon each of these issues before dealing with the main subject of this chapter, which is 
the compatibility of the monetary theories of the scholastics with the prevailing market practices of the time.

Our knowledge of the spread of world trade and its influence on economic thinking has changed considerably over time. When Marx wrote his Capital he contended that the world "trade and world market date from the sixteenth century, and from then the modern history of capital starts to unfold" (Marx 1977: 247). As such, Marx believed that scientific economic analysis began only in the seventeenth century when the growth of economy was such that certain abstractions, for example, value as congealed abstract labor, became possible (Marx 1977: 174-175). Given this line of thinking, which will be discussed in Chapter 5, Marx contended that Aristotle could not come up with the abstract concept of labor because of his historical limitation. But Marx does not appear to have been aware of the extent of growth of the world market in the thirteenth and fourteenth centuries. As Hadden has commented on Marx's dating of capitalism, "before the advent of capital in Marx's sense, relations of exchange and commerce had begun proliferating so that the ultimate appearance of capital could take place" (Hadden 1994: 49). To this one must add Langholm's comment that it "is a matter of historical irony that the Age of Reason had cut Marx off from the scholastic tradition which had long since found its way to a type of labor explanation of the precise textual focus which he argues against Aristotle" (Langholm 1979: 76).

The discovery of the rapid growth of markets in the age of scholasticism is, therefore, relatively new, and it is often expressed in glowing terms. Raymond de Roover (1953: 23), for example, writes with reference to the thirteenth century that it is a period characterized by "drastic change in the methods of doing business or in the organization of business enterprise." Similarly, Bridbury (1992: 154) argues that the thirteenth century, as most economic historians would have it, is the "culminating age of medieval achievement." Some recent studies of the scholastics era have produced even greater claims. Joel Kaye, for instance, argues that it is the monetized economy of the fourteenth century that explains the natural philosophy of the scholastic writers and "their preoccupation with measurement, gradation, and the quantification of qualities" (Kaye 1998: 2). Indeed, Kaye goes on to argue that monetary practices in the marketplace led individuals, such as Buridan and Oresme, to develop highly sophisticated proto-mechanistic or protoscientific view of nature, a view that would ultimately make the development of the "new" science by Copernicus and Galileo possible (Kaye 1998: 246). Similarly, Diana Wood contends that from "the late twelfth century the European economy underwent a spectacular transformation" (Wood 2002: 5). ${ }^{2}$

If the growth of monetized economy is as spectacular as some historians would have it, then one would expect drastic changes in monetary theory relative to that of Aristotle's. As Oresme's concept of exchange of labor for goods and money or the scholastics concept of "just price" indicates, there are, of course, some changes. But despite these changes monetary theory remained essentially Aristotelian with respect to two fundamental assumptions. First, as we have seen in the case of Oresme, it is assumed that the origin of money lies in the difficulties 
of barter. Second, following Aristotle, it is argued that exchange is characterized by equality.

In this chapter I argue that these fundamental assumptions are contrary to the medieval market practices, which unlike the ancient economy is quite known to us. That is, not only was barter not difficult in the age of commercial revolution, but it was also carried out side by side with monetary exchanges and, indeed, in some cases was preferred to monetary transactions. Furthermore, the medieval exchange was fraught with fraud and deceit and this made the Aristotelian concept of equality in exchange even more meaningless. To be more specific, in the first section I review the concept of equality and justice in the writings of the scholastics, particularly that of Thomas Aquinas. Various interpretations of "just price" are looked at briefly and it is concluded that whatever the interpretation, the just price theory is incompatible with the real market practices as conveyed in the medieval manuscripts. The second section is devoted to explaining the nature and structure of these medieval or "abacus manuscripts." The third section deals with the "rules of barter" that one finds in these writings. Here, various barter mechanisms are discussed, and it is shown that the lack of arithmetical knowledge can result in one being cheated in barter. Indeed, the more complex the barter scenario, the greater the chance of losing in trade. Using the notations introduced in Chapter 2, the fourth section presents formal models of different barter scenarios. This helps to achieve a clearer understanding of the medieval exchange and sets the stage for further analysis in future chapters. The fifth section returns to the issue of the difficulties of barter. In light of what had been said in the previous sections, it is argued that the scholastic notion of the difficulties of barter is contrary to the reality of the medieval market, since not only is barter not difficult in this period, but it is also actually preferred to monetary exchange. This is followed, in the sixth section, by the argument that the scholastic notion of "just price" and equality of exchange is also contrary to the medieval market practices, which are characterized by swindle, deceit, and inequality. Concluding remarks concerning the methodological legacy of Aristotle and the discrepancy between scholastics' ideal market as opposed to the real one are presented in the last section.

\section{Equality and justice in exchange}

With the growth of markets in the late Middle Ages and the emergence of such abstract concepts as labor, the Aristotelian concept of equality of exchange becomes more complicated. Such complications are evident in the writings of not only the later generations of scholastics, such as Nicholas Oresme, but also in that of the earlier generation, such as Thomas Aquinas.

As we saw in the previous chapter, the closest that Aristotle came to a substance that makes exchange equal was "need" or "demand." But since need or demand cannot be quantified, Aristotle settled for the next best alternative: money. In his commentary on Aristotle, Aquinas repeated all of these. He wrote, 
for example, that "things can be measured by one standard... this one standard which truly measures all things is demand. This includes all commutable things inasmuch as everything has a reference to human need" (Aquinas 1964: 426). But he went on to say, "because currency as a measure ascertaining quantity retains its value longer, all goods must be evaluated in currency ... Money equates commutable goods, as a certain measure making them commensurate" (Aquinas 1964: 428). ${ }^{3}$

In between these, Aquinas tossed in other possible substances of exchange not found in Aristotle. One substance is "expense." This appears when Aquinas tries to explain why the exchange between "one house" and "one sandal" is not one to one by arguing that "for the builder incurs more expense in building one house than a shoemaker in making one sandal" (Aquinas 1964: 421). Another substance mentioned by Aquinas that Aristotle had barely touched upon is "work" or "labor." Aquinas argues that when the "work of the shoemaker exceeds in number the work of the farmer" then "many sandals are exchanged for one bushel of wheat" or "if the farmer gave a bushel of wheat for a sandal, he would have a surplus of labor in his product" (Aquinas 1964: 426-427). ${ }^{4}$ Yet another substance is "labor and cost," as in the case when to have "just exchange, as many sandals must be exchanged for one house" as the builder "exceeds the shoemaker in his labor and cost" (Aquinas 1964: 426). Similar substances were put forward by Albertus Magnus, Aquinas's teacher, when he wrote: "as the builder exceeds the shoemaker in labor and expense and in utility of his work, so many shoes are required to equal the house in value." 5 Here, of course, the usefulness of work is also tossed in as a possible substance of equal exchange.

These new substances appear to have been attempts to make sense of Aristotle's nonsensical equation of exchange. They try to argue that hidden behind Aristotle's equation, "A is equal to $5 \mathrm{C}$," there must be something like "the number of work necessary to produce $\mathrm{A}$ is equal to the number of work necessary to produce $5 \mathrm{C}$ " or "the expenses associated with the production of $\mathrm{A}$ is equal to the expenses associated with the production of 5C." Indeed, we see traces of the classical theory of value when Aquinas unconsciously corrects Aristotle's equation of exchange by saying that "a number of sandals are equal in value to one house" (Aquinas 1964: 426 , emphasis added). ${ }^{6}$ Yet what "value" means is defined nowhere.

The extent to which potential substances of exchange, such as "labor and expenses," play a role in the formation of the scholastics "just price" theory has been, and continues to be, a subject of controversy. As de Roover writes in a seminal paper: "In the view of many economists the just price is a nebulous concept invented by pious monks who knew nothing of business or economics and were blissfully unaware of market mechanism" (de Roover 1958: 418). According to this view, de Roover argues, the producer "should not charge more for his labor and expenses than would enable him to maintain his status" (de Roover 1958: 419). In contrast to this view, de Roover contends that "the just price did not correspond to cost of production as determined by the producer's social status, but was simply the current market price" (de Roover 1958: 420-421). 


\section{Justice in exchange and the medieval economy}

de Roover's contention has not been accepted universally. Some have argued that there was an evolution in economic thinking from the concept of just price as one covering labor and expense to one being identical to the current market price, particularly in the case of Thomas Aquinas. Baldwin, for example, contended that in "his Commentary to the Ethics, Thomas considered both the cost of production and the current price as possible bases for the just price. When, however, he wrote the Secunda-secundae of Summa theologica 5 or 6 years later he definitely decided for the current price" (Baldwin 1959: 78). But this view too has been challenged. Langholm, for example, pointed out that the two works were "written simultaneously" and, therefore, there could not have been an evolution of thought (Langholm 1979: 33). In opposition to Baldwin and de Roover, Langholm put forward a third view: the just price theory was a precursor to the Marshallian "long-run equilibrium price" (Langholm 1979: 34). According to this marginalist reading, Aristotle provided fodder for the scholastic writers to develop some elementary marginalist supply and demand theory:

Albertus Magnus reasoned that the normal level of price must have something to do with cost... Thomas and many others repeated it. But Thomas also reasoned that the normal price must reflect human wants; many later authors repeated this and developed it into a demand theory. As a matter of fact, each of the original commentators suggested both criteria, but circumstances caused their emphases to differ, hence a cost theory has come to be associated with Albert, a market (supply-demand) theory with Thomas Aquinas.

(Langholm 1979: 35-36)

This Whiggish view of the history of economic thought has become quite popular and is recited in numerous books, particularly in textbooks. ${ }^{7}$

The aforementioned interpretations, however, do not exhaust the range of possible readings of the "just price theory." Hollander, for example, has argued that in Aquinas both versions of just price "are to be found depending upon the problem under investigation" and that "there is little evidence to show that Aquinas related analytically the market price to the production costs in the classical or neoclassical fashion" (Hollander 1965: 616). According to Hollander, "Aquinas was not an analyst of economic phenomena, and we cannot ascribe to him a full-fledged Marshallian theory of price determination involving a recognition of the relationship between supply curves of various runs" (Hollander 1965: 629).

A more recent commentator, Kaye, finds "none of these positions satisfactory" (Kaye 1998: 98). He contends that the identification of just price with market price "brought with it serious theological, ethical and metaphysical difficulties" (Kaye 1998: 98). Instead, he quotes Aquinas as saying that the "just price of things sometimes is not precisely determined," but "rather consists in a certain estimate" (Kaye 1998: 99). Relying on this quotation, Kaye then contends that Aquinas laid the foundation for the concept of just price as one lying along a 
"latitude," not a "precise arithmetical point but as a range along a continuum of value" (Kaye 1998: 100, emphasis in the original). From the perspective of economic analysis this last interpretation does not say much except that just price can be almost anything, especially since the "range along a continuum of value" and even the concept of "value," as distinct from "price," remains unclear. ${ }^{8}$

Whichever interpretation one chooses, the fact remains that the just price theory, similar to the theory of the difficulties of barter, has virtually nothing to do with the medieval practices in the actual marketplace. Indeed, the view that the "the just price is a nebulous concept invented by pious monks" might not be that far from the truth. Why? Because the medieval merchants have left behind detailed manuscripts dealing with their commercial practices, and these manuscripts do not support any notion of justice in exchange. To the extent that these manuscripts also shed light on the development of modern mathematics, as well as the mechanistic naturalism of the Enlightenment, they have been subjects of numerous studies by those interested in the history of mathematics and sociology of knowledge. Yet, when it comes to economic content, these manuscripts have hardly been studied. ${ }^{9}$ In the next three sections I look at the nature, structure, and economic lessons of these manuscripts. Afterward, I examine what these manuscripts mean for the scholastic concepts of difficulties of barter and justice and equality in exchange.

\section{The "abacus manuscripts"}

The mathematical writings of Muslim scholars, particularly the Algebra (1831) of Muhammad Ibn Musa Al-Khwarizmi's, established a unique tradition among the medieval European merchants and scholars for writing manuscripts teaching mathematics. ${ }^{10}$ The tradition, which can be observed in the Liber Abaci (2002 [1202]) of Leonardo of Pisa or Fibonacci, consists of introducing the reader to Arab numerals, followed by teaching the four basic arithmetical operations: addition, subtraction, multiplication, and division. ${ }^{11}$ This is usually followed by the explanation of the "golden rule" or the "rule of three," where a missing fourth term in two equal ratios is found. ${ }^{12}$ Once arithmetical operations are explained, business problems, such as those dealing with barter, pricing, profit calculations, partnerships, and mixture of coins, are discussed. Afterward, more esoteric and academic concepts dealing with algebra and geometry may be analyzed. In between, many problem situations are presented. Some of these problems are real, dealing with everyday living scenarios, whereas some are fictitious, simply designed for pedagogical purposes. ${ }^{13}$ Problems dealing with business practices fall within the first group.

It should be pointed out that the manuscripts written by Fibonacci, and a host of academic mathematicians who followed him, are somewhat different from those written by the merchants. The merchants were interested in providing practical business training, particularly for their children. As such they had established special educational facilities that in Italy were referred to as "schools of abacus" or, more accurately, scuola or bottegha d'abaco (Van Egmond 1976: 65; Swetz 


\section{Justice in exchange and the medieval economy}

1987: 21). Their reckoning masters were, in turn, called the masteri d'abaco (Van Egmond 1976: 66; Swetz 1987: 21). The manuscripts written by these masters, which Van Egmond (1976: 4) refers to as "books of the abacus" or abaci, were designed mostly for conducting business affairs. ${ }^{14}$ As such, even though some may have dealt with theoretical issues, the main motive of these books was to teach mathematics for business practices (Van Egmond 1976: 12-18). A perfect example of such manuscripts is the Treviso Arithmetic of 1478 that appears to be the first printed book of its kind. It starts by saying:

Here beginneth a Practica, very helpful to all who have to do with that commercial art commonly known as the abacus.

I have often been asked by certain youths in whom I have much interest, and who look forward to mercantile pursuits, to put into writing the fundamental principles of arithmetic, commonly called the abacus.

(Swetz 1987: 40)

Given the practical nature of these types of manuscripts, Swetz (1987: 29) refers to them as practica.

It is worth noting that the tradition of writing and teaching books of abacus appeared not just in Italy, but elsewhere in Europe, even though somewhat later. These works usually had in their titles the word "arithmetic." According to Natalie Zemon Davis (1960: 19), for example, the "French commercial arithmetics were the major and almost the only printed material for the technical instruction of French merchant and banker in the XVI ${ }^{\text {th }}$ century." The same can be said for other countries in Europe, particularly England, where books on commercial arithmetic appear well into the sixteenth century. One such example is the Well-Spring of Science, written by Humfrey Baker and published in 1568. The subtitle of this book, Teaching the Perfect Worke and Practise of Arithmetick, both in Numbers and Fractions, clearly indicates the nature of the work, and the book's table of contents still shows the usual format of the books of abacus, beginning with an introduction to Arab numerals and concluding with the issues immediately relevant to the practices of merchants.

Having looked at the nature and structure of these writings let me now turn to their monetary lessons. As we shall see, two important lessons can be drawn from these manuscripts: first, not only is barter not difficult, but it is also carried on regularly and in some cases preferred to monetary exchange. Second, contrary to Aquinas's teaching in his "Question 77," concerning "buying and selling," the name of the game in exchange is not refraining from "fraud," but actually practicing and teaching deceit; not avoiding "sin" in exchange, but engaging in all kinds of prohibited behavior; not making "moderate business profit," but gaining as much as possible in trade (Aquinas 1975: 213, 219, 229).

\section{The "Rules of Barter"}

As mentioned earlier, one of the features of the abacus manuscripts is that it contains a section, usually entitled the "Rules of Barter," that deals with direct 
exchange. This is indicative of the prevalence and importance of direct exchange in the medieval and renaissance periods, something that, of course, has been acknowledged by the economic historians as well. Herman Van Der Wee (1977), for example, acknowledges the growth of money economy in the later Middle Ages, but he adds: "Pure barter did not immediately disappear from the local economy even in the sixteenth and seventeenth century. The use of credit facilities in the money sector even enhanced the opportunities for barter transactions in so far as it encouraged barter on an extended time basis" (Van Der Wee 1977: 290). ${ }^{15}$

The abacus manuscripts, however, tell us more than the pervasiveness and significance of barter. By providing specific problem situations they tell us what the rules of barter are and how the merchants are to conduct themselves in the marketplace. The number of problem situations varies from text to text; some, such as the Treviso Arithmetic, have only a few, whereas others, such as the WellSpring of Science, contain many examples of barter situations. The latter actually devotes an entire chapter, "Of the Rules of Barter: That Is to Say, to Change Ware for Ware," to this issue and presents 12 problem situations (Baker 1568: 248).

The complexity of the problem situations also varies from one text to another. But in general we find three types of barter situations with increasing complexity. The first type, which in some of the abacus manuscripts is called baratto semplice, is a simple case of barter where barter values are simply proportional to prices (Van Egmond 1976: 186). We find an example of this type of barter in Treviso Arithmetic: "Two merchants wish to barter. The one has cloth at 5 lire a yard, and the other has wool at 18 lire a hundredweight. How much cloth should the first have for 4564 hundredweights of wool?" (Swetz 1987: 151). It should be noted that even though goods are directly exchanged for one another in the above example, the unit of account is money. This fact, which will be discussed later, appears in all the examples concerned with barter.

The above problem is a simple and straightforward example of the application of the "Rule of Three" or the "Golden Rule" (Baker 1568: 70). Such a problem becomes more involved in some abaci manuscripts by extending the number of exchanges. For example, Treviso Arithmetic gives the example of one merchant exchanging "1 pexo of balsam worth 150 ducats" against another merchant's "wax of 5 ducats per hundredweight, sugar at 6 ducats a hundredweight, and ginger at 8 ducats a hundredweight" (Swetz 1987: 152-153).

The second type of barter is more complex. In this case, the regular price is different from the barter value. Van Egmond refers to the first as the "cash price" or "the true price of the good" and to the second as the "barter price" or the "price at which it was being offered" (Van Egmond 1976: 186). Treviso Arithmetic provides this example:

There are two merchants of whom the one has cloth worth 22 soldi a yard, but holds it in barter at 27 soldi. The other has wool which is worth in the country 19 lire per hundredweight. Required is to know how much he must ask per hundredweight in barter so that he may not be cheated.

(Swetz 1987: 152, emphasis added) 


\section{Justice in exchange and the medieval economy}

Note that in the above example the price of cloth is less than its barter value. This difference is not accidental. ${ }^{16}$ We see the same thing in the Well-Spring of Science:

Two Merchants will change their merchandize, the one with the other. The one of them hath Cloth of $7 \mathrm{~s} .1 \mathrm{~d}$. the yard, to sell for ready money, but in barter he will sell it for $8 \mathrm{s.} 4 \mathrm{~d}$. The other hath Cinnamon of $4 \mathrm{~s} .7 \mathrm{~d}$. the pound, to sell for ready money; I demand how he shall sell for it in barter that he be no loser?

(Baker 1568: 248, emphasis added)

Why the barter value is higher than the price will be discussed shortly. For the time being, however, let us note that these examples refer to the possibility of getting "cheated" or becoming a "loser" in barter if one is unfamiliar with the "Golden Rule." Kurt Vogel expresses this problem symbolically by stating:

If one of the two parties (A) sets the cash value of his good $b_{1}$ and the bartervalue $s_{1}$, and the other party (B) sets the cash value $b_{2}$ and the barter-value $\mathrm{s}_{2}$, then the exchange is only right and nobody is cheated, if the following is true: $b_{1}: s_{1}=b_{2}: s_{2}$.

(Vogel 1978: 68)

There are also some examples in the Well-Spring of Science that express the concept of getting cheated or losing in barter in terms of "just price" and "overprice":

Two Merchants will barter their merchandize the one with the other: The one of them hath Chamblets, of $21.18 \mathrm{~s} .4 \mathrm{~d}$. the piece, to sell for ready money, and in barter he will sell the piece for $41.3 \mathrm{~s} .4 \mathrm{~d}$. The other hath fine Caps of $35 \mathrm{~s} .10 \mathrm{~d}$. the dozen, to sell in barter. I demand what the dozen of Caps were worth in ready money? Ans. Say, if $41.3 \mathrm{s.} 4 \mathrm{~d}$. which is the over-price of the piece of chamblet, become of $21.8 \mathrm{~s} .4 \mathrm{~d}$. which was the just price of the same, of what shall come $35 \mathrm{~s} .10 \mathrm{~d}$. which is the overprice of the dozen caps?

(Baker 1568: 248, emphasis added)

Note that the expression "just price" is used by Baker in the sense of the actual market price, which is similar to the way some scholastics used the expression. The second expression, "overprice," however, is not found in the scholastics' writings and appears to be only part of the language of the marketplace. These concepts of just price and overprice seem to correspond, respectively, to Van Egmond's "true price" and "barter price."

The third type of barter is still more complex, and it involves payments both in cash and in kind. Van Egmond refers to these types of problems as baratto composto or "compound barter" (1976: 187). The Well-Spring of Science explains the problem this way:

When a merchant overselleth his merchandize, and he will have also some part of his over-price in ready money: as the $1 / 2$ the $1 / 3$, or the $1 / 4$ etc. $\mathrm{He}$ 
must subtract the same part of money from the just price, and also from the over-price of his merchandize: and the two numbers that remain after the subtraction is made, shall be the two numbers in the Rule of Three: the just price of the second merchant shall be the third number: to know how much he shall over-sell the part of his merchandize.

(Baker 1568: 255-256)

The first example of compound barter in Baker's Well-Spring of Science is this:

Two merchants will change their merchandize the one with the other, the one of them has Wooll at 51 . the 100 pounds weight to sell for ready money, and in barter he will sell it for 6 li. And yet he will have the 1/3, in ready money. The other hath cloth of $13 \mathrm{~s} .4 \mathrm{~d}$. the yard to sell for ready money. I would know how he shall sell the same in barter? Answ. Take the 1/3 of 6 li which is the over-price of 100 of Wooll, and that is 2 li. The which you must abate from 5 li. Which is the just price of the C of Wooll, and also abate it from 61 . which is the over-price, and there shall rest 31 . and 41 . for the two first numbers in the Rule of Three; then take $13 \mathrm{~s} .4 \mathrm{~d}$. which is the just price of a yard of cloth, for the third number: Then multiply and divide, and you shall find $17 \mathrm{s.} 9$ d. 1/3 for so much shall the second sell his cloth in barter.

(Baker 1568: 256)

As posed, neither the problem nor its solution is clear. The solution, in particular, is stated mechanically and lacks explanation. This is not a unique case and is understandable. Without the use of the algebra, it is difficult to express the solution, especially for merchants who are concerned merely with practical matters. Vogel (1978: 69) notes the difficulty and tries to formulate the solution: "In another, especially frequent group of problems, it is stated that A demands from B that certain part of his good, $1 / \mathrm{n}$, be paid in cash. Yet without any explanation, the following formula is used: $\left(b_{1}-s_{1} / n\right):\left(s_{1}-s_{1} / n\right)=b_{2}: s_{2}$." But Vogel himself does not fully explain how the formula is derived. In the next section, I explain and formalize the solution, but a verbal expression would be the following.

Let us return to the problem posed in the Well-Spring of Science. The first merchant sets the price of wool at 1,200 d.- that is, 5 li. $\times 240 \mathrm{~d}$./li.hundredweight and the second merchant sets the price of cloth at $160 \mathrm{~d}$. This means effectively that 160/1,200 hundredweights of wool can barter for 1 yard of cloth. When it comes to complex barter, however, the first merchant asks the second $1440 \mathrm{~d}$.- that is, 6 li. $\times 240 \mathrm{~d}$./li.- -worth of cloth per hundredweight. This means that as far as the wool merchant is concerned, 160/1,440 hundredweights of wool barters for 1 yard of cloth. In the case of compound barter, however, the wool merchant would like to barter 160/1,440 hundredweights of wool for $2 / 3$ of a yard of cloth and $1 / 3$ of a yard worth of cloth in cash. But then how much cash is this? Since, from the perspective of the wool merchant, $160 \mathrm{~d}$. purchases a yard of cloth, then $1 / 3$ of a yard worth of cloth is equivalent to $160 / 3 \mathrm{~d}$. Thus the wool merchant would deduct $160 / 3 \mathrm{~d}$. worth of wool from his own 
payment of wool in exchange for $2 / 3$ of a yard of cloth. But then again, how much wool is $160 / 3 \mathrm{~d}$. worth of wool? Since 1,200 d. purchases 1 hundredweight of wool, $160 / 3 \mathrm{~d}$. worth of wool is equivalent to $160 / 3,600$ hundredweight of wool. Hence, according to the wool merchant, 0.066 hundredweight of wool - that is, 160/1,440 hundredweight of wool minus 160/3,600 hundredweight of woolbarters for $2 / 3$ of a yard of cloth. Or, alternatively, 0.099 hundredweight of wool should barter for 1 yard of cloth. But since each yard of cloth sells for $160 \mathrm{~d}$,, from the perspective of the wool merchant, a hundredweight of wool should sell for $160 \mathrm{~d} . / 0.099$ or 6.66 li. per hundredweight of wool. The cloth merchant would then have to match this price if he is to avoid being cheated. Using the rule of three, he should set his price at $213.33 \mathrm{~d}$.- - that is, $(160 \mathrm{~d}$. $\times 6.66 \mathrm{li}.) / 5 \mathrm{li}$.- - per yard or $17.77 \mathrm{~s}$. per yard, which is the price arrived at by Baker. This mode of calculation, as we shall see soon, leads to the same numerical solution proposed by Baker and the algebraic solution offered by Vogel.

Before formally presenting the three types of barter discussed earlier, it should be noted that more complex cases of barter, involving more opportunity for cheating, were also possible. In some cases, for example, the exchange of goods involves future payments. In these problems, which Vogel, following Geronimo Cardano (1539), calls Transmutatio cum expectatione temporis, the two merchants set their prices and barter values as before; however, one merchant wants to deliver his goods in the future and the second merchant has to decide when to deliver his own (Vogel 1978: 71). Such cases would obviously involve calculation of interest payments. The complexity of the problem is increased when one side also asks for a fraction of the goods to be delivered in cash (Vogel 1978: 72).

\section{Formalization of the "Rules of Barter"}

We can get a clearer picture of the medieval exchange mechanism by formalizing the various barter scenarios discussed above. The formalization will also come in handy in the analysis of exchange in later chapters.

Let the symbols $\lambda$ and $\beta$, which were used in Chapter 2, represent, respectively, the relations "sell(s) for" and "barter(s) for" defined on the set of units of useful objects, $u$. Also let $u_{i}$ and $u_{j}$, respectively, sell for $p_{i \mathrm{~m}}$ and $p_{j \mathrm{~m}}$ amounts of a unit of money commodity, $u_{\mathrm{m}}$, that is, $u_{i} \lambda p_{i \mathrm{~m}} u_{\mathrm{m}}, u_{j} \lambda p_{j \mathrm{~m}} u_{\mathrm{m}}$. We can say that $p_{i \mathrm{~m}} u_{\mathrm{m}}$ and $p_{j \mathrm{~m}} u_{\mathrm{m}}$ are the prices of $u_{i}$ and $u_{j}$, respectively.

Let us also assume that $u_{i}$ barters for $b_{i j}$ amount of a unit of $u_{j}$, that is, $u_{i} \beta b_{i j} u_{j}$. We can call $b_{i j} u_{j}$ the $U_{j}$-barter-value of $u_{i}$. This simply means that $\left(u_{i} / b_{i j}\right) \beta u_{j}$ or $b_{j i} u_{i} \beta u_{j}$, where $b_{j i}=1 / b_{j i}$. Similarly, $b_{j i} u_{i}$ will designate the $U_{i}$-barter-value of $u_{j}$. As we saw in the previous section, there are three barter scenarios:

1 Simple barter Two traders, $T_{i}$ and $T_{j}$, exchange products. They can either engage in cash or barter transactions.

Cash transaction:

$T_{i}$ offers $u_{i}$ for $p_{i \mathrm{~m}} u_{\mathrm{m}} . T_{j}$ offers $u_{j}$ for $p_{j \mathrm{~m}} u_{\mathrm{m}}$. 
Barter transaction:

$T_{i}$ offers $u_{i}$ for $b_{i j} u_{j}$, where $b_{i j}=p_{i \mathrm{~m}} / p_{j \mathrm{~m}}$. Similarly, $T_{j}$ offers $u_{j}$ for $b_{j i} u_{j}$, where $b_{j i}=p_{j \mathrm{~m}} / p_{i \mathrm{~m}}$.

Effectively:

$$
u_{i} \beta\left(p_{i \mathrm{~m}} / p_{j \mathrm{~m}}\right) u_{j}
$$

2 Complex barter

Cash transaction:

Again, $T_{i}$ offers $u_{\mathrm{i}}$ for $p_{i \mathrm{~m}} u_{\mathrm{m}} \cdot T_{\mathrm{j}}$ offers $u_{j}$ for $p_{j \mathrm{~m}} u_{\mathrm{m}}$.

Barter transaction:

$T_{i}$ sets his "price" in barter higher than before, that is, $p_{i \mathrm{~m}}^{\prime} u_{\mathrm{m}}>p_{i \mathrm{~m}} u_{\mathrm{m}}$. If $T_{j}$ is arithmetically ignorant, then he offers $u_{j}$ at $p_{j \mathrm{~m}} u_{\mathrm{m}}$ as before. The result is

$$
u_{j} \beta b_{i j}^{\prime} u_{j}
$$

where $b_{i j}^{\prime}=p_{i \mathrm{~m}}^{\prime} / p_{j \mathrm{~m}}$ and $T_{j}$ gets cheated. The opposite would occur if $T_{i}$ sets his price as before and $T_{j}$ takes advantage of $T_{i}$ 's ignorance by setting a higher price than before. But if both traders engage in deception, then

$$
b_{i j}^{\prime}=p_{i \mathrm{~m}}^{\prime} / p_{j \mathrm{~m}}^{\prime}=p_{i \mathrm{~m}} / p_{j \mathrm{~m}}
$$

This means that we are back at

$$
u_{i} \beta b_{i j} u_{j}
$$

If neither side cheats, of course, we get the same result.

It should be noted here that in the case of simple barter, the relation $\beta$ is non-reflexive, symmetric, and transitive. But when one side cheats and the other does not, the relation is not even transitive. We return to this issue in Chapter 7, when a matrix of exchange is constructed based on the medieval exchange.

3 Compound barter

Cash transaction:

Again, $T_{i}$ offers $u_{i}$ for $p_{i \mathrm{~m}} u_{\mathrm{m}} \cdot T_{j}$ offers $u_{j}$ for $p_{j \mathrm{~m}} u_{\mathrm{m}}$. Barter transaction:

$T_{i}$ expects a fraction, $1 / n$, of $u_{j}$ in cash. In so doing he sets his price even higher than before, that is, $p_{i \mathrm{~m}}^{\prime \prime} u_{\mathrm{m}}>p_{i \mathrm{~m}}^{\prime} u_{\mathrm{m}}$.

What is this new price? Let us examine. In the case of complex barter $T_{i}$ expected

$$
u_{i} \beta b_{i j}^{\prime} u_{j} \quad \text { or } \quad\left(1 / b_{i j}^{\prime}\right) u_{i} \beta u_{j} \quad \text { or } \quad\left(p_{j \mathrm{~m}} / p_{i \mathrm{~m}}^{\prime}\right) u_{i} \beta u_{j}
$$

With the condition of $1 / n$ of $u_{j}$ in cash, $T_{i}$ expects

$$
\left.\left(p_{j \mathrm{~m}} / p_{i \mathrm{~m}}^{\prime}\right)\right) \beta\left\{\left[(n-1) u_{j} / n\right]-\left[(1 / n) u_{j} \text { in terms of money }\right]\right\}
$$




\section{Justice in exchange and the medieval economy}

But from the perspective of $T_{i},(1 / n) u_{j}$ in terms of money is the same as $\left(p_{j \mathrm{~m}} / n\right) u_{\mathrm{m}}$, since

$$
u_{j} \lambda p_{j \mathrm{~m}} u_{\mathrm{m}}
$$

Thus we have

$$
\left(p_{j \mathrm{~m}} / p_{i \mathrm{~m}}^{\prime}\right) u_{i} \beta\left\{\left[(n-1) u_{j} / n\right]-\left[(1 / n) p_{j \mathrm{~m}} u_{\mathrm{m}}\right]\right\}
$$

But since from the perspective of $T_{i}$

$$
\left(p_{j \mathrm{~m}} / n p_{i \mathrm{~m}}\right) u_{i} \lambda(1 / n) p_{j \mathrm{~m}} u_{\mathrm{m}}
$$

Then

$$
\begin{aligned}
& \left(p_{j \mathrm{~m}} / p_{i \mathrm{~m}}^{\prime}\right) u_{i} \beta\left\{\left[(n-1) u_{j} / n\right]-\left[\left(p_{j \mathrm{~m}} / n p_{i \mathrm{~m}}\right) u_{i}\right]\right\} \\
& {\left[\left(p_{j \mathrm{~m}} / p_{i \mathrm{~m}}^{\prime}\right)-\left(p_{j \mathrm{~m}} / n p_{i \mathrm{~m}}\right)\right] u_{i} \beta\left[(n-1) u_{j} / n\right]} \\
& {[n /(n-1)]\left[\left(p_{j \mathrm{~m}} / p_{i \mathrm{~m}}^{\prime}\right)-\left(p_{j \mathrm{~m}} / n p_{i \mathrm{~m}}\right)\right] u_{i} \beta u_{j}}
\end{aligned}
$$

This simply means that $T_{i}$ expects $u_{i} \beta b_{i j}^{\prime \prime} u_{j}$, where

$$
b_{i j}^{\prime \prime} u_{j}=u_{j} /\left\{[n /(n-1)]\left[\left(p_{j \mathrm{~m}} / p_{i \mathrm{~m}}^{\prime}\right)-\left(p_{j \mathrm{~m}} / n p_{i \mathrm{~m}}\right)\right]\right\}
$$

But how much is $b_{i j}^{\prime \prime} u_{j}$ in terms of money? In other words, what is the "price" of $u_{i}$, that is, $p_{i \mathrm{~m}}^{\prime \prime} u_{\mathrm{m}}$, set in this barter by $T_{i}$ ? Since $u_{j} \lambda p_{j \mathrm{~m}} u_{\mathrm{m}}$, then

$$
p_{i \mathrm{~m}}^{\prime \prime} u_{\mathrm{m}}=p_{j \mathrm{~m}} u_{\mathrm{m}} /\left\{[n /(n-1)]\left[\left(p_{j \mathrm{~m}} / p_{i \mathrm{~m}}^{\prime}\right)-\left(p_{j \mathrm{~m}} / n p_{i \mathrm{~m}}\right)\right]\right\}
$$

After simplifying, we have

$$
p_{i \mathrm{~m}}^{\prime \prime} u_{\mathrm{m}}=u_{\mathrm{m}} /\left\{[n /(n-1)]\left[\left(1 / p_{i \mathrm{~m}}^{\prime}\right)-\left(1 / n p_{i \mathrm{~m}}\right)\right]\right\}
$$

If $T_{j}$ is ignorant, then he offers $u_{j}$ at $p_{j \mathrm{~m}} u_{\mathrm{m}}$, as before.

Once we reverse the situation, then $T_{i}$, who is ignorant, offers $u_{i}$ at $p_{i \mathrm{~m}} u_{\mathrm{m}}$ as before. But $T_{j}$ would cheat and offer $u_{j}$ at

$$
p_{j \mathrm{~m}}^{\prime \prime} u_{\mathrm{m}}=u_{\mathrm{m}} /\left\{[n /(n-1)]\left[\left(1 / p_{j \mathrm{~m}}^{\prime}\right)-\left(1 / n p_{j \mathrm{~m}}\right)\right]\right.
$$

Exchange is "fair" if, when both sides cheat, the ratio of barter values, or new "prices," is the same as the ratio of original prices, that is

$$
p_{j \mathrm{~m}}^{\prime \prime} u_{\mathrm{m}} / p_{i \mathrm{~m}}^{\prime \prime} u_{\mathrm{m}}=p_{j \mathrm{~m}} u_{\mathrm{m}} / p_{i \mathrm{~m}} u_{\mathrm{m}}
$$

This means

$$
\left[\left(1 / p_{i \mathrm{~m}}^{\prime}\right)-\left(1 / n p_{i \mathrm{~m}}\right)\right]:\left[\left(1 / p_{j \mathrm{~m}}^{\prime}\right)-\left(1 / n p_{j \mathrm{~m}}\right)\right]=p_{j \mathrm{~m}} / p_{i \mathrm{~m}}
$$


Multiplying both sides of the equation by $p_{i \mathrm{~m}}$, we get

$$
\left[\left(p_{i \mathrm{~m}} / p^{\prime}{ }_{\mathrm{im}}\right)-(1 / n)\right]:\left[\left(1 / p_{j \mathrm{~m}}^{\prime}\right)-\left(1 / n p_{j \mathrm{~m}}\right)\right]=p_{j \mathrm{~m}}
$$

Dividing the right side of the equation by $p^{\prime \prime}{ }_{j \mathrm{~m}}$ and the left side by its equivalent, we have

$$
\begin{aligned}
& \left\{[n /(n-1)]\left[\left(p_{i \mathrm{~m}} / p_{i \mathrm{~m}}^{\prime}\right)-(1 / n)\right]\right\}=p_{j \mathrm{~m}} / p_{j \mathrm{~m}}^{\prime \prime} \\
& {\left[\left(n p_{i \mathrm{~m}}-p_{i \mathrm{~m}}^{\prime}\right)\right]:\left[n p_{i \mathrm{~m}}^{\prime}-p_{i \mathrm{~m}}^{\prime}\right]=p_{j \mathrm{~m}} / p_{j \mathrm{~m}}^{\prime \prime}} \\
& \left(p_{i \mathrm{~m}}-p_{i \mathrm{~m}}^{\prime} / n\right):\left(p_{i \mathrm{~m}}^{\prime}-p_{i \mathrm{~m}}^{\prime} / n\right)=p_{j \mathrm{~m}} / p_{j \mathrm{~m}}^{\prime \prime}
\end{aligned}
$$

This is the same result that Baker expresses without any explanation. It is also what Vogel expresses as " $\left(b_{1}-s_{1} / n\right):\left(s_{1}-s_{1} / n\right)=b_{2}$ : $s_{2}$."

\section{The "difficulties of barter" revisited}

Looking back at the lessons of abacus manuscripts we can see how wrong headed the monetary teachings of the scholastics were in the face of medieval market practices. As was noted at the beginning of this chapter, the scholastics, such as Oresme, repeated Aristotle's claim that money evolved out of the difficulties of barter. Similar to Aristotle, Oresme did not explicitly state what these difficulties are, but bits and pieces of the answer can be found in his writings, as well as in those of other scholastics.

In discussing money as the instrument of exchange, Oresme himself gives us a hint about the difficulties of barter when he tries to explain why money is "a fit tool for the work" (Oresme 1956: 5). Money is well suited for exchange, he argues, because it is "easy to handle and to feel with hands, light to carry and that a small portion of it should purchase a large quantity of natural riches" (Oresme 1956: 5). A few pages later, he adds that trade is sometimes "large" or "small" and money is suitable for this purpose, and, furthermore, money made of gold is "easy to carry and to count" (Oresme 1956: 7). Setting aside concepts such as money being easy to handle, we see in these statements basically two of the three reasons for the so-called difficulties of barter that later generations of economic thinkers would codify: the difficulties associated with needing a unit of account and a means of subdivision. Oresme does not refer to the third and often mentioned difficulty, that is, the "double coincidence of wants." But this idea had been around for a long time and Oresme was probably aware of it. The Roman jurist Paul had already stated centuries before Oresme that the "coincidence was not always readily found, that when you had what I wanted I had what you were willing to give" (quoted in Wood 2002: 82; see also Monroe 1966: 10). As Monroe (1966: 22) points out, Thomas Aquinas, indeed, makes a reference to this difficulty.

The three alleged difficulties of barter, however, appear to exist only in the minds of the Aristotelian medievalists. As the abaci manuscripts show, the merchants in the medieval markets do not appear to face any such difficulties. 
In particular, barter is practiced on a regular basis without anyone running into the problem of the "double coincidence of wants." One reason for this is that the number of goods exchanged appears to be relatively limited. As Van Egmond notes, there are certain "major products" that are dealt with in the abaci, such as "wool, finished cloth, pepper, grain, and wine" (Van Egmond 1976: 188). There are also some other, minor products, that appear in these manuscripts. For example, in fifteenth-century Treviso Arithmetic, besides wool and cloth, one example of barter involves balsam, wax, and ginger. Similarly, in sixteenth-century WellSpring of Science, which was written when markets had become more extensive, besides the usual commodities, we encounter the exchange of such things as cinnamon, tapestry, caps, tin, lead, iron, and steel. The limited number of goods traded is a major factor in preventing the emergence of the problem of double coincidence. But there are other factors. The trade routes and the locations of markets were well established in the late Middle Ages and renaissance period. This further prevents the emergence of the problem of "double coincidence of wants."

The limited numbers of goods exchanged would also prevent the emergence of the difficulty associated with needing a unit of account. If the numbers of commodities bartered are relatively small, the complication of keeping track of numerous exchange ratios will not arise. Indeed, as we have seen, the abaci examples of the exchange of "ware for ware" do not seem to convey any difficulty whatsoever with keeping track of complicated numbers, since all barter values are expressed in terms of money of account. This brings up an important issue often mentioned by the historians of money.

Contrary to the usual assumption of economic theory, according to which money of account must also fulfill the function of medium of exchange, in the medieval and renaissance periods the medium of exchange often does not play the role of money of account. As Peter Spufford points out, in "most parts of late medieval Europe, and in many places up to the eighteenth or even the nineteenth century, a dichotomy existed in the functions of money. On the one hand money of account was the measure of value, whilst on the other, the actual coin was the medium of exchange and the store of wealth" (Spufford 1988: 411, emphasis in the original). Similarly, John F. Chown distinguishes between money of account or "ghost money" and the real coins (Chown 1994: 17-20). ${ }^{17}$ This dichotomy between different functions of money points out that in reality barter can be conducted on the basis of a ghost money, a unit of account based on non-existing real coins. In other words, the mere existence of a fictitious unit of account can prevent the emergence of the complication of keeping track of a large number of exchange ratios.

As far as the third difficulty of barter is concerned, that is, the need for a means of subdivision, the problem is also non-existent, or at least not important when it comes to the reality of the medieval barter. As we have seen, most of the major goods bartered in this period are for practical purposes divisible. There are, occasionally, some non-divisible items bartered as well. For example, Baker's second problem involves the exchange of "Chamblets" that in barter sell for 
"4l. 3 s. 4 d." per piece and "Caps" that sell, also in barter, for " 35 s. 10 d." per "dozen" (Baker 1568: 248). This means that one piece of "Chamblet" should exchange for 2.33 dozen "Caps," which is, of course, not a round number. But Baker does not seem to be bothered at all by this problem. It appears, therefore, that for practical purposes, the non-divisibility of some commodities does not inhibit barter. This is particularly true when money is available and part of the payment, as we have seen, may involve cash.

In the final analysis none of the difficulties of barter that are usually mentioned is encountered in the medieval market. Indeed, as the abacus manuscripts show, barter is not only a common feature of the medieval market, but it also appears to be preferred to monetary exchange. Why the preference? Various explanations have been offered. ${ }^{18}$ But the answer clearly lies in the discussion in the previous sections, which shows the possibility of cheating in the act of barter and coming out ahead. Since this swindle makes much of the scholastics" "just price" theory irrelevant, further elaboration is in order.

\section{"Just price" and equality of exchange revisited}

As we saw earlier, the medieval merchants could offer a good at its actual price, what Baker calls "just price," or at its barter value, what Baker refers to as the "overprice." The actual price itself was set using markup pricing techniques. That is, the price not only included the cost per unit, but also a desired profit per unit. This is, for example, evident in the chapter on "Of Losses and Gains in the Trade of Merchandize" in the Well-Spring of Science, where prior to discussing barter, Baker discusses how to calculate the market price, which includes a profit margin (Baker 1568: 193). Similar procedures are found in other abaci manuscripts. For example, Davis quotes the sixteenth-century writer La Roche on how to calculate the cost per unit of a good and "sell it to one's profit at so much gain per livre or at the rate of so much per cent" (Davis 1960: 21).

In teaching markup techniques the medieval merchants, of course, show no sign of the scholastics' fixation with "moderate gain." Davis correctly recognizes this when, with reference to the French writings on commercial arithmetic, she writes:

The authors of these arithmetics may have to some extent worried about the sin of avarice and whether it inevitably expressed itself in commerce and finance. When they came to write texts, however, whatever moral concerns they had were generally put aside, and they became first and foremost conveyors of technique. Thus the setting of prices was discussed solely in terms of costs and desired profits, with none of the familiar references of the theologian and moralist to just price.

(Davis 1960: 21) $)^{19}$

The concept of "overprice," however, goes beyond teaching markup techniques. The purpose of the "overprice," as we saw in the previous sections, 


\section{Justice in exchange and the medieval economy}

was to gain, through deceit, a greater profit margin. ${ }^{20}$ On this point, Davis writes: "Deception was a frequently alleged temptation of the business life" and the process of bartering "involved a certain amount of evident deception" (1960: 22). Davis gives an example from an early sixteenth-century manuscript: "Two merchants want to barter their merchandise and deceive (tromper) each other, one in pepper, the other in cloth. He who has the pepper wants to sell at 25 francs the hundred in barter what is worth only 20 francs in current cash" (Davis 1960: 22). Davis goes on to say: "Although a work of about the same time claimed the goal of the Rule of Barter was 'to keep oneself from being deceived or tricked and from deceiving or tricking others,' later in the century we see a non-committal description: 'Bartering is nothing but giving one piece of merchandise for another in hope of coming out in a better position" (Davis 1960: 22). Actually, this definition of barter appears in earlier manuscripts as well. Kurt Vogel (1978: 68), for example, quotes the following from Luca Pacioli's 1494 Summa de Arithmetica: "Barter is nothing but giving a good for another in order to get more." Richard Hadden also supports this view and, with reference to Vogel's analysis of how barter values must be set in order to avoid getting cheated, states that in exchange "proportion becomes the language of gain" (Hadden 1994: 90). As we saw in the previous sections, proportion is indeed the language of gain.

In sum, contrary to what the Aristotelian scholastics claimed, barter not only was not difficult in the medieval era but it was also actually preferred to cash transaction because in barter an arithmetically astute merchant could make more profit than what the usual markup pricing would allow. How much profit could be made, as we saw earlier, would depend on the level of arithmetical knowledge of the two parties. Full knowledge on the part of the two merchants would result in a "fair exchange," where the barter values were proportional to prices and profit was confined to the markup. Similarly, one could say, complete lack of knowledge on the part of both merchants would result in "fair exchange" as well. However, complete knowledge on the part of one merchant and complete lack of it on the part of the other would result in maximum gain for the knowledgeable merchant. $^{21}$

What is the lesson of the abacus manuscripts for the mathematical notion of equality of exchange that the scholastics inherited from Aristotle? From what has been said in the previous sections, one could show that this concept has no more relevance for the medieval market than it did for the ancient economy.

Let us return to the analysis of the relations of exchange. The qualitative barter relation, $B$, is clearly non-reflexive, since no good is exchanged for itself. The relation, however, is clearly symmetric, since $U_{i} B U_{j}$ implies $U_{j} B U_{i}$, for all $i, j=1, \ldots, n$. It is difficult to say whether the relation is transitive or not without a more thorough investigation of exchange in the medieval era. The abacus manuscripts seem to suggest that anytime a useful object is offered for sale, it is simultaneously offered for direct exchange. Also, the examples of exchange given in these manuscripts imply that some goods may be exchanged for numerous other goods. If we take these examples at their face value, we can assume that the relation $B$ is transitive, that is, $U_{i} B U_{j}$ and $U_{j} B U_{k}$ imply $U_{i} B U_{k}$, 
for all $i, j, k=1, \ldots, n$. But even with this assumption, the quantitative barter relation is still not an equivalence relation, since it fails the reflexivity property. Moreover, such a relation, unlike the mathematical relation of equality, is defined on the set of heterogeneous objects. Thus under no condition can the qualitative relation $B$ be viewed as the mathematical relation of equality.

As far as the properties of the qualitative relations "purchase(s)," $P$, and "sell(s) for," $S$, are concerned, there is nothing more to say beyond what was said in the previous chapter. The same holds for the monetary relation, $M=P \cup S$. Since none of these relations is reflexive or transitive, none is an equivalence relation; therefore, none can be viewed as a mathematical relation of equality. Finally, since the medieval exchange embraces both barter and monetary relation-and that is how the medievalists seem to have used the term "exchange"-we can combine the two relations as "exchange(s) for," $E=B \cup M$. This relation, as discussed in the previous chapter, is symmetric. It is also transitive, if barter is transitive. But it is still not reflexive. Therefore the scholastics were wrong in assuming that the relation has anything to do with the mathematical relation of "equality." This being the case, the enigmatic concept of geometry of exchange appears to be nothing more than complete nonsense.

But what can be said about the quantitative relation of exchange? Looking back at the earlier sections, we see the following concerning the quantitative relation of barter, $\beta$. As far as reflexivity and symmetry are concerned, the relation $\beta$ is similar to $B$. But is it necessarily true that if $B$ is transitive, so is $\beta$ ? In other words, is it necessarily true that if $U_{i} B U_{j}$ and $U_{j} B U_{k}$ imply $U_{i} B U_{k}$, then $u_{i} \beta b_{i j} u_{j}$ and $u_{j} \beta b_{j k} u_{k}$ imply $u_{i} \beta\left(b_{i j} \times b_{j k}\right) u_{k}$ ? To put it yet differently, is it necessarily the case that $b_{i k}=b_{i j} \times b_{j k}$ ?

The answer to this question is negative. If $B$ is transitive, $\beta$ is also transitive if and only if cheating does not occur, that is, the condition of simple barter prevails. But if complex or compound barter is the rule of exchange, that is, a good is given for another "in order to get more," the quantitative relation of barter could be intransitive if arithmetical knowledge is imperfect. Thus, we may say that if the medieval economy is a model of exchange, the quantitative relation of barter could be intransitive. The same can be said of the quantitative relation of exchange, which we can designate by $\xi$. Even if $E$ is transitive, $\xi$ might be intransitive if cheating occurs and arithmetical knowledge on the part of some merchants is not perfect. The intransitivity of $\xi$ by itself rules out the relation of exchange being an equivalent relation. But even if $\xi$ was transitive, it would not still be reflexive. Hence the medieval relation of exchange was neither qualitatively nor quantitatively identical to the mathematical relation of equality. We will return to these issues in Chapter 7 of this book.

\section{Conclusion}

As has been argued by recent historians, and clearly reflected in the abacus manuscripts, the commercial revolution of the late Middle Ages brought about a rapid monetization of the economy. Whether it was this monetization that 


\section{Justice in exchange and the medieval economy}

ultimately made the works of Copernicus and Galileo possible, as Kay has suggested, is uncertain. ${ }^{22}$ What is certain, however, is that it was shortly after the rapid development of merchant capitalism that the Scientific Revolution began. Also certain is that one of the first outcomes of this revolution was to weaken the chokehold that Aristotle had on natural sciences and, eventually, eradicate it altogether. Yet, when it came to social knowledge, Aristotle's grip continued throughout the commercial revolution despite the increasing monetization of economy. Monetary theory, in particular, remained substantially Aristotelian and at odds with the reality of the marketplace. Even though the scholastics went beyond Aristotle in formulating certain abstract concepts, such as labor, they mostly accepted Aristotle's propositions that barter is difficult and the relation of exchange is that of mathematical relation of equality.

As far as the first proposition is concerned, the scholastics gave a biblical flavor to Aristotle's story. But essentially they repeated his argument that the difficulties of direct exchange had led to the invention of money in some primordial time. Yet, as the abacus manuscripts show, in the real market merchants engaged in direct and indirect exchange without any difficulties and, indeed, expressed preference for indirect exchange because barter was considered to be "nothing but giving a good for another in order to get more." This incongruence between Aristotle's teaching and the reality of the market practices should have made the scholastics doubt the accuracy of his teachings. But the medieval Schoolmen put Aristotle's authority above that which could easily be observed in the marketplace. In this, they also adopted Aristotle's method of speculative reasoning and rational reconstruction of monetary world.

The second proposition of Aristotle was even more incongruent with the reality of the medieval market. Neither the relation of barter nor monetary relation, nor the combination of the two can, in any shape or form, be conceived as the mathematical relation of equality. Such relations, unlike the mathematical relation of equality, are not defined on the set of real numbers, nor are they equivalent relations. Of course, the nuances of modern mathematics were not available to the scholastics. However, for people who were concerned with numbers and measuring everything it was not impossible to discern that in the realm of pure mathematics a number is identical to itself, but when it comes to the market a particular good never exchanges for itself.

Finally, looking back at the analysis of this chapter, we can say that the concept of "just price" made no sense at all in light of the reality of the medieval market practices, however one interprets the concept. The scholastics, as mentioned earlier, were attempting to make sense of Aristotle's nonsensical equation of exchange. In this, they considered various possible substances that could bring about equality in exchange, including labor, expense, or a combination of the two. As such, one usual interpretation of "just price" is a price that merely covers the cost of production. But the markup technique that the authors of the abacus manuscripts taught their students does not support this concept of "just price." On top of the cost of production, the merchants added a desired profit and in this, as Davis correctly points out, they showed no sign of moral restraint. Thus if the just 
price is interpreted to mean selling a good at cost of production, or even at cost of production plus a "moderate business profit," to use Thomas Aquinas's expression, then the just price theory had no sense of the reality. This is even more so for those Whiggish interpretations that see the just price theory as a precursor to the marginalist theory of price, a theory that has never had any affinity with the reality of the marketplace to begin with.

The concept of the "just price" as the current market price does not make much sense either, unless one assumes that "just" has no meaning whatsoever. The medieval market practices, as portrayed in the abacus manuscripts, were characterized not by moderate gain, but by avarice, not by honesty, but by fraud and deceit. The rule of the game in these markets was to take advantage of arithmetical ignorance of others to gain as much profit as possible. As such, the merchants used barter, asked for partial cash payment, resorted to futures market, etc., to increase the "price" of the good. Unless one is prepared to say that whatever price the merchants set was just and however they tried to swindle the uninformed was ethical, the concept of just price as the prevailing market price has no meaning.

In the final analysis what de Roover (1958: 418) scornfully claims to be the "view of many economists that the just price is a nebulous concept invented by pious monks who knew nothing of business or economics and were blissfully unaware of market mechanism" is not that far from the truth. The concept was indeed nebulous. However one looks at it, it makes very little sense. But it is hard to argue that the monks were "blissfully unaware of the market mechanism." The chances are that they were aware of what was happening in the markets and what the merchants were teaching one another in the abacus manuscripts. But they found the harmonious picture of the market that the great authority, Aristotle, drew, combined with the biblical teachings, far more attractive than a complex picture of the real market characterized by swindle, dishonesty, and inequality.

It was this same method of analysis, namely, ignoring the real market in favor of an imaginary one, which the classical political economists adopted. A representative case is Adam Smith, whose theory of money and exchange will be analyzed in Chapter 4. 


\section{The bartering savage and the equation of exchange}

In his Great Transformation, Karl Polanyi wrote that a "host of writers on political economy, social history, political philosophy, and general sociology had followed in Smith's wake and established his paradigm of the bartering savage as an axiom of their respective science" (Polanyi 1957: 44, emphasis added). He further argued that this paradigm has shaped the orthodox economic theory of the development of the market, a theory in which the propensity to exchange eventually would give rise to long-distance trade. But, Polanyi contended:

The logic of the case is, indeed, almost the opposite of that underlying the classical doctrine. The orthodox teaching started from the individual's propensity to barter; deduced from it the necessity of local markets, as well as division of labor; and inferred, finally, the necessity of trade, eventually foreign trade, including long-distance trade. In light of our present knowledge we should almost reverse the sequence of the argument: the true starting point is long-distance trade, a result of geographical location of goods, and of the "division of labor" given by location. Long-distance trade often engenders markets, an institution which involves acts of barter, and if money is used, of buying and selling, thus eventually, but by no means necessarily, offering to some individuals an occasion to indulge in their alleged propensity for bargaining and haggling.

(Polanyi 1957: 58)

In supporting this argument, Polanyi refers to anthropological studies as well as medieval history of Europe, when the "short flowering of the famous fairs of Europe was another instance where long-distance trade produced a definite type of market" (1957: 60).

Chapter 3, of course, lends support to Polanyi's thesis concerning the primacy of long-distance trade over local trade and how a whole host of classical writers, particularly Adam Smith, have it backward, that is, starting from the bartering savage and ending with the world market. What is missing from Polaner's discussion, however, is a detailed analysis of Smith's theory of barter and the crucial role that the savage plays in this theory. ${ }^{1}$ This chapter attempts to remedy 
this shortcoming. As is shown in the next three sections, the savage, which replaces the image of Aristotle's barbarians or the scholastics' sons of Adam, unambiguously solves the ancient equation of exchange by means of his toil and trouble. Yet, as contended in the fourth section, Smith would ultimately face the same difficult question that Aristotle faced: what is the nature of the substance that would solve the equation of exchange in a monetary economy? Here, it will be argued that Smith's answer falls apart and goes no further than that of Aristotle. The last section concludes that the preoccupation of Smith and other classical political economists with the equation of exchange was the epitome of the Aristotelian method of constructing an economic theory without any reference to the reality of the marketplace.

\section{The inconvenience of barter and emergence of money}

The task that Adam Smith faced in developing a theory of exchange and money was similar to that encountered by the scholastics. They both had to resolve the nature of exchange, given what had been handed down by Aristotle. Smith was, of course, familiar with Aristotle, since we find references to both Ethica Nicomachea and Politica in his writings (Smith 1976, 1978, 1983). It has also been argued that through Hutcheson, Pufendorf, and Grotius, Smith was also familiar with the works of the scholastics (de Roover 1955: 188; Bowley 1973: 93).

When it comes to constructing a theory of exchange and money, however, Smith's historiography differs substantially from that of Aristotle or the scholastics. Here we do not see any mention of the first "family" or the "sons of Adam." Instead, what we observe are "four distinct stages which mankind pass thro: 1st, the Age of Hunters; 2dly, the Age of the Shepherds; 3dly, the Age of Agriculture; and 4thly, the Age of Commerce" (Smith 1978: 14). These stages, of course, are mostly fictitious. The first stage, for example, in the Lectures on Jurisprudence is concocted by Smith when he states that "we suppose 10 or 12 persons of different sexes settled in an uninhabited island" (Smith 1978: 14). Shortly after, the concept of islanders is replaced by that of "savage nations," such as the "North American Indians," who are "hunters" (Smith 1978: 15-16). In the Wealth of Nations, however, Smith establishes his "lowest and rudest state of society" directly on his view of "the native tribes of North America" (Smith 1976: 689-690). The last stage, the "age of commerce," corresponds to Smith's own era, which is also referred to as the "civilized" or "commercial society" (Smith 1976: 26, 37). In this scheme, the first and the last stages of history play a crucial role in the development of Smith's monetary theory, as we see shortly.

In the Wealth of Nations Smith tries to relegate barter to his first stage of history, or the stage of "savage nations." As such, he tries to play down the importance of barter in the "civilized society" by arguing, for example, that "when barter ceases, and money has become the common instrument of commerce, every particular commodity is more frequently exchanged for money than for any 
other commodity" (Smith 1976: 49). The news of the death of barter, however, appears to be premature, since in the next sentence he writes

The butcher seldom carries his beef or his mutton to the baker, or the brewer, in order to exchange them for bread or for beer; but he carries them to the market, where he exchanges them for money, and afterwards exchanges that money for bread and for beer.

(Smith 1976: 49)

Indeed, from reading the Wealth of Nations one can conclude that barter was still practiced in mid-eighteenth-century England, since Smith refers to it no less than 13 times in the work, mostly in the early chapters where his theory of price is constructed. Yet, turning barter into a relic of the past appears to be a theoretical necessity in developing the concept of money in the Wealth of Nations. This development takes place in chapter 4 of the Wealth of Nations, under the heading "Of the Origin and Use of Money" (Smith 1976: 37). The line of argument starts with "when the division of labor first began to take place" (Smith 1976: 37).

Smith's point of departure resembles more of Plato's derivation of money than that of Aristotle. However, as we saw in Chapter 2, Plato traces the origin of money to the origin of the city via the division of labor. But in the case of Smith the division of labor is traced back to the "rude ages of society" (Smith 1976: 38). The line of argument, however, soon aligns itself with the traditional Aristotelian view when the notion of difficulties of barter is introduced. This is done in the same sentence containing the concept of "division of labor," when Smith continues to say that "this power of exchanging must frequently have been very much clogged and embarrassed in its operation" (Smith 1976: 38).

We return to Smith's concept of exchange very shortly. But the question at this point is: What are the difficulties of exchange that Smith has in mind? In both the Cannon and Skinner editions of the Wealth of Nations the editors have remarked that Smith's notion of the difficulties of barter, or the whole paragraph regarding barter, resembles paragraphs 19 and 20 of Joseph Harris's An Essay upon Money and Coins (Harris 1757: 34-39). But actually there is little resemblance between Smith and Harris on the issue of barter and its difficulties.

Harris starts his section on barter with little fanfare by simply stating: "The first commerce amongst men, was undoubtedly carried on by barter, or the exchange of one commodity for another" (Harris 1970: 34). This is immediately followed by the statement: "But as men and arts increased, a mere barter of commodities became inconvenient, and insufficient, in abundance of instances" (Harris 1970: 34). The two inconveniences of barter mentioned by Harris are "the endless difficulties people were under to suit one another" and that "there was no scale, or measure, by which the proportion of value which goods had to one another, could be ascertained" (Harris 1970: 35).

Smith's discussion of the difficulties of barter, which follows his elaborate story of the division of labor, is merely confined to the mismatch of wants, and even this is presented in Smith's unique way. When the first division of 
labor starts, he opines, the problem of surplus arises and this leads to the "inconveniency" of barter:

One man, we shall suppose, has more of a certain commodity than he himself has occasion for, while another has less. The former consequently would be glad to dispose of, and the latter to purchase, a part of this superfluity. But if this latter should chance to have nothing that the former stands in need of, no exchange can be made between them. The butcher has more meat in his shop than he himself can consume, and the brewer and the baker would each of them be willing to purchase a part of it.

(Smith 1976: 37)

It is, of course, interesting to note that the term "purchase" surreptitiously enters into the discussion of barter in the "savage state." So, too, enter into this discussion Smith's three favored economic characters in the "civilized society": the butcher, the brewer, and the baker.

This is basically the extent of Smith's discussion of barter and its alleged inconvenience. After a relatively short passage on the subject, Smith moves on to develop money. Thus, unlike Harris, we see in Smith no mention of the second purported difficulty of barter, namely the need for a unique measure of value. Whether this is intentional or merely an oversight is not clear. Smith appears to be aware of this presumed difficulty, since he mentions it elsewhere. For example, in the Lectures on Jurisprudence he notes that when "people deal in many species of goods, one of them must be considered as the measure of value" (Smith 1978: 499). This is illustrated by discussing the exchange of three goods and how "if we have hundred different commodities, there are ninety nine values of each arising from a comparison with each of the rest" (Smith 1978: 499). The conclusion is that as "these cannot easily be remembered, men naturally fall upon one of them to be a common standard with which they compare the rest" (Smith 1978: 499).

Another difficulty not mentioned by Smith is the notion of the indivisibility of goods as opposed to money. The concept does appear in this same chapter, "On the Origin and Use of Money," but in the context of the discussion of why money should be made of metals. Here, after concocting many stories concerning the "probable" use of "different commodities" as money, Smith mentions the possible use of "cattle" in the "rude age of the society" as an "instrument of commerce" (Smith 1976: 38). He then adds: "Salt is said to be a common instrument of commerce and exchanges in Abyssinia" (Smith 1976: 38). These two stories, in turn, are combined into one difficult exchange: "The man who wanted to buy salt, for example, and had nothing but cattle to give in exchange for it, must have been obliged to buy salt to the value of a whole ox, or a whole sheep at a time" (Smith 1976: 39). The difficulty is then resolved if "instead of sheep or oxen, he had metals to give in exchange for it, he could easily proportion the quantity of the metal to the precise quantity of the commodity which he had immediate occasion for" (Smith 1976: 39).

Once Smith recites the fable of how metallic money emerges, he moves on to successive stories about money, such as how and why metals were coined and 


\section{Bartering savage and equation of exchange}

stamped. Many of these fables, of course, were recited by Aristotle and were passed on from one writer to another. The story-telling comes to an end when Smith finally writes: "It is in this manner that money has become in all civilized nations the universal instrument of commerce, by the intervention of which goods of all kinds are bought and sold, or exchanged for one another" (Smith 1976: 44). What follows these statements is an abrupt, almost disjunctive paragraph: "What are the rules which men naturally observe in exchanging them either for money or for one another, I shall now proceed to examine. These rules determine what may be called the relative or exchangeable value of goods" (Smith 1976: 44). These lines set the stage for dealing with the equation of exchange. But, before going any further, it is worth noting that the peculiar nature of Smith's presentation, that is, first positing money and then discussing the nature of exchange, might have something to do with the fact that the method of presentation in the Wealth of Nations does not follow the more pedagogical method in the Lectures on the Jurisprudence. In the report of 1762-1763, Smith states that he would first deal with the "rules of exchange, or what regulates the price of commodities" and then "money" (Smith 1978: 353). Under the "rules of exchange" he discusses the "two sorts of price on commodities," that is, "the natural and market price" (Smith 1978: 353 and 356). Once price has been discussed, he then introduces money as a "measure of value" (Smith 1978: 353). He follows a similar procedure in the 1766 report. Here, he starts with what "circumstances regulate the price of commodities" and arrives at money (Smith 1978: 494). In the Wealth of Nations, however, he reverses this process, that is, he introduces money first and then discusses the rules of exchange. In this work, a full discussion of the "natural and market price of commodities" is postponed until Chapter 7. Given Smith's theoretical difficulties with the concept of exchange, which will be discussed shortly, neither the latter nor the earlier method of presentation is logically meaningful, but the earlier approach is less disjunctive and has a better flow.

\section{Exchange and the meanings of "value""}

In Smith's writings the word "exchange" sometimes appears next to "barter," as in the case of the famous expression "to truck, barter and exchange," which is found three times in chapter 2 of the Wealth of Nations. The expression also appears numerous times by itself. A careful reading indicates that he mostly uses "exchange" in a broad sense, embracing both direct and indirect transactions. For example, in the first mention of the term in chapter 1, Smith speaks of how a workman would "exchange a great quantity of his own goods for a great quantity, or, what comes to the same thing, for the price of a great quantity of theirs [other workmen's goods]" (Smith 1976: 22). Or, in chapter 2, in an attempt to prove the mercantile aspect of human nature, including that of the "beggar," he states that the "old clothes which another bestows upon him he exchanges for other old clothes which suit him better, or for lodging, or for food, or for money" (Smith 1976: 27). 
The same broad use of the term "exchange" appears in the aforementioned passage concerning "the rules which men naturally observe in exchanging them [goods] either for money or for one another." Thus, when Smith $(1976: 38,60)$ uses "exchange for," or "exchanges for," he is referring to the same relation of exchange, $E$, that we encountered in the previous chapters, a relation that comprises both "barter(s) for," $B$, and "monetary relation," $M$. The last relation, as we saw in the earlier chapters, can be viewed as a union of the relations "purchases," $P$, and "sell(s) for," $S$. But how does Smith view these relations? Does he see them in the same way that generations of economic thinkers did before him, that is, a mathematical relation of equality? Moreover, does he distinguish between the qualitative and the quantitative aspects of these relations?

We can start answering these questions by looking at the famous passage that appears immediately after the paragraph inquiring about the "rules of exchange":

The word VALUE, it is to be observed, has two different meanings, and sometimes expresses the utility of some particular object, and sometimes the power of purchasing other goods which the possession of that object conveys. The one may be called "value in use;" the other, "value in exchange." The things which have the greatest value in use have frequently little or no value in exchange; on the contrary, those which have the greatest value in exchange have frequently little or no value in use. Nothing is more useful than water: but it will purchase scarce anything; scarce anything can be had in exchange for it. A diamond, on the contrary, has scarce any value in use; but a very great quantity of other goods may frequently be had in exchange for it.

(Smith 1976: 44-46)

The above is reminiscent of Aristotle's passage that we saw in Chapter 2:

Of everything which we possess there are two uses: both belong to the thing as such, but not in the same manner, for one is the proper, and the other the improper or secondary use of it. For example, a shoe is used for wear, and is used for exchange; both are uses of the shoe. He who gives a shoe in exchange for money or food to him who wants one, does indeed use the shoe as a shoe, but this is not its proper or primary purpose, for a shoe is not made to be an object of barter.

(Aristotle 1946, Book I, Part IX: 1257ª-10)

The resemblance between the two passages, of course, does not mean that Smith is reading Aristotle directly, since the distinction between the "two uses" of an object had become quite common by Smith's time. But Smith's passage shows how difficult it is, even in the mid-eighteenth century, to make something theoretically meaningful out of Aristotle's original distinctions. Actually, Smith's passage is more problematic than that of Aristotle for the following reason. 


\section{Bartering savage and equation of exchange}

To begin with let us note that throughout the passage Smith uses the expressions "things," "goods," "objects," and "commodities" interchangeably. ${ }^{3}$ This is already indicative of Smith's loose language and his lack of precision in constructing concepts needed to handle the issue of exchange. ${ }^{4}$ Another noticeable problem is that Smith's "object" appears both in the sense of a class of objects, such as "water," and as a quantitatively defined object, such as " $a$ diamond." This problem rules out any hope of distinguishing between the quantitative and the qualitative aspects of the exchange relation. The third detectable problem is that Smith, despite all his earlier storytelling about barter and development of money, does not realize the uniqueness of the money commodity or the difference between the relation of barter and monetary relation. This problem is already evident in the phrase "exchanging them either for money or for one another," which appears prior to the aforementioned passage. But it is also evident in the phrase "water will purchase scarce anything," which appears in the passage. All of these combined would lead Smith to use completely incoherent expressions, such as "the power of purchasing other goods," "value in exchange," and "greatest value in exchange." Let me briefly explain how some of these conceptual ambiguities arise.

In the first sentence Smith uses the expression "utility of some particular object" and in the second he suggests to call it "value in use." Smith's "value in use" is relatively a straightforward concept. As I have argued elsewhere, however, given the neoclassical transformation of the concept of "utility," what Smith meant by "utility" or "value in use" might appear ambiguous (Fayazmanesh 1998a). But a careful reading of Smith's works would remove any such ambiguities. For example, in the third sentence of the aforementioned passage Smith speaks of things "having value in use." However, the fourth sentence makes it clear that by this phrase he means that a class of objects is useful. But what does it mean to be useful? Again if we read Smith carefully, it becomes clear that being useful is the same thing for Smith as having some use. In the Lectures, for example, Smith writes that "a thing of no use, as a lump of clay, brought into the market will give no price" (Smith 1978: 358). But what does "having a use" mean? The answer is what one means in everyday language, that is, serving for something. This is clearly stated in many of his comments. For example, with reference to "diamonds and other jewels," Smith writes that "one can hardly say what they serve for" (Smith 1978: 333). He also writes, with reference to precious stones in general, that their "use we can hardly conceive," or that "they are of no use, but as ornaments" (Smith 1976: 191, 1978: 358). It therefore appears that for Smith a class of objects has value in use, if it has a use, that is, if it serves a purpose.

Given the above understanding, it becomes clear what Smith means when he says something has "greatest" or "little" value in use in the third sentence. A class of objects, one might say, has greater or smaller value in use relative to another class of objects, if it has greater or smaller number of uses; this is precisely how Smith is thinking since we see clear evidence of it in many passages in Smith's writings. For example, he writes at one point that among metals "if we except iron," silver and gold are "most useful" since, among their other uses, "household 
utensils" can be better made from them (Smith 1978: 370). ${ }^{5}$ Similarly, as we saw earlier, he considered a lump of clay to have "no use," that is, zero use, and the precious stones in general to have "hardly" any use except as "ornaments," that is, one use. If this is the case, the example in the fourth sentence makes sense: as a class, water has more value in use than diamonds, since it has more uses.

Similar to the previous chapters, one could simplify the arguments by formalizing Smith's concept of "value in use." For example, suppose $O$ represents the set of classes of objects and $S$, the set of "uses." The word "has," symbolized by the letter $H$, might be viewed as a binary relation from the set of objects to the set of uses, that is, $H \subset O \times S$. Thus, we can say a class of objects, $O_{1}$ has value in use if and only if there exists a non-empty set $S_{1}$ such that $O_{1} H S_{1}$. With this in mind, we can say a class of objects $O_{1}$ has greater value in use than another class of objects $\mathrm{O}_{2}$ if and only if $n>m$, where $n$ and $m$ stand for the number of elements in the set of uses of the classes of objects $O_{1}$ and $O_{2}$, respectively.

It should be noted here that what was said earlier concerning "a class of objects having value in use" holds equally well for "a given amount of an object." However, one cannot use the two concepts interchangeably, as Smith does. Clearly, an object may have value in use as a class but not as a given quantity. One must, therefore, eliminate one of the two concepts in Smith's passage. Given that Smith often refers to an object as a class, I would eliminate the second. Moreover, in the earlier analysis, one could easily replace the phrase "value in use" with the common word "usefulness" without any loss of meaning. Indeed, Smith's expression "value in use" is redundant and is merely a play on the word "value."

Let us now turn to Smith's other meaning of "value," that is, "value in exchange." Unlike "value in use," "value in exchange" is a fuzzy concept and difficult to decipher. The phrase is used by Smith in a similar fashion as "value in use." In this sense, objects "have," along with "value in use," something called "value in exchange," as, for example, the third sentence in the aforementioned passage makes it clear. But is Smith referring here to the class of objects or an individual object? The fourth sentence implies that water, as a class, has something called "value in exchange" and the next sentence switches to individual objects, such as a diamond. This lack of a clear distinction between objects as a class and quantitatively defined objects makes understanding the concept of "great" or "little" value in exchange even more difficult. The problem is confounded by the fact that barter and monetary relations run side by side in conceptualizing "value in exchange." For example, the fourth sentence implies that a class of objects, such as water, has value in exchange in the sense that it "will purchase" other objects, or other objects "can be had in exchange for it." The former is clearly a monetary concept and the latter implies barter. Here we can also see that Smith makes no theoretical distinction between money and non-money commodities, since water, a non-money commodity, is thought to be capable of "purchasing" something.

"Value in exchange" or "exchangeable value," therefore, appears to be a fuzzy concept and its fuzziness seems to stem from numerous confusions. But before discussing how these confusions actually create such a concept let us note the 


\section{Bartering savage and equation of exchange}

following. As was pointed out in Chapter 3, one can view the qualitative relation of "exchange(s) for," $E$, as the union of the qualitative relation of "barter(s) for," $B$, and the qualitative monetary relation, $M$. The last relation itself embraces "purchase(s)," $P$, and "sell(s) for," $S$. Given the relation $E$, one can develop a meaningful concept of "value in exchange" in this manner: Any value in use, $U_{i}$, that satisfies the relation of exchange, $E$, "has value in exchange." This concept is similar to what is implied in some of Smith's sentences. One can also state meaningfully that any value in use, $U_{i}$, that satisfies $E$ " $i s$ a value in exchange." This second concept, discussed in Chapter 5, mostly appears in Marx's writings. But there is another way by which one can give meaning to "value in exchange." This involves the quantitative relation of "exchange(s) for," $\xi$. Here one can say that whatever precedes $\xi$ has as its value in exchange whatever comes after $\xi$. For example, if

$$
u_{i} \xi a_{i j} u_{j} \quad \text { and } \quad u_{i} \xi a_{i k} u_{k}
$$

then one can say that $u_{i}$ has value in exchange of $a_{i j} u_{j}$ or $a_{i k} u_{k}$. But such expressions would be quite fuzzy for the following reasons. $a_{i j} u_{j}$ and $a_{i k} u_{k}$ are units of two different values in use and cannot both be "value in exchange" of $u_{i}$.

This problem can be resolved by saying that $a_{i j} u_{j}$ is the " $\mathrm{U}_{j}$-value in exchange value" and $a_{i k} u_{k}$ is the " $U_{k}$-value in exchange" of $u_{i}$. But there is yet another problem. $\xi$ refers to either barter or monetary relations, but not both simultaneously. Thus even stating something like " $a_{i j} u_{j}$ is the $U_{j}$-value in exchange of $u_{i}$ " is still fuzzy since it conflates the concept of barter value and price. In other words, assuming that $\lambda$ represents the quantitative relation of "sell(s) for" that we saw in Chapter $3, u_{i} \xi a_{i j} u_{j}$ can stand for either:

$$
u_{i} \beta a_{i j} u_{j} \quad \text { or } \quad u_{i} \lambda a_{i j} u_{j}
$$

In the first case we can say that $a_{i j} u_{j}$ is the $U_{j}$-barter-value of $u_{i}$. In the second case, however, we have to say that $U_{j}$ must be the money commodity with $u_{j}$ as its unit, and $a_{i j} u_{j}$ must represent the price of $u_{i}$.

Let us now return to Smith's concept of "value in exchange" or "exchangeable value" in light of the complexities discussed above. Actually, we can reconstruct his fuzzy concept in the following way. Consider the following direct exchanges:

$$
u_{i} \beta b_{i j} u_{j} \quad \text { and } \quad u_{i} \beta b_{i k} u_{k}
$$

As we saw above, based on these exchanges, one could write the following meaningful statements:

$1 \quad u_{i}$ has a $U_{j}$-barter-value of $b_{i j} u_{i}$, and

$2 u_{i}$ has a $U_{k}$-barter-value of $b_{i k} u_{k}$. 
But if we use a loose language or unwarranted abstraction we can transform statements 1 and 2 into the following fuzzy statements:

$1.1 u_{i}$ has barter-value of $b_{i j} u_{j}$, and

$2.1 u_{i}$ has barter-value of $b_{i k} u_{k}$.

Looser language can result in even fuzzier statements such as

$1.2 u_{i}$ has barter-value.

Not recognizing the distinction between classes of objects and quantitatively defined objects could lead to

$1.3 U_{i}$ has barter-value.

Not distinguishing between the properties of barter and monetary relations could result in the statement

$1.4 U_{i}$ has exchange-value.

Finally, expressing the last statement in a more Smithian language, we have

$1.5 U_{i}$ has value in exchange.

Now, all classes of objects, as well as quantitatively defined objects, "have" or even "are exchangeable values."

The above steps explain how a fuzzy concept called "value in exchange" comes into being. Smith develops this concept, which is alien to the language of the marketplace, by resorting to unwarranted abstractions. Thus, a statement such as "a one carat diamond has greater copper-barter-value than a one gallon of water" becomes "a diamond has greater value in exchange than water." $\mathrm{He}$ also makes no clear distinctions between properties of "barter(s) for" and "purchase(s)." Thus, objects have "power of purchasing" or "value in exchange," where the latter clearly refers to direct exchange. Furthermore, he moves freely between classes of objects and quantitatively defined objects. Thus, both "water" and "a diamond" have value in exchange. Given all such confusions, Smith arrives at the fuzzy concept of "exchangeable value of objects."

But what can we make of "great" or "little value in exchange"? The aforementioned exchanges, and the first two proper statements, imply that $u_{j}$ has greater $U_{i}$-barter-value than $u_{k}$, if $b_{i k}>b_{i j}$ or, alternatively, if $1 / b_{i j}>1 / b_{i k}$, or if $b_{j i}>b_{k i}$. But by the time we reach the last statement, we would be saying such things as $U_{j}$ has greater value in exchange than $U_{k}$, a statement that technically speaking is meaningless, and this, too, is precisely what happens in Smith's writing. 


\section{Bartering savage and equation of exchange}

In sum, "value in exchange" or "exchangeable value," as well as greater and smaller "value in exchange" are fuzzy concepts that Smith invents, and the fuzziness has to do primarily with unwarranted abstractions, lack of distinction between properties of barter and monetary relations, not recognizing the uniqueness of the money commodity, and the lack of distinction between objects as a class and quantitatively defined objects. Given all these problems, one must say that at the dawn of the Industrial Revolution the theories of money and exchange had advanced very little beyond those put forward by Aristotle. Indeed, Aristotle's passage concerning the uses of objects is less problematic than Smith's famous passage concerning the meaning of "value."

\section{Solving the equation of exchange in the "rude state of society"}

However confusing Smith's famous passage might be, it is amenable to reconstruction. Once ambiguities are set aside, we can re-express the passage in the following way:

The popular and ambiguous expression "value of something" can have two different meanings. One is the set of uses of a class of objects. This, we call the "value in use" of that class of objects. The other is a certain quantity of a second class of objects, $\mathrm{X}$, that barters for a given quantity of the first class of objects. We call this second quantity the "X-value in barter" of the first. We say a class of objects has value in use if it has a non-empty set of uses. In this sense a class of objects has greater value in use than another class of objects if it has a greater number of uses. We also say a given quantity of an object has an X-value in barter of $r$, where $r$ stands for the amount of the class of objects X. It is frequently the case that a class of objects having greater value in use than another, has, as a unit of exchange, a smaller X-value in barter than the other. For example, water has greater value in use than diamonds; however, a gallon of water has a smaller copper-value in barter than a one carat diamond.

As we can see from the aforementioned reconstruction, the point of the argument is quite simple, and, contrary to the "neoclassical" economists' claim, there is nothing "paradoxical" about it. ${ }^{6}$ It simply states that usefulness does not determine specific barter values or price. The question then becomes: "What does?"

Smith's most well-known and reasonable answer to the earlier question is found in the concept of the bartering savage at the beginning of chapter 6:

In that early and rude state of society which precedes both the accumulation of stock and the appropriation of land, the proportion between the quantities of labor necessary for acquiring different objects seems to be the only circumstance which can afford any rule for exchanging them for one another. If among a nation of hunters, for example, it usually costs twice the labor to 
kill a beaver which it does to kill a deer, one beaver should naturally exchange for or be worth two deer. It is natural that what is usually the produce of two days' or two hours' labor, should be worth double of what is usually the produce of one day's or one hour's labor.

(Smith 1976: 65)

The manner in which the problem is posed is essentially similar to that of Aristotle. Aristotle's (1946, Book I, Part IX: 1257a 15-40) "barbarous nations" is replaced with the "early and rude state of society" or the "nation of hunters," which, as mentioned earlier, is based on Smith's vision of "the native tribes of North America." Also replaced is Aristotle's (1949, Book V, Part V: 1133 ${ }^{\text {b25) }}$ concept of "five beds that exchange for a house" with the concept of two deer that exchange for one beaver. Moreover, the concept of "is" or "are equal," which appears in Aristotle's five "beds are equal to a house" (Aristotle 1949: Book V, Part V: $1133^{\mathrm{a}} 5-30,1133^{\mathrm{b}}$ 25), is replaced by the concept of "is worth," as in the case of "one beaver ... be worth two deer." "To express the ideas symbolically, we can say that if

$$
u_{i} \beta b_{i j} u_{j}
$$

then Aristotle would view this exchange as

$$
u_{i}=b_{i j} u_{j}
$$

and Smith will see it as

$$
u_{i} w b_{i j} u_{j}
$$

where $w$ stands for the relation "is worth." But for Smith this relation is the same as

$$
l_{i}=l_{j}
$$

where $l$ stands for, to use a Marxian concept, the quantity of abstract, materialized labor necessary to produce certain quantities of a useful object. Of course, Smith's concept of labor does not go beyond that of "toil and trouble," and such complicated concepts as abstract materialized labor do not appear in his writings. ${ }^{8}$

We can say that after nearly 2,000 years, Smith's bartering savage finally, and relatively unambiguously, solves the equation of exchange: one beaver exchanges for - or is worth or equal to - two deer, because the produce of two days' labor "should be worth" double the produce of one day's labor. This is, of course, a rudimentary version of what in the language of Marxian economics is often referred to as the labor embodied theory, and in the language of Smith, as well as other classical political economists, can be called "labor bestowed" theory of value. ${ }^{9}$ However rudimentary, one cannot find this straightforward solution to 


\section{Bartering savage and equation of exchange}

the equation of exchange in Aristotle's writings. Nor can one find such a precise statement of the problem and its solution in the writings of the scholastics. ${ }^{10}$ Yet, Smith's solution is neither conceptually unambiguous nor applicable to the other stages of history, especially the "civilized" or "commercial society." To refresh the reader's memory, let me briefly restate the problems involved.

Smith's solution, even for the age of the bartering savage, is not unique. As is well known, he introduces a second solution to the equation of exchange, the so-called labor commanded. This solution, of course, as David Ricardo points out, cannot be the same as the first, since the "labor bestowed" is wage rate invariant and "labor commanded" is not. ${ }^{11}$ But given Smith's numerous confusions and loose language, it is expected that he would not see the difference between the two solutions. Actually, the "labor commanded" solution precedes the "labor bestowed" solution in the Wealth of Nations. Indeed, it appears right after Smith tells the reader of his intention to "investigate the principles which regulate the exchangeable value of commodities" and proceeds to show "what is the real measure of this exchangeable value; or, wherein consists the real price of all commodities" (Smith 1976: 46). He writes at the beginning of chapter 5:

Every man is rich or poor according to the degree in which he can afford to enjoy the necessaries, conveniences, and amusements of human life. But after the division of labor has once thoroughly taken place, it is but a very small part of these with which a man's own labor can supply him. The far greater part of them he must derive from the labor of other people, and he must be rich or poor according to the quantity of that labor which he can command, or which he can afford to purchase. The value of any commodity, therefore, to the person who possesses it, and who means not to use or consume it himself, but to exchange it for other commodities, is equal to the quantity of labor which it enables him to purchase or command. Labor, therefore, is the real measure of the exchangeable value of all commodities.

(Smith 1976: 47, emphasis added)

This "labor commanded" solution to the problem of exchange reflects the "truck system" that still prevailed in the English economy of Smith's time, that is, the system of payment of wages in kind. ${ }^{12}$ However, given the Smithian method of analysis, in the age of the bartering savage not only were wages paid, but they were also paid sometimes in kind. In other words, even in the "rude state" one could "command labor" with goods. Thus, in the context of allowances for "superior hardship" and "skill" of labor, Smith writes:

In the advanced state of society, allowances of this kind, for superior hardship and superior skill, are commonly made in the wages of labor; and something of the same kind must probably have taken place in its earliest and rudest period. 
In this state of things, the whole produce of labor belongs to the laborer; and the quantity of labor commonly employed in acquiring or producing any commodity is the only circumstance which can regulate the quantity of labor which it ought commonly to purchase, command, or exchange for.

(Smith 1976: 65)

So, certain "quantity of labor" in the savage state not only exchanges for certain other "quantity of labor," but it can also purchase and command it. Again, one could express the idea symbolically by starting from

$$
u_{i} \beta a_{i j} u_{j}
$$

But since Smith moves freely between barter and monetary relation, the above relation also reads

$$
u_{i} \rho a_{i j} u_{j}
$$

where $\rho$ represents the quantitative relation "purchases." Furthermore, since goods also could purchase labor directly, then

$$
u_{i} \rho l_{\mathrm{i}}^{\prime} \quad \text { or } \quad a_{i j} u_{j} \rho l_{j}^{\prime}
$$

where $l^{\prime}$ represents the quantity of "labor commanded." But given that there is no distinction between "labor bestowed" or "labor commended" in Smith, we can say

$$
u_{i} w b_{i j} u_{j} \quad \text { implies } \quad l_{i}^{\prime}=l_{j}^{\prime}=l_{i}=l_{j}
$$

Thus, both "labor commanded" and "labor bestowed" solve the bartering savage's equation of exchange.

\section{"Civilized nations" and the solution to the equation of exchange}

In Smith's estimate neither "labor bestowed" nor "labor commanded" are exactly the "principles which regulate exchangeable value of commodities" in the last stage of society (Smith 1976: 46). In such a society money becomes more of a regulator than labor:

But when barter ceases, and money has become the common instrument of commerce, every particular commodity is more frequently exchanged for money than for any other commodity. The butcher seldom carries his beef or his mutton to the baker, or the brewer, in order to exchange them for bread or for beer; but he carries them to the market, where he exchanges them for money, and afterwards exchanges that money for bread and for beer. The 


\section{Bartering savage and equation of exchange}

quantity of money which he gets for them regulates, too, the quantity of bread and beer which he can afterwards purchase. It is more natural and obvious to him, therefore, to estimate their value by the quantity of money, the commodity for which he immediately exchanges them, than by that of bread and beer, the commodities for which he can exchange them only by the intervention of another commodity; and rather to say that his butcher's meat is worth three pence or four pence a pound, than that it is worth three or four pounds of bread, or three or four quarts of small beer. Hence it comes to pass that the exchangeable value of every commodity is more frequently estimated by the quantity of money, than by the quantity either of labor or of any other commodity which can be had in exchange for it. ${ }^{13}$

(Smith 1976: 49, emphasis added)

We are back to the old Aristotelian solution of the equation of exchange. As we saw in the case of Aristotle, underneath the equation " $\mathrm{A}=5 \mathrm{C}$ " is another equation: certain units of money $=$ certain units of money or $\mathrm{B} / 2=5(\mathrm{~B} / 10)$, where "A" is a house, "C" a shoe, and "B" the money of account (Aristotle 1949, Book V, Part V: 1133 ${ }^{\mathrm{b}} 25$ ). In the case of Smith, one can say that hidden behind "certain amount of meat is worth certain amount of beer" is the equation "certain amount of money is equal to certain amount of money."

But this solution poses the same problem for Smith that it posed for Aristotle: money, as Aristotle stated, is "not always worth the same," that is, it is not a perfect measure of value (Aristotle 1949, Book V, Part V: 1133 ${ }^{\mathrm{b}} 5-20$ ). Smith expresses the problem in this manner:

Gold and silver, however, like every other commodity, vary in their value, are sometimes cheaper and sometimes dearer, sometimes of easier and sometimes of more difficult purchase... As it costs less labor to bring those metals from the mine to the market, so when they were brought thither they could purchase or command less labor... But as a measure of quantity, such as the natural foot, fathom, or handful, which is continually varying in its own quantity, can never be an accurate measure of the quantity of other things; so a commodity which is itself continually varying in its own value, can never be an accurate measure of the value of other commodities.

(Smith 1976: 49-50)

This variability in the "value" of money commodity causes Smith, once again, to reconsider labor as a better measure, but now the argument is even more peculiar: "Equal quantities of labor, at all times and places, may be said to be of equal value to the laborer" (Smith 1976: 50). This time the issue is how much "labor" is worth to the laborer. With this in mind, once again, he states:

Labor alone, therefore, never varying in its own value, is alone the ultimate and real standard by which the value of all commodities can at all times and places be estimated and compared. It is their real price; money is their nominal price only.

(Smith 1976: 51) 
Here "labor commanded" theory reappears again and recasts doubt on the usefulness of "labor" as a measure:

But though equal quantities of labor are always of equal value to the laborer, yet to the person who employs him they appear sometimes to be of greater and sometimes of smaller value. He purchases them sometimes with a greater and sometimes with a smaller quantity of goods, and to him the price of labor seems to vary like that of all other things. It appears to him dear in the one case, and cheap in the other.

(Smith 1976: 51)

But if neither labor commanded nor money is exactly the solution to the equation of exchange, is there anything else left?

Smith tries to answer this question by introducing the element of time into the measure of value and the equation of exchange when he states:

From century to century, corn is a better measure than silver, because, from century to century, equal quantities of corn will command the same quantity of labor more nearly than equal quantities of silver. From year to year, on the contrary, silver is a better measure than corn, because equal quantities of it will more nearly command the same quantity of labor.

(Smith 1976: 54)

By now, Smith's arguments have become too convoluted to expect any meaningful resolution of the equation of exchange. As is well known, Smith will soon abandon the labor-bestowed and labor-commanded theories of value for a more tangible price theory, one that, following Marx's methodological critique of Smith, Sraffa called the "adding up theory" of price. ${ }^{14}$

In the final analysis Adam Smith followed the Aristotelian tradition of viewing exchange as an equation. The equation, however, could not be solved by Smith unambiguously and definitively beyond the age of the mythical bartering savage. The same holds true of other attempts by the classical political economists. David Ricardo, for example, affirmatively repeated Smith's labor-bestowed theory of value as the key to solving the equation of exchange in the fictitious age of primitive hunters and fishermen. But from the perspective of Ricardo's completely ahistorical point of view reality gets even more warped since in the savage state everything modern, including "capital," can still be found: "Even in that early state to which Adam Smith refers, some capital, though possibly made and accumulated by the hunter himself, would be necessary to enable him to kill his game" (Ricardo 1817: 22-23). Here the line of demarcation between Smith's proverbial rude state and the civilized society became completely obscure and the "principle that the quantity of labor bestowed on the production of commodities regulates their relative value" is only "modified" by such things as the "employment of machinery and other fixed and durable capital" or by the "the unequal durability of capital, and by the unequal rapidity with which it is returned to its employer" (Ricardo 1817: 30, 38). 


\section{Bartering savage and equation of exchange}

\section{Conclusion}

Viewing exchange as a relation of equality was not confined to Adam Smith and his fellow proponents of labor-bestowed theory of value. Even the opponents of the theory held on to some version of the equation of exchange. The most noticeable case is that of Samuel Bailey who waged the sharpest attack on Ricardo's concept of intrinsic value. "When," wrote Bailey, "we regard two objects as subjects of choice or exchange, we appear to acquire the power of expressing our feelings with precision, we say, for instance, that one A is, in our estimation, equal to two B" (Bailey 1967: 3). "But," he went on to say, "this is not the expression of positive, but of relative esteem; or, more correctly, of the relation in which A and B stand to each other in our estimation" (Bailey 1967: 3). Here, setting aside the concept of relative esteem, Bailey, too, appeared to view the two objects of exchange, $\mathrm{A}$ and $\mathrm{B}$, as somehow equal. Elsewhere, however, he expressed the equation of exchange as "value of $\mathrm{A}$ is equal to the value of B" and argued correctly that this expression means "neither more nor less than this, that $\mathrm{A}$ will exchange for B" (Bailey 1967: 7). Yet, Bailey did not make any attempt to decipher the properties of the relation "will exchange for." Instead, he chose Adam Smith's most ambiguous and problematic definition of value, that is, "the power of purchasing other goods," and several geometric analogies - which Marx correctly called "insipid"- to launch his assault on Ricardo (Bailey 1967: 4; Marx 1971: 143-144). Ultimately, Bailey's repeated assertion that value denotes "nothing positive or intrinsic, but merely the relation in which two objects stand to each other as exchangeable commodities" did nothing to change the longstanding Aristotelian view of exchange (Bailey 1967: 4). Indeed, by transforming the usual classical expression "is worth" back to "is equal," Bailey contributed to the survival of the equation of exchange and, as we see in Chapter 5, made Marx's rewriting of Aristotle's equation as " 5 beds $=1$ house" that much easier (Marx 1977: 151).

In sum, similar to Aristotle and many subsequent generations of economic thinkers, the classical proponents of the labor-bestowed theory of value, as well as its opponents, continued to view exchange as an equation. In so doing they adopted the Aristotelian method of constructing a theory of exchange without any reference to the reality of the marketplace. In the case of Smith, adopting such a method was somewhat ironic since he was, after all, the author of such pieces as "The History of Astronomy" (Smith 1980). ${ }^{15}$ This work, which was written nearly 18 years prior to the publication of the Wealth of Nations, clearly indicates that Smith was well versed with the problems of the Aristotelian physics and Galileo's methodological criticism of it, primarily on the basis of not conforming to reality. ${ }^{16}$ Yet, this did not seem to stop Smith from adopting Aristotle's method when it came to constructing a theory of exchange. In this, as it has been argued in this essay, the paradigm of bartering savage merely replaced the earlier paradigms of the bartering barbarians and sons of Adam.

The exchange of the savage subsequently became the first step in the construction of a fictitious economy that, as Marx would rightly observe, was 
the "unimaginative conceits of the eighteenth-century Robinsonades" (Marx 1973: 83). In such an economy all the attributes of a real market would vanish. One such attribute, which has periodically and in particular in the late twentieth century, received the attention of some historians of economics and methodologists was the higgling and haggling in the marketplace. In any real market in which barter is a dominant or even a surviving feature one would expect to see such bargaining to take place. Indeed, in the Wealth of Nations Smith shows his awareness of such acts when, in the context of discussing "the real measure of the exchangeable" and the issue of "hardship" and "ingenuity" of labor, he writes:

But it is not easy to find any accurate measure either of hardship or ingenuity. In exchanging indeed the different productions of different sorts of labor for one another, some allowance is commonly made for both. It is adjusted, however, not by any accurate measure, but by the higgling and bargaining of the market, according to that sort of rough equality which, though not exact, is sufficient for carrying on the business of common life.

(Smith 1976: 48-49)

In a number of other places in the Wealth of Nations Smith also refers to the act of bargaining. Yet, none of this, as Vivienne Brown (1994) notes, plays any role in Smith's theory of price determination. ${ }^{17}$ Instead, the combination of a fictitious market with some vaguely understood Newtonian concepts ultimately result in the theory of "natural price" as the "center of repose" to "which the prices of all commodities are continually gravitating" (Smith 1976: 75). In this narrative, as Brown rightly observes in the case of Locke's Essay, the "language of the market is inevitably suspect" (Brown 1994: 80). But this suspicion, as my argument implies, starts not with haggling but with the most basic language of the market, simple expressions such as "barters for," "purchases," "sells for," and "exchanges for." Smith, similar to many generations of economic thinkers before and after him, would never ask what such terms actually signify in a real market; he never observes how market transactors behave in reality; and, therefore, it never occurs to him to ask such simple questions as "what barters for what?" or "what buys what?"18 Instead, he concocts his own fictitious market and highly ambiguous expressions, such as "value in exchange," the "power of purchasing," "real exchangeable value," "real value," "real price," "natural price," etc.

The classical tradition of theorizing about exchange without any reference to the real market, of course, was challenged at times by those who insisted that the point of departure of the theory must be the actual market. One such person was William Thornton whose attack on classical theories of exchange and price determination has received much attention, particularly in the aforementioned symposium on higgling and haggling in the marketplace. Even though Thornton's assault was mostly directed against the fact that the traditional supply and demand analysis ignores such things as "higgling," his criticism went beyond the issue of the 


\section{Bartering savage and equation of exchange}

mechanism of price determination (Thornton 1869: 51, 82). By attacking the old theories, Thornton challenged implicitly a methodology, one that constructs a theory of exchange with no reference to any actual market. For example, Thornton's references to price mechanism in the Dutch and English auctions were ultimately references to "typical" market transactions (Thornton 1869: 50). Or, in discussing the assumption that "goods are offered unreservedly," he appeals to the real world by saying that "such is scarcely ever... the fact" (Thornton 1869: 55). Similarly, in discussing the exchange between labor and employer, the act of higgling between the two, and the employer's attempt to reduce wages, he writes numerous "instances of general reductions of wages brought about in this manner will readily occur to anyone at all conversant with industrial, and especially with manufacturing, history" (Thornton 1869: 82). Such rare appeals to discrepancy between theory and reality, however, not only did not have an impact on classical economics, which by the time of Thornton was on its way out, but also had no impact on the "neoclassical" theory of exchange that was emerging. ${ }^{19}$ 


\section{Primitive communities, the equation of exchange, and proper point of departure}

In chapter 2 of the first volume of Capital, after discussing the lack of commodity exchange among such communities as an "ancient Indian commune or an Inca state," Marx writes:

The exchange of commodities begins where communities have their boundaries, at their points of contact with other communities, or with members of the latter. However, as soon as products have become commodities in the external relations of a community, they also, by reaction, become commodities in the internal life of the community. Their quantitative exchangerelation is at first determined purely by chance. They become exchangeable through the mutual desire of their owners to alienate them. In the meantime, the need for others' objects of utility gradually establishes itself. The constant repetition of exchange makes it a normal social process. In the course of time, therefore, at least some part of the products must be produced intentionally for the purpose of exchange. From that moment the distinction between usefulness of things for direct consumption and their usefulness in exchange becomes firmly established. Their use-value becomes distinguished from their exchange-value. On the other hand, the quantitative proportion in which things are exchangeable becomes dependent on their production itself. Custom fixed their values at definite magnitudes.

(Marx 1977: 182)

The above account of the origin of exchange and, implicitly, money appears to be less fanciful than anything written before by economic thinkers. This is, of course, expected from someone who, for his own time, is well versed in history. Indeed, Marx appears to have a keen eye when it comes to barter, monetary relation, and the origin of money and makes many references to these topics in Grundrisse, A Contribution to the Critique of Political Economy, Theories of Surplus Value, and Capital. Yet, as we see later, when it comes to money and exchange, not even Marx can escape the strong influence of Aristotle.

This chapter is organized as follows. In the first section Marx's theory of the origin of exchange, the difficulties of barter, and the development of money is examined. It is argued that this theory is somewhat different from those put forward by 
other economic thinkers, but it is, nevertheless, unsubstantiated. Moreover, Marx believes that his theory of the origin of exchange is similar to that of Aristotle's. The second section is devoted to Marx's perfection of Aristotle's equation of exchange. How Marx replaces Aristotle's expression "is equal" with the mathematical symbol of "=," how he contends that the equation is an impossible one, and how he resolves the dilemma and reduces the relation of exchange to that of equality will be examined in this section. The third section concentrates on the second source of the concept of exchange as a relation of equality, namely, a convoluted concept of exchange-value inherited from the classical political economists. The fourth and fifth sections are devoted to whether Marx's theoretical exposition of money in Capital and A Contribution are based on the Aristotelian concepts of barter and relation of exchange. A long-lasting controversy over Marx's multiple points of departure in Capital and the relation between these beginning points and an imaginary barter economy is discussed in these two sections. It is argued in the fourth section that Marx's second point of departure, which leads to the development of money, has all the trappings of a barter economy. Furthermore, it is contended in the fifth section that the first point of departure is an isolated commodity found in capitalism, but such a commodity, according to Marx, can also be found in isolation in a pre-capitalist economy in which barter occurs. The concluding remarks in the last section deal with Marx's unique and innovative contributions to monetary theory and methodology, which are held back by the Aristotelian influence.

\section{The origin of exchange and money}

As we saw in the previous section, Marx contends in Capital that exchange begins on the boundaries of different communities and then spreads inward. Even though this contention does not appear to be as far-fetched as the previous claims concerning the origin of exchange, it still remains unsubstantiated, particularly since Marx's knowledge of primitive communities was quite limited. ${ }^{1}$ Marx does not state what is the source of his information concerning "ancient Indian commune or an Inca state." Nor does he indicate which other ancient community began exchanging on its boundaries. Actually, in a similar passage in A Contribution Marx refers to Aristotle as the originator of the idea of exchange between communities. Here, in a more extensive discussion of barter than that which appears in Capital, he states:

In fact, the exchange of commodities evolves originally not within primitive communities, ${ }^{*}$ but on their margins, on their borders, the few points where they come into contact with other communities. This is where barter begins and moves thence into the interior of the community, exerting a disintegrating influence upon it. The particular use-values which, as a result of barter between different communities, become commodities, e.g., slaves, cattle, metals, usually serve also as the first money within these communities... The 
gradual extension of barter, the growing number of exchange transactions, and the increasing variety of commodities bartered lead, therefore, to the further development of the commodity as exchange-value, stimulates the formation of money and consequently has a disintegrating effect on direct barter.

(Marx 1970: 50)

The asterisk in the first sentence refers to a footnote in which Marx writes:

Aristotle makes a similar observation with regard to the individual family considered as the primitive community. But the primitive form of the family is the tribal family, from the historical dissolution of which the individual family develops. "In the first community, indeed which is the family, this art" (that is, trade) "is obviously of no use."

(Marx 1970: 50)

Marx's reading of Aristotle is, of course, quite generous. As we saw earlier, Aristotle speaks of the "first community... which is the family" (Aristotle 1946, Book I, Part IX: 1257 $15-40$ ). This primordial family is obviously not the "primitive community," such as the "ancient Indian commune or an Inca state," that Marx has in mind. So it seems Marx is reading into Aristotle more than what is there.

Marx follows the remarks by a comment concerning the "difficulties of barter" leading to the development of money:

Economists usually reason that the emergence of money is due to external difficulties which the expansion of barter encounters... For example commodities as use-values are not divisible at will, a property which as exchange-values they should possess. Or it may happen that the commodity belonging to A may be use-value required by B; whereas B's commodity may not have any use-value for A. Or the commodity-owners may need each other's commodities but these cannot be divided and their relative exchangevalues are different.

(Marx 1970: 50-51)

It should be emphasized that Marx criticizes the notion of difficulties of barter and the emergence of money not because the notion has no historical basis, but because he believes that economists view the evolution of money to be the result of "technical inconvenience" and forget that difficulties of barter "arise from the evolution of exchange-value and hence from that of social labor as universal labor" (Marx 1970: 50-51). As will be discussed later, Marx himself tries to develop money theoretically on the basis of the evolution of exchange-value.

Similar views, concerning the difficulties of barter, are expressed in "The Chapter on Money" in Grundrisse. Here Marx writes: "In direct barter, every article cannot be exchanged for every other; a specific activity can be exchanged 
only for certain specific products. Money can overcome the difficulties inherent in barter only by generalizing them, making them universal" (Marx 1973: 149-150).

In this earlier work, we also see a very short discussion of the "crudest barter" taking place among "Negroes on the West African coast," where the "commodities are first transformed into bars in the head and in speech before they are exchanged for one another" (Marx 1973: 142). Once again, however, the source of this claim remains unmentioned. The most interesting aspect of this claim is that in order "to cover the excess of one value over another in exchange, in order to liquidate the balance, the crudest barter, just as with international trade today, requires payment in money" (Marx 1973: 142-143). But if barter is difficult, why do "Negroes on the West African coast," as well as international traders, use barter, given that money actually exists? Or if barter can coexist with money, could it be that the theory of the difficulties of barter leading to the development of money is false? These issues do not make Marx question the received view of barter and the development of money. Indeed, even though Marx recognizes the existence of barter in international trade in his own lifetime, he nevertheless continues to view barter as something primitive. This view is expressed in many places, such as in A Contribution and Capital, as we saw earlier, and in Grundrisse and Theories of Surplus Value, as we shall see shortly. In the last work Marx argues that in "direct barter the bulk of production is intended by the producer to satisfy his own need... What is exchanged as a commodity is the surplus and it is unimportant whether this surplus is exchanged or not" (Marx 1968: 508-509). This is indeed the primordial concept of barter, where supposedly primitive communities or individuals exchange goods for one another. The concept obviously has nothing to do with the actual history, such as the medieval economy, where we often see profit and not the satisfaction of individual needs as the motive behind barter.

Before ending this section let me reiterate Marx's account of the development of money. As noted above, in A Contribution Marx claims that the first money, supposedly slaves, cattle, or metals, appears within primitive communities. This claim is problematic for at least two reasons. First, it is unsubstantiated and, therefore, it remains no more than a folktale. Second, it is unclear what Marx means by "money." He clearly distinguishes between a measure of value, which he calls "money of account," and a means of circulation (Marx 1977: 195). Marx also recognizes that for a commodity to be money it must function both as a unit of account and as a means of exchange, and, in this sense, only "[g]old (or silver)" is money (Marx 1977: 227). If this is the case, then such things as slave and cattle, which might have been used as units of account, are not exactly money. The problem is also confounded by the fact that in Capital Marx writes the following:

Nomadic peoples are the first to develop the money-form, because all their worldly possessions are in the movable and directly alienable form, and because of this mode of life, by continually bringing them into contact with foreign communities, encourages the exchange of products. Men have often made man himself into primitive material of money, in the shape of slaves.

(Marx 1977: 183) 
This account of the development of money does not exactly fit the argument that money developed within some primitive communities. Also, the argument that money developed by nomads - since their worldly possession was movable - is different from saying that difficulties of barter led to the development of money.

In sum, Marx's claims concerning barter, its difficulties, and the origin of money are at times unsubstantiated, unclear, and even contradictory. Nevertheless, it seems for the most part he believes that exchange begins between some primitive communities and that the difficulties of barter lead to the emergence of money. As we shall see, it is this belief that explains Marx's theoretical exposition of the emergence of money in both A Contribution and Capital. But before examining this issue, Marx's concept of the relation of exchange, which is greatly influenced by Aristotle, must be examined.

\section{Aristotle and the relation of exchange}

In a well-known passage in Capital dealing with the concept of "equivalentform," Marx refers to Aristotle as "the great investigator who was the first to analyze the value form, like so many other forms of thought, society and nature" and states:

In the first place, he states quite clearly that the money-form of commodities is only a more developed aspect of the simple form of value, i.e. of the expression of the value of a commodity in some other commodity chosen at random, for he says:

5 beds $=1$ house

is indistinguishable from

5 beds $=$ a certain amount of money

He further sees that the value-relation which provides the framework for this expression of value itself requires that the house should be qualitatively equated with the bed, and that these things, being distinct to the senses, could not be compared with each other as commensurable magnitudes if they lacked this essential identity. "There can be no exchange," he says, "without equality and no equality without commensurability."

(Marx 1977: 151)

What is interesting about this passage is not that Marx traces the origin of the concept of exchange relation to Aristotle but that he perfects this concept in at least two ways.

First, he turns Aristotle's ambiguous geometry of exchange into his own famous "equation" of exchange, expressing the relation of exchange by the mathematical symbol " $=. " 2$ This is a new development in the history of the theory of 
exchange, since even though many economists in the classical era had also viewed the exchange relation as a relation of equality, they did not express it in a mathematical form. For example, as pointed out in Chapter 4, when Samuel Bailey (1967: 2-3) writes that in the act of exchange "one A is in our estimation equal to two B," he does not use the symbol "=," as does Marx.

Second, while Aristotle was unclear about the nature of the uniform substance that lies behind the relation of exchange, Marx is quite clear about the underlying substance. As it is well known, Marx argued that the uniform substance is "value" or "congealed quantities of homogeneous human labor, i.e. of human-power expended without regard to the form of its expenditure" (Marx 1977: 128). But, according to Marx, Aristotle faltered and abandoned the further analysis that would have led to the concept of value when he wrote: " 'It is, however, in reality, impossible that such unlike things can be commensurable,' i.e. quantitatively equal" (Marx 1977: 151). Aristotle, Marx contends, "himself tells us what prevented any further analysis":

the lack of a concept of value. What is the homogenous element, i.e. the common substance, which the house represents from the point of view of the bed, in the value expression of for the bed? Such a thing, in truth, cannot exist, says Aristotle. But why not? Towards the bed, the house represents something equal, in so far as it represents what is really equal, both in the bed and the house. And that is-human labor.

However, Aristotle himself was unable to extract this fact, that, in the form of commodity-values, all labor is expressed as equal human labor and therefore as labor of equal quality, by inspection from the form of value, because the Greek society was founded on the labor of slaves, hence had its natural basis the inequality of men and their labor powers. The secret of the expression of value, namely the equality and equivalence of all kinds of labor because and in so far as they are human equality had already acquired the permanence of a fixed popular opinion. This however become possible only in a society where the commodity-form is the universal form of the product of labor, hence the dominant social relation is the relation between men as possessors of commodities. Aristotle's genius is displayed precisely by his discovery of a relation of equality in the value expression of commodities. Only the historical limitation inherent in the society in which he lived prevented him from finding out what "in reality" this relation of equality consisted of.

(Marx 1977: 151-152)

To make Marx's argument short we can say the following. Aristotle rightly saw the relation of exchange as one of equality, that is, "=," as in the case of " 5 beds $=1$ house." Also, he rightly saw that, as qualitatively different objects, beds and houses could not possibly be equal, that is, as physical objects, 5 beds ₹ 1 house. However, given Aristotle's historical limitation, he could not see that 5 beds are equal to 1 house as something else, namely, as values. To put it even more concisely, from Marx's perspective, Aristotle's expression 
" 5 beds $=1$ house" can only make sense if it is read as " 5 beds as congealed abstract labor $=1$ house as congealed abstract labor."

This argument concerning the nature of the exchange relation " $=$ " is repeated in various places in Marx's economic writings. It is actually the basis for one of the most important and neglected lines in the early pages of Capital, namely that "clearly, the exchange relation of commodities is characterized precisely by its abstraction from their use-values" (Marx 1977: 127). As I have argued elsewhere, had it been noticed that by this statement Marx means that the relation of exchange, "=," is characterized not by abstraction from the usefulness or utility of beds and houses, but from beds and houses as physical objects, the long-lasting controversy over the so-called derivation of value would have been settled much earlier (Fayazmanesh 1994).

In sum, Aristotle seems to have left a lasting impression on Marx's concept of the relation of exchange and his famous "derivation of value by analysis of the equations in which every exchange-value is expressed," a derivation that Marx tries a number of times to perfect (Marx 1977: 94). This, of course, does not mean that Marx's concept of exchange stems directly from Aristotle. As mentioned in Chapter 4, Marx's immediate predecessors, the classical political economists, also saw the relation of exchange as expressing a common, equal substance. But they used mostly expressions such as "is worth," rather than "is equal" to express the exchange relation. Marx's unique twist is to express the relation of exchange by a mathematical symbol and then argue that such a relation does not make sense unless it is understood in a particular way.

Before going to the next section it should be pointed out that in representing the relation of exchange, Marx, too, uses the expression "is worth." But he views this expression as identical to "=." For example, in Capital, he writes "x commodity A = y commodity B" and then translates it to mean "x commodity A is worth y commodity B" (Marx 1977: 139, emphasis added). In addition to "is worth," Marx uses, among others, the concepts of "as good as," "replaceable," "congruence," "parity," and "identity" to express the relation of exchange. ${ }^{3}$ This perceived terminological equivalence is a manifestation of technical confusion on Marx's part. As was argued in Chapter 4, the symbol "=" is used in mathematics to express a relation defined on the set of numbers, and if used in any other way, the two sides of the symbol must have the same dimension. Moreover, "=" is an equivalence relation in the sense that it is reflexive, symmetric, and transitive. But a relation such as "is worth"-which, as an expression that is actually used in market exchange, seems to be Marx's most reasonable expression of the exchange relation-is not an equivalence relation, since it is surely not reflexive. Furthermore, the two sides of the equation do not have the same dimension. Thus, "is worth" cannot be identical to "is equal" in any strict sense. But, as we shall see shortly, Marx is using the relation "=" very strictly. ${ }^{4}$

\section{The relation of exchange and exchange-value}

There is also another reason for Marx to believe that the exchange relation is a relation of equality. This has to do with the conceptual ambiguity surrounding 


\section{The equation of exchange and proper point of departure}

Marx's expression "exchange-value." The expression is obviously related to the classical concept of "value in exchange" or "exchangeable value," which, as discussed in Chapter 4, is also technically unclear. Marx, similar to Smith and his followers, has a difficult time making something unambiguous and meaningful out of the term "exchange-value." He uses this expression in many different senses without being aware of the differences: (1) as a relation between useful objects, (2) as certain quantities of a useful object that can be exchanged for a unit of another useful object, (3) as a form of appearance of value, and (4) as a class of useful objects that can be exchanged for another class of useful objects. Some of these concepts of exchange-value reinforce Marx's view of exchange as a relation of equality, as will be shown later.

The clearest expression of the first concept of exchange-value appears in the early part of $A$ Contribution: "Exchange-value seems at first to be a quantitative relation, the proportion in which use-values are exchanged for one another. In this relation they constitute equal exchangeable magnitudes" (Marx 1970: 28). The same line, of course, appears in Capital as well (Marx 1977: 126). This concept of "exchange-value" stems from a unique way of viewing the relation between "use-value" and "exchange-value" that Marx developed in Grundrisse, a view that cannot be found among earlier classical political economists. The new concept appears when Marx starts to think of "value" not in the classical sense of "the unity of use-value and exchange-value" but in the sense of "content" and "form":

Use-value is presupposed even in simple exchange or barter. But here, where exchange takes place only for the reciprocal use of the commodity, the usevalue, i.e., the content, the natural particularity of the commodity has as such no standing as an economic form. Its form, rather is exchange-value. The content apart from this form is irrelevant; it is not a content of the relation as a social relation.

(Marx 1973: 267)

These remarks are significant in two respects. ${ }^{6}$ First, they show the beginning of certain conceptual rupture between Marx's economic categories and those of classical economists. Use-value is viewed here as a "content" whereas exchangevalue is viewed as a "form" or "social relation." Moreover, as a content use-value seems to coincide with "the natural particularity of the commodity." If this is the case, a commodity, rather than having use-value, as was mostly the case for the classicals, now appears to be a use-value. ${ }^{7}$ Exchange-value then appears as a social relation between these use-values.

Before going any further, it should be noted that conceptualizing use-value and exchange-value in terms of "content" and "form" lends itself well to the relational reconstruction of these concepts discussed in the previous chapters. For example, looking back at Chapter 2 and assuming that $B$ stands for "barter(s) for" and $U$ for the set of use-values, then the set of "exchange-values," $V$, can be viewed as

$$
V=\left\{U: U_{i} B U_{j} \text {, for all } i, j=1, \ldots, n \text { and } i \neq j\right\}
$$


Here one can say that $V$ consists of a content, $U$, on which a relation, $B$, is defined. This would be a unique way of thinking of "use-values" and "exchangevalues" in terms of "content" and "form." In this sense an "exchange-value" conveys a relation, but it is not itself a relation, as Marx would have it.

The second sense in which "exchange-value" is used by Marx is very close to how classicals used "value in exchange." In this sense a commodity has an "exchange-value" rather than is an "exchange-value." For example, in $A$ Contribution Marx writes: "The exchange-value of a palace can be expressed in a definite number of tins of boot-polish" (Marx 1970: 28). Here, by exchangevalue of a palace Marx clearly means certain quantities of tins of boot-polish. This concept of exchange-value is in fact generalized in the Theories of Surplus Value, where in response to Bailey, Marx writes that "If we speak of the value in exchange of a thing, we mean in the first instance of course the relative quantities of all other commodities that can be exchanged for the first commodity" (Marx 1971: 128, emphasis in the original). In this case, "exchangevalue" becomes a quantitative concept, similar to that of the classical political economists. As such it would suffer from some of the same problems that was discussed in the case of Smith. For example, in the early pages of Capital, after discussing the exchange of a quarter of wheat for " $x$ boot-polish, $y$ silk or $z$ gold, etc.," Marx writes:

$\mathrm{x}$ boot-polish, y silk, or z gold, etc., each represents the exchange-value of one quarter of wheat. Therefore $\mathrm{x}$ boot-polish, y silk, $\mathrm{z}$ gold, etc., must, as exchange-values, be mutually replaceable or of identical magnitude. It follows from this that, firstly, the valid exchange-values of a particular commodity express something equal, and secondly, exchange-value cannot be anything other than the mode of expression of the "form of appearance," of a content indistinguishable from it.

(Marx 1977: 127)

In other words, $x$ boot-polish $=y$ silk $=z$ gold $=$ one quarter of wheat. This concept of exchange-value clearly exhibits the same set of confusions and unwarranted generalizations that was discussed in the case of Adam Smith. Without repeating what was said in Chapter 4, let me just note that if one realizes that the $x$ boot-polish, $y$ silk, and $z$ gold are not simply "exchange-values" of a quarter of wheat but " $x$ boot-polish-barter-value," " $y$ silk-barter-value," and " $z$ gold-bartervalue" of a quarter of wheat, then one would not see them as "mutually replaceable" or of "identical magnitude." That is, if "exchange-value" is defined unambiguously, there would be less chance of viewing the relation of exchange as "=."

In the aforementioned passage from Capital we also see a third meaning of "exchange-value": "the 'form of appearance,' of a content indistinguishable from it." This definition stems from Marx's concept of "science," which he extends to political economy as well. ${ }^{8}$ In accordance to his distinction between "real internal framework" and "apparent framework," Marx views "value in exchange" as the 


\section{The equation of exchange and proper point of departure}

"form of appearance" or the phenomenal form of value (Marx 1977: 148, 174-175). In other words, Aristotle's equation

$$
5 \text { beds }=1 \text { house }
$$

is merely the form of appearance of another equation:

5 beds as congealed abstract labor $=1$ house as congealed abstract labor

This concept, too, clearly reinforces viewing the relation of exchange as an equality relation, since if commodities are equal as values, then they are also equal as exchange-values.

There is also a fourth concept of "exchange-value" in Marx, that is, a class of useful objects that would exchange for another. We can see the clearest expression of this usage when, in the "Notes on Adolph Wagner," Marx states that insofar as a use-value is "a bearer of exchange-value . . . it is itself 'exchange-value" " (Marx 1975a: 198, emphasis in the original). In this sense a use-value that exchanges for another is, once again, an exchange-value rather than having exchange-value. Such a concept can be arrived at by resorting to the same unwarranted generalization and errors that we saw in the case of Adam Smith. Without repeating the steps in the transition from having exchange-value to being exchange-value, we can simply say that by dropping the $x, y$, and $z$, the boot polish, silk, and gold all become simply exchange-values. This would make these use-values appear to be identical to one another.

In sum, Marx's view of the relation of exchange as that of equality has its source in Aristotle and a whole host of economic thinkers who followed the Aristotelian view of exchange. But this view is also reinforced by Marx's many different and ambiguous notions of exchange-value. The result is that Marx reduces his many expressions of exchange relation - such as "is worth," "as good as," "replaceable," "congruence," "parity," "identity," etc. - to the mathematical relation of "=." In this reduction, Marx does not notice that some of these expressions have properties that are incompatible with the notion of "is equal." Such an oversight is, at least partly, due to the force of tradition originally laid down by Aristotle.

The old notion of equality in exchange also prevents Marx from seeing that the relation of exchange is clearly embedded in everyday language of the marketplace and in his own language and analysis when, for example, he writes that something is "bartered for" something else or when he refers to "M-C" as "a purchase" and "C-M" as "a sale" (Marx 1974: 118, 1977: 205). Such relations, as argued in this book, are not identical to the relation of equality. It is mainly because Marx assumes from the very start that exchange involves the give and take of some equal substance that he is prevented from carrying forward his unique insights concerning exchange.

Having now looked at Marx's contentions concerning the historical development of money and his notion of exchange as a relation of equality, his attempt to introduce money theoretically can be examined. As seen below, this attempt is quite controversial. 


\section{Monetary theory and history: the second point of departure}

To what extent is Marx's theoretical development of money at the beginning of Capital or A Contribution influenced by his Aristotelian concept of barter and relation of exchange? Answering this requires answering a related question: Is the point of departure of Capital historical or logical? If the former, does Marx's belief that primitive communities engaged in barter influence Capital's beginning point? I answer these questions in the next two sections.

In his famous letter of April 2, 1858, to Engels, and with reference to the plan for "capital," Marx writes that the transition from "capital to landed property is at the same time historical" and, similarly, "the transition of landed property to wage labor is not only dialectical but historical" (Marx 1975b: 97). Later, in this same letter and with reference to his plan for the section on money, Marx writes:

Money, as the exposition of its functions shows, posits the requisite of value which enters circulation, maintains itself in circulation and at the same time it posits circulation - that is, money posits capital. This transition is also historical. The antediluvian form of capital is trading capital, which always develops money. At the same time real capital arises from money, or merchants' capital, which gains control of production.

(Marx 1975b: 100)

According to the above explanations, certain parts of Marx's economic treatise, including part II of the first volume of Capital, that is, "The Transformation of Money into Capital," or the circuit $\mathrm{M}-\mathrm{C}-\mathrm{M}^{\prime}$, as well as the takeover of the merchants' capital by productive capital, or the circuit M-C...P...C-M', are reflective of history. But is part I of Capital, particularly the circuit C-M-C and the whole development of "money-form" by means of a series of equation, also reflective of history?

Since there is no answer to this question in the aforementioned letter to Engels, and finding a direct answer elsewhere is difficult, a long-standing controversy about the issue has developed. The controversy starts with Engels's 1859 review of $A$ Contribution when in discussing Marx's method of presentation and the relation between logical and historical method it is stated:

The logical method of approach was therefore the only suitable one. This, however, is indeed nothing but the historical method, only stripped of its historical form and diverting chance occurrences. The point where this history begins must also be the starting point of the train of thought, and its further progress will be simply the reflection, in abstract and theoretically consistent form, of historical course. Though the reflection is corrected, it is corrected in accordance with laws provided by the actual historical course.

(Marx 1970: 225)

After arguing that Marx's method of presentation in A Contribution essentially is an abstract version of history stripped of "chance occurrences," Engels 
contends: "Political economy begins with commodities, with the moment when products are exchanged, either by individuals or primitive communities" (Marx 1970: 225).

Engels's comments surely give the impression that Marx starts his economic treatise with simple exchange or barter. The argument is also coupled with Engels's famous contention that the point of departure of Capital is "simple commodity production," a scenario that has often been interpreted as a fictitious stage of production by the opponent of Engels's interpretation (Arthur 1997: 14). This appears, for example, when in the discussion of how concepts are developed in their "process of historical or logical formation" Engels writes in the preface to the third volume of Capital that at the beginning of first volume:

Marx takes simple commodity production as his historical proposition, only later, proceeding from this basis, to come on to capital... he proceeds precisely there from the simple commodity and not from a conceptually and historically secondary form, the commodity as already modified by capitalism.

(Marx 1981: 103)

This argument, as Christopher Arthur (1997) notes, subsequently appears in different forms in some discussions of Marx's method, particularly those of Ronald Meek (1958).

The opponents of this argument, such as Arthur himself, often deny that Marx's point of departure was "simple commodity production" or "barter." They point out that the expression "simple commodity production" is not even found in Marx's economic writings (Arthur 1997: 13). More importantly, they contend that the economic stage of "simple commodity production," which has never existed, cannot be the point of departure of Capital. This is because Marx's method of analysis is not "linear" in the sense of starting from a bartering economy and ending with a capitalist economy, but it is rather circular in the sense that it "bends back" on itself (Arthur 1997: 30). ${ }^{9}$

In some cases it is also argued that there are multiple points of departure in Capital. For example, in referring to Banaji's (1979) essay, Arthur argues that Capital has two points of departure: one "analytical" - that is, the commodity, "from which we separate out value" - and the other "synthetic"- that is, "value," from which more "complex relationships" are developed (Arthur 1997: 26). However, neither of these points, it is contended, has anything to do with the "simple commodity production" or barter. Finally, it is contended that beginning a theoretical exposition along the line of history defies Marx's argument in the 1857 Introduction to the Critique of Political Economy that economic categories should not appear in a historical order but "in accordance with the articulation of the existing system" (Arthur 1997: 11).

Which side of this controversy, if any, is correct? It should be admitted at the outset that Marx's method of presentation at times is extremely convoluted and that it is quite possible that he, himself, might have been unclear as to what is being done and why. Indeed, one can dismiss the last of the above arguments - that a 
historical point of departure defies Marx's argument in the 1857 Introduction-as a non-starter. The commodity satisfies almost none of the criteria for a proper beginning point set forth in the 1857 Introduction. ${ }^{10}$ Indeed, Marx's plan in the 1857-1858 manuscripts for writing an economic treatise goes through so many changes that one cannot accept what is stated on the method of presentation in these manuscripts as definitive. But what about the other points raised by the opponents of Engels's interpretation? Could they be right?

Let us start with the issue of multiplicity of the starting point. It is true that there are not just one, but at least two points of departure in Capital, one at the very beginning, that is, the first section of "Chapter 1: The Commodity", and another, a few pages later, in the third section of the same chapter entitled "The Value-form, or Exchange-value" (Marx 1977: 125, 138) ${ }^{11}$ It would be more fruitful to look at the second point of departure first, since it sheds light on the first starting point.

Having "derived" value from the form of appearance of the commodity, Marx begins a new trajectory, which is explained as such: "In fact we started from exchange-value, or the exchange relation of commodities, in order to track down the value that lay hidden within it. We must now turn to this form of appearance of value" (Marx 1977: 139). The most common value-form, Marx argues, is the money-form. The task, according to Marx, is "to show the origin of this moneyform ...t to trace the development of the expression of value contained in the value-relation of commodities from its simplest, almost imperceptible outline to the dazzling money-form" (Marx 1977: 139, emphasis added). To carry out the task, Marx starts with "(a) The Simple, Isolated, or Accidental Form of Value," and proceeds to "(b) The Total or Expanded Form of Value," "(c) The General Form of Value," and “(d) The Money Form” (Marx 1977: 139, 154, 157, 162).

The "simple, isolated or accidental form" is expressed by the equation of exchange discussed earlier, that is, " $\mathrm{x}$ commodity $\mathrm{A}=\mathrm{y}$ commodity $\mathrm{B}$ or: $\mathrm{x}$ commodity A is worth y commodity B" (Marx 1977: 139). Even though in the analysis of this form Marx does not mention barter, there are plenty of reasons to believe that the analysis is reflective of a barter system.

First, Marx wants to "show the origin of money-form." And from what was discussed earlier, we know that he believes, as did Aristotle, that the origin of money is to be found in barter. So, it seems that starting analytically from barter fits well with Marx's concept of historical development of exchange and money.

Second, as we saw earlier, Marx contends, with reference to the beginning of exchange of commodities, that the "proportions in which they are exchangeable are at first quite a matter of chance" (Marx 1977: 182). Given this "matter of chance" exchange, is it just sheer accident that he calls the point of departure of his theoretical development of money "The Simple, Isolated, or Accidental Form of Value" and starts the section with the exchange of two commodities? This surely does not appear to be the case. Indeed, in discussing each form, some of Marx's comments make it quite clear that his theoretical development runs parallel to what he perceives to be the historical development of money. For example, with regard to the first form he writes: "This form, it is plain, appears in practice only in the early stages, when the products of labour are converted into commodities 
by accidental occasional exchanges" (Marx 1977: 158). As far as the second form is concerned, he states: "The expanded form of value comes into actual existence for the first time when a particular product of labour, such as cattle, is no longer exceptionally, but habitually, exchanged for various commodities" (Marx 1977: 158). This statement is quite compatible with Marx's idea, mentioned earlier, that as a result of barter between different communities, such commodities as cattle began to play the role of money. In reference to the third form, he argues: "By this form, commodities are, for the first time, really brought into relation with each other as values, or permitted to appear to each other as exchange-values" (Marx 1977: 158). Finally, with regard to the last form, that is, money-form, he states: "Among the commodities...there is one in particular which has historically conquered this advantageous position: gold" (Marx 1977: 162).

Third, certain passages in Marx reinforce the belief that the entire analysis of simple exchange pertains to a barter economy. For example, in Capital, just before the passage concerning exchange on the boundaries of communities, Marx writes:

The direct exchange of products has the form of the simple expression of value in one respect, but not as yet in another. That form was $\mathrm{x}$ commodity $\mathrm{A}=\mathrm{y}$ commodity $\mathrm{B}$. The form of direct exchange is $\mathrm{x}$ use-value $\mathrm{A}=\mathrm{y}$ use-value $\mathrm{B}$.* The articles A and B in this case are not as yet commodities, but become so only through the act of exchange. The first way in which an object of utility attains the possibility of becoming an exchange-value is to exist as a non-use-value, as quantum of use-value superfluous to the immediate needs of its owner.

(Marx 1977: 181-182) $)^{12}$

Given that, once exchange has taken place and useful objects have turned into commodities, the form of direct barter is precisely the same as the "Simple, Isolated, or Accidental Form of Value," one has no choice but to conclude that Marx's analysis of money starts with "direct barter." The above asterisk, which appears as a footnote, does not help the matter either. Here Marx writes:

So long as a chaotic mass of articles is offered as the equivalent for a single article (as is often the case among savages), instead of two distinct objects of utility being exchanged, we are only at the threshold of even the direct exchange of product.

(Marx 1977: 181)

Here, it seems, despite all his criticism of the classical writers' imageries, Marx is invoking the image of Smith's bartering savages to construct a theory of exchange and money. But who the savages are and whether they are the same as the "primitive communities" remain unclear.

Fourth, as mentioned earlier, Marx believes in the existence of certain historical stages, such as those of merchant's and productive capital. Given this belief, he puts forward the circuits $\mathrm{M}-\mathrm{C}-\mathrm{M}^{\prime}$ and $\mathrm{M}-\mathrm{C} \cdots \mathrm{P} \ldots \mathrm{C}-\mathrm{M}^{\prime}$ as reflecting history. Following Aristotle he also believes, as it has been pointed out, that there is a stage in human history where communities barter with one another regularly and 
subsequently barter moves into the interior of the communities themselves. Given this belief, it is only natural to expect that he views his second point of departure as reflecting history as well.

It is no wonder, therefore, that many people, including Marx's closest associate, Engels, read his method of presentation as one starting from "simple commodity production" and direct barter. Given what was said earlier, one surely gets the impression that the analysis, in so far as the second point of departure is concerned, is based on some false notion of history. ${ }^{13}$ It is also no wonder that Marx let Engels's review of $A$ Contribution pass without any objection. ${ }^{14}$

\section{Monetary theory and history: the first point of departure}

We can now return to the first point of departure, which appears as these famous lines in Capital: "The wealth of societies in which the capitalist mode of production prevails appears as the 'immense collection of commodities'; the individual commodity appears as its elementary form. Our investigation therefore begins with the analysis of the commodity" (Marx 1977: 125). Marx, of course, subsequently goes on to say that the commodity has a twofold aspect, a use-value and an exchange-value. Similarly, he writes in A Contribution: "The wealth of bourgeois society, at first sight, presents itself as an immense accumulation of commodities, its unit being a single commodity. Every commodity, however, has a twofold aspect—use-value and exchange-value" (Marx 1970: 27, emphasis in the original). As mentioned earlier, looking at these lines, opponents of Engels's interpretation have argued that (1) this is not a beginning that has its roots in the economic stage of "simple commodity production," (2) the expression "simple commodity production" cannot be found anywhere in Marx, and (3) Marx's overall method of analysis is circular, starting and ending with the commodity in a capitalist economy, albeit in a "dialectical" fashion. ${ }^{15}$

Let us start with the second point of contention and then proceed to the first and third. Even though one cannot find the expression "simple commodity production" in Marx's writings, one does encounter the term "simple commodity." By "simple commodity" Marx means a use-value and an exchange-value or, going beyond the form of appearance, a use-value and a value. For example, in the "Result of the Immediate Process of Production" Marx writes in reference to the "form assumed by capital" that "like the simple commodity, it possesses the double shape of use-value and exchange-value" (Marx 1977: 979, emphasis added).

Marx distinguishes this "simple commodity" from the commodity that results from capitalist production, i.e., a commodity that is a use-value and the sum of constant, variable, and surplus value. The difference is expressed in a number of places such as this:

The commodity that emerges from capitalist production is different from the commodity we began as the element, the precondition of capitalist production. We began with the individual commodity viewed as an autonomous article ... the commodity as the product of capital can be said to contain both paid and unpaid labour... 


\section{The equation of exchange and proper point of departure}

As the product of capital, the commodity embodies the total value of capital together with the surplus value, unlike the original commodity, which appeared to us as an autonomous thing.

(Marx 1977: 953-954)

Clearly, by Marx's own admission, the commodity that is found at the beginning of Capital is the "simple commodity" and not the commodity produced by capital. But this creates a major problem.

The opening lines in Capital and A Contribution that we saw earlier give the illusion that the starting point is the commodity produced under the capitalist mode of production. The same impression is given when Marx writes in the "Notes on Adolph Wagner":

In the first place I do not start out from "concepts," hence I do not start out from "the concept of value," and do not have "to divide" these in any way. What I start out from is the simplest social form in which labor-product is presented in contemporary society, and this is the "commodity." I analyze it, and right from the beginning, in the form in which it appears. Here I find that it is, on the one hand, in its natural form, a useful thing, alias a use-value; on the other hand, it is a bearer of exchange-value, and from this view point, it is itself "exchange-value." Further analysis of the latter shows me that exchange-value is only a "form of appearance," the autonomous mode of presentation of the value contained in the commodity, and then I move on to the analysis of the latter.

(Marx 1975a: 198, emphasis in the original)

How can the initial commodity not be the product of capital and yet be found in the "contemporary society"?

The answer to this question, I believe, lies in the catchwords that we saw in Capital - such as the "isolated," "simple" social form or the "individual" commodity in its "elementary" form - or the expressions that we found in $A$ Contribution - such as a "single" commodity. Apparently, Marx is not looking at a commodity as the product of capital, but at the commodity in the capitalist economy that is taken singly, individually, elementally, in isolation from other commodities. Such a commodity can be found in pre-capitalist modes of production as well where there are some isolated pockets of commodity production. This interpretation is supported well by the following passage in the "Result of the Immediate Process of Production":

We begin with the commodity, with this specific social form of the productfor it is the foundation and premise of capitalist production... Prior to capitalist production a large part of what was produced did not take the form of commodities, nor was it produced for that purpose. What is more, a large proportion of the products that went into production were not commodities and did not go into the process of production as commodities. The transformation 
of produce into commodities occurred only at isolated points; it affected only the surplus produce, or only particular sectors (such as manufactured goods). Produce as a whole did not enter into the process as merchandise, nor did it emerge as such from the process. Nevertheless, within certain limits both goods and money were circulated and hence there was a certain evolution of trade: this was the premise and the point of departure for the formation of capital and the capitalist mode of production. We regard the commodity as just such a premise and we proceed from the commodity as capitalist production in its simplest from. On the other hand, however, the commodity is a product, a result of capitalist production. What began as one of its components turns out later to be its own product. Only on the basis of capitalist production will the commodity become the general form of product.

(Marx 1977: 1059-1060, emphasis added)

The point of departure of Capital is, therefore, the "simple commodity" that one can theoretically isolate in a capitalist economy or can find in isolation in pre-capitalist economies, where trade in commodities occurred. This point of departure does not imply the existence of an economic stage based exclusively on "simple commodity production." It merely implies the existence of trade and exchange of commodities.

If this reading of Marx is correct, then Engels was wrong in assuming that Marx's point of departure was the real or imaginary stage of "simple commodity production." But equally wrong are the critics of Engels who argue that the point of departure of Marx has nothing to do with pre-capitalist economies or barter and trade. The isolated commodity in a capitalist economy, which is taken as the point of departure in Capital, is similar to the commodity produced in isolation in pre-capitalist economies, where exchange could take on the form of barter.

The last point of the critics of Engels, namely, that Marx's method of analysis in capital was circular and, therefore, not historical is also incorrect. As is evident from the earlier discussion, Marx did believe that his overall method of presentation is circular. But he also believed that the method is historical. This is clearly stated in the "Result" when he writes:

As the elementary form of bourgeois wealth, the commodity was our point of departure, the prerequisite for the emergence of capital. On the other hand, commodities appear now as the product of capital.

The circular nature of our argument corresponds to the historical development of capital. Capital is predicated on the exchange of commodities, trade in commodities, but it may be formed at various stages of production, common to all of which is the fact that capitalist production does not yet exist, or only exists sporadically. On the other hand, a highly developed commodity exchange and the form of the commodity as the universally social form of the product can only emerge as the consequence of the capitalist mode of production.

(Marx 1977: 949, emphasis in the original) 


\section{The equation of exchange and proper point of departure}

The second paragraph in the above passage, which the commentators on Marx's method have invariably ignored, cannot be any clearer about the circular method of Capital being also historical. ${ }^{16}$ The passage also supports what was said earlier, that is, that the commodity which appears at the very beginning of Capital can be viewed as an isolated commodity either in a capitalist economy or in a precapitalist economy, where some commodity production, or even "sporadic" capitalist production, might take place.

In the final analysis it appears that Marx's method of presentation is along what he perceives to be the historical development of capital, and this holds not only for the transition from merchant's capital to productive capital but also for both points of departure. The second point clearly starts with some ill-conceived history, namely, the isolated, accidental exchange of commodities or, to use Marx's expression, "direct barter." The first point is more complex, since it starts with a commodity taken in isolation in a capitalist economy. But such a commodity, Marx seems to believe, could also be found in isolation in a pre-capitalist economy that might engage in barter. These two points of departure are perfectly in tune with Marx's belief that exchange begins on the boundaries of primitive communities and then spreads inward, a view that he attributes to Aristotle. Hence, it appears to this author that the Aristotelian concepts of exchange and the development of money not only affect Marx's theoretical views on these matters but also negatively influence his method of presentation.

\section{Conclusion}

Marx is one of the few economists who approaches monetary analysis from the perspective of a philosopher and historian. As a philosopher, particularly one who is familiar with the philosophy of science prevalent at the time, he is concerned with the issue of method of presentation, particularly the notion of the proper point of departure. ${ }^{17}$ This is clearly reflected in the complexity of how he starts his theory of money. Moreover, as a philosopher, Marx brings in new insights to monetary analysis. For example, his entire vision concerning use-value being the "content" and exchange-value being the "form" of the content, which was discussed earlier, is unique and has potential for the kind of relational analysis that this writer has been concerned with. As we see later in this book, such unique distinctions have also influenced other writers concerned with monetary theory, such as Krause (1982).

Various other philosophical issues involving money that Marx raises are also insightful and worth pondering when dealing with monetary matters. For example, in a section entitled "The Method of Political Economy" in his 1857 Introduction, Marx argues that the seventeenth-century tradition began with the "living whole, with population, nation, state, several states, etc.; but they always conclude by discovering through analysis a small number of determinate, abstract, general relations such as division of labor, money, value, etc." (Marx 1973: 100, emphasis added). He then contends that once these abstract concepts had been established, there began the second tradition "which ascended from the 
simple relations, such as labor, division of labor, need, exchange-value, to the level of state, exchange between nations and the world market" (Marx 1973: 100-101). This second tradition, Marx goes on to say, "is obviously the scientifically correct method" (Marx 1973: 101). Even though in discussing this second method Marx does not mention money, it is clear from his discussion of the seventeenth-century tradition that beginning with money, too, could be considered by him as "scientifically the correct method." 18 Indeed, "Notebook I," which appears immediately after the 1857 Introduction, starts with the "Chapter on Money" (Marx 1973: 115). ${ }^{19}$ But by the time he develops much of his economic theory in Grundrisse his overall plan of presentation becomes "(1) Value, (2) Money, (3) Capital in general." ${ }^{20}$ All this indicates the importance of money in Marx's overall theoretical construct and his concern with the issue of when, where, and how to deal with the matter.

As a historian, Marx often shows an approach to monetary theory that is unique and at times based on the real economic history. For example, as mentioned earlier, he stated unambiguously that his analysis of the transition from merchant's capital to productive capital, or the movement from the circuit $\mathrm{M}-\mathrm{C}-\mathrm{M}^{\prime}$ to $\mathrm{M}-\mathrm{C} \cdots \mathrm{P} \cdots \mathrm{C}-\mathrm{M}^{\prime}$, follows the contours of history. To this extent, Marx's method of analysis not only becomes realistic, but it could also become very helpful in constructing a realistic monetary theory. For example, the transition from merchant's capital to productive capital can help us answer why a barter economy that was flourishing in the age of commercial revolution disappeared and gave rise to almost a "pure money economy," an issue that is discussed in Chapter 7.

Thus, in the final analysis, Marx, the philosopher and historian, did try to incorporate some elements of real monetary history in his monetary theory. But, as discussed in this chapter, Aristotle's influence was too strong when it came to monetary matters. Marx generously attributed his own theory of the origin of barter and money to Aristotle. He approvingly talked of Aristotle's equation of exchange. He perfected the equation by replacing Aristotle's "is equal" with the mathematical notation "=." He offered an unambiguous solution by arguing that the equation does not make sense unless it represents an exchange of congealed abstract labor. He started his Capital not with a real economy, such as the medieval economy dominated by the merchant's capital, but with some convoluted "commodity," a starting point that after nearly a century and a half later remains a subject of controversy. He commenced his theory of money with what appears to be imaginary primitive communities bartering with one another. In sum, not even Marx, the unique thinker who came to economics as a philosopher and historian, could escape the strong grip of the "great investigator," Aristotle. 


\section{Mademoiselle Zélie and the "scientific" theory of exchange}

Chapter 1 of William Stanley Jevons's Money and Mechanism of Exchange begins with the following:

\section{Barter}

Some years since, Mademoiselle Zélie, a singer of the Théâtre Lyrique at Paris, made a professional tour round the world, and gave a concert in the Society Islands. In exchange for an air from Norma and a few other songs, she was to receive a third part of the receipts. When counted, her share was found to consist of three pigs, twenty-three turkeys, forty-four chickens, five thousand cocoa-nuts, besides considerable quantities of bananas, lemons, and oranges. At the Halle in Paris, as the prima donna remarks in her lively letter, printed by $\mathrm{M}$. Wolowski, this amount of live stock and vegetables might have brought four thousand francs, which would have been good remuneration for five songs. In the Society Islands, however, pieces of money were very scarce; and as Mademoiselle could not consume any considerable portion of the receipts herself, it became necessary in the mean time to feed the pigs and poultry with the fruit.

(Jevons 1875: 1)

After citing another example of direct exchange, the point of Jevons's story becomes clear: "In modern civilized society the inconveniences of the primitive method of exchange are wholly unknown," and "barter is actually the sole method of commerce among many uncivilized races" (Jevons 1875: 2). Jevons subsequently extends this account of barter among the "uncivilized races" to the past as well: "The earliest form of exchange must have consisted in giving what was not wanted directly for that which was wanted. This simple traffic we call barter or truck" (Jevons 1875: 3, emphasis in the original).

Jevons's account of the origin of money is a modern version of an old story: sometimes in the past there must have been some people who exchanged goods directly with one another. As we saw in the previous chapters, for Aristotle these people were either the first divided family or the barbarians; for the scholastics, the sons of Adam; for Smith, the native tribes of North America; and for Marx, the primitive communities exchanging on their borders. Jevons replaces all these 
fictitious people with one, the inhabitants of the Society Islands. The plight of the "civilized" Mademoiselle Zélie, who finds herself in the midst of these "uncivilized" people, then becomes the vehicle to systematize the notion of the "difficulties of barter." In this systematization, Jevons formulates, as the titles of consecutive sections indicate, three difficulties: "Want of Coincidence in Barter," "Want of a Measure of Value," and "Want of Means of Subdivision" (Jevons 1875: 2-6, emphasis in the original).

But how does Jevons's systematic account of the difficulties of barter and emergence of money, which appears in many modern textbooks, stand up against reality? Moreover, how does the story figure into the theories of exchange put forward by Jevons and his more influential marginalist fellow traveler, Léon Walras? Answering these questions is the main focus of this chapter. In the first section the fictitious nature of Jevons's theory of pure barter economy and the emergence of money is pointed out by contrasting the theory with the medieval exchange, as well as anthropological and historical studies. The second and third sections look at Jevons's concept of "science of economics" and the "scientific" theory of exchange, as they appear in his Theory of Political Economy. It is shown in these sections that the notions of the difficulties of barter and necessity of money play absolutely no role in Jevons's theory of exchange. Indeed, it is argued, money disappears in this "scientific" theory of exchange, and its disappearance is the direct result of making exchange fit theories borrowed from physics, such as the theory of the lever. The fourth and fifth sections focus on Walras's similar attempt to make the theory of exchange "scientific" and resemble the physico-mathematical sciences, such as mechanics or hydrodynamics. Here, too, it is contended, money is actually a fly in the ointment of the "scientific" theory of exchange. Therefore, similar to Jevons, Walras has to ignore money, at least until his theory of capital comes into play. The last section sums up the irrelevance of Mademoiselle Zélie to the new, "scientific" theory of exchange that was developed by the marginalist pioneers.

\section{The difficulties of barter}

"The first difficulty in barter," according to Jevons, "is to find two persons whose disposable possessions mutually suit each other's wants." In supporting this assertion, Jevons harks back not to Aristotle's barbarians, but to Smith's bartering savage: "A hunter having returned from a successful chase has plenty of game, and may want arms and ammunition to renew the chase" (Jevons 1875: 4). But, according to Jevons, the savage faces the problem of finding a suitable trader: "those who have arms may happen to be well supplied with game, so that no direct exchange is possible" (Jevons 1875: 4).

As we saw in Chapter 3 on medieval exchange, individuals entered into systematic barter without encountering any apparent difficulty with the "want of coincidence in barter." Merchants seemed to know full well who was where and what was available for trade. The practice of direct exchange, of course, did diminish as capitalism developed and markets became all dominating. Yet, as 


\section{The "scientific" theory of exchange}

was noted in the chapter on Smith, barter continued to survive well into the classical era. Interestingly enough, a few paragraphs after Mademoiselle Zélie's story, Jevons is forced to admit that barter is still practiced in his own time by means of such newspapers as The Exchange and Mart and, therefore, "we must assume that the offers are sometimes accepted, and that the printing press can bring about, in some degree, the double coincidence necessary to an act of barter" (Jevons 1875: 4-5).

Jevons writes

A second difficulty arises in barter... At what rate is any exchange to be made? If a certain quantity of beef be given for a certain quantity of corn, and in like manner corn be exchanged for cheese, and cheese for eggs, and eggs for flax, and so on, still the question will arise- - How much beef for how much flax, or how much of any one commodity for a given quantity of another? In a state of barter the price-current list would be a most complicated document, for each commodity would have to be quoted in terms of every other commodity, or else complicated rule-of-three sums would become necessary.

Subsequently, Jevons goes on to say that all

such trouble is avoided if any one commodity be chosen, and its ratio of exchange with each other commodity be quoted... The chosen commodity becomes a common denominator or common measure of value, in terms of which we estimate the values of all other goods.

(Jevons 1875: 5, emphasis in the original)

The story, once again, is an old one. Some people, somehow, somewhere, sometimes in the past, as Aristotle began the folktale, felt the need for all goods to be "measured by some one thing," and money was, therefore, introduced (Aristotle 1949, Book V, Part V: 1133a25). But who chose the money commodity, when, how, and where?

As we saw in the previous chapters, the answer varies according to who is telling the story. In the case of Jevons, however, there is no direct answer to the question in the section on barter. But Jevons's historiography-which appears in chapter 5 of his Money and Mechanism of Exchange, and which is basically a rehash of Adam Smith's four stages of history-seems to imply that money came into being in the age of the bartering savage. Under the heading "Currency in the Hunting State," Jevons tells the reader how, after the hunt, the "proceeds of the chase" is divided by the savage, between meat, which is consumed, and the non-perishable skin, which "became one of the earliest materials of currency" (Jevons 1875: 19-20).

Similar to Smith, Jevons's fable is based on the European image of the "North American Indians" and the "Hudson's Bay Company" exchanging furs, which, 
"in spite of their differences of quality and size, long formed the medium of exchange" (Jevons 1875: 20). In retelling this legendary Smithian folktale, Jevons does not appear to be affected at all by anthropological studies of the North American Indians in the latter half of the ninteenth century. Nor is he concerned, as a historian of money should be, with the information that was readily available at this time on the real economies, such as the medieval economy. In the markets of the late Middle Ages, as was pointed out, merchants exchanged goods with great ease and without running into the difficulty of the "want of a measure of value," because they had such a measure, that is, money. Indeed, we do not know of any economy in which systematic barter takes place without the presence of money. But above all Jevons is not bothered at all by the logic of his own story: given the primitive conditions of the bartering savage and the fact that her needs and exchanges were presumably quite limited, why does the savage run into the complication of numerous exchange ratios and the need for a measure of value?

The third, but "a minor inconvenience of barter," Jevons writes, "arises from the impossibility of dividing many kinds of goods" (Jevons 1875: 6). The "tailor," he goes on to say, "as we are reminded in several treatises on political economy, may have a coat ready to exchange, but it much exceeds in value the bread which he wishes to get from the baker, or the meat from the butcher" (Jevons 1875: 6). But again, as we saw in the case of medieval barter, merchants did not appear to be bothered by the issue of non-divisibility of some commodities, especially since money was available and part of the payment involved cash.

After a short discussion of this last "inconvenience of barter," Jevons throws cold water on his whole argument concerning the difficulty of barter by saying:

In the present day barter still goes on in some cases, even in the most advanced commercial countries, but only when its inconveniences are not experienced. Domestic servants receive part of their wages in board and lodging: the farm laborer may partially receive payment in cider, or barley, or the use of a piece of land. It has always been usual for the miller to be paid by a portion of the corn which he grinds. The truck or barter system, by which workmen took their wages in kind, has hardly yet been extinguished in some parts of England.

(1875: 6, emphasis in the original)

According to the aforementioned passage, if money were available, then the inconveniences of barter are not experienced and barter could persist, at least, on a small scale. ${ }^{1}$ In other words, the difficulties of barter are only encountered if we have a pure barter economy. But has there ever been such an economy?

From what has been said so far, the answer to this question appears to be no. The concept of pure barter economy is based solely on the tales of the bartering barbarians, sons of Adam, and the savage. Indeed, as some modern day anthropologists and economic historians have argued, there is no evidence for the existence of a pure barter economy either in the past or in the present. The anthropologist Caroline Humphrey, for example, notes: "No example of barter economy, pure 
and simple, has ever been described, let alone the emergence from it of money; all available ethnography suggests that there never has been such a thing" (Humphrey 1985: 48). According to Humphrey, had economists actually studied modern cases of communities in which barter does take place, they would have been led to different conclusions concerning barter and the origin of money. By using the Lhomi of north-east Nepal as a case study, Humphrey demonstrates that, contrary to the prevalent economic theories, the "search for coincidence of wants is not necessary, since the time and place of barter for common items was established long in the past" (Humphrey 1985: 56). Or with regard to the complication arising from keeping track of numerous exchange ratios, she contends that in "practice this is not the case ... many items are never traded," and Lhomi's barter "follows limited and well known "tracks" " (Humphrey 1985: 57). In general, Humphrey (1992: 2) argues that barter "has been misconstrued largely because of the persistence of the creation-myth in classical and neoclassical economics that in barter lie the origins of money and hence of modern capitalism. In this perspective money originates as a solution to the problem of barter."

Many historians of money have also expressed similar views. Paul Einzig, for example, with reference to the usual citations of Jevons's anecdotal examples of difficulties of barter - such as the one involving a Mademoiselle Zélie and the inhabitants of Society Islands-writes: "What the economists quoting these and other similar instances do not appear to realize is that the difficulties complained of are not inherent in the system of barter. They are largely anomalies arising from sudden contact between two civilizations" (Einzig 1966: 342). According to Einzig, the " 'double coincidence' (to quote the word of Jevons) that must arise is by no means difficult to achieve in a small community where everybody knows a great deal about everybody else's products and requirements" (Einzig 1966: 342). "Nor is the difference between value of the objects to be exchanged, or time lag between their delivery," Einzig goes on to say, "an unsurmountable obstacle" (Einzig 1966: 344). Einzig concludes his criticism of Jevons by saying that "it seems to be a mistake to assume that barter became reduced to absurdity at an early phase of economic progress. The chances are that in the majority of communities it survived long after its replacement by some form of monetary system" (Einzig 1966: 344). Similar views are expressed more recently by Glyn Davies (1994: 9-10) who argues that most "modern textbooks on money" base their account of barter not on "the mainstream of human progress" but on existing precapitalist communities. Such books, according to Davies, present the "rise of money on the misleadingly narrow and mistaken view of the alleged disadvantages of barter to the exclusion of other factors" (Davies 1994: 10). "Barter," Davies goes on to say, "has, undeservedly, been given a bad name in conventional economic writing, and its alleged crudities have been exaggerated" (Davies 1994: 10).

The usual view of barter, as systematized by Jevons, has also been challenged occasionally by some economists who are aware of anthropological studies. For example, Galbraith and Darity (1994: 182-183) call the usual account of the development of money the "rationalist explanation," according to which "a need for money came to exist, at some long distance date in the past, as trade developed 
between individuals and communities and as societies wrestled with the difficulties of systems of barter." They then dismiss the validity of this "rationalist idea" and argue that anthropological "evidence on primitive societies suggests that where money is absent, so too is exchange itself" (Galbraith and Darity 1994: 183). "That is," they contend, "without money no alternative mechanisms, such as barter, exist for establishing the equivalence of value of one good for another" (Galbraith and Darity 1994: 183). They conclude by arguing that if "the anthropological evidence is a guide to history, it would be more accurate to say that the invention of money coincides with the innovation of trade rather than that money merely provides a convenient and efficient way to conduct a human activity conceived and initiated without it" (Galbraith and Darity 1994: 183).

In the final analysis, there is no evidence for the existence of a pure barter economy, and, therefore, the notion of the inconveniences of barter giving rise to money is nothing more than a myth. Yet, despite the lack of evidence for the claim and protestations from anthropologists, historians of money and even some economists, the story that Aristotle originally manufactured and Jevons managed to systematize prevails to this day and appears in many books, particularly textbooks. Even in the most modern and highly sophisticated theories of money, as we see in Chapter 7, Jevons's story plays a central role. But before looking at such theories, the question that needs to be addressed is this: How did the so-called neoclassical economists, including Jevons, incorporate the issue of difficulties of barter in their utility theory and how did they view exchange itself?

\section{Turning economics into a "science"}

Even though in chapter 2 of Money and Mechanism of Exchange Jevons attempts to downplay the importance of barter in order to develop the concept of money, he does not appear to be able to leave the issue of barter behind. Indeed, at the beginning of chapter 2 he reduces all exchange to barter when he writes: "Exchange has been called the barter of the superfluous for the necessary, and this definition will be correct if we state it as the barter of the comparatively superfluous for the comparatively necessary" (Jevons 1875: 8, emphasis in the original). This reduction of exchange to barter also appears in Jevons's attempt "to construct a theory of the nature of exchange and value," a theory that, according to Jevons, has been explained in his previous work, The Theory of Political Economy, and has been "independently arrived at" by Léon Walras (Jevons 1875: 10). Our attention must therefore turn to Jevons's earlier work. But before doing so, we get a glimpse of what Jevons has to say in The Theory of Political Economy in the Money and Mechanism of Exchange itself.

"Every act of exchange," states Jevons, "presents itself to us in the form of a ratio between two numbers" (Jevons 1875: 10, emphasis in the original). He then writes:

The word value is commonly used, and if, at current rates, one ton of copper exchanges for ten tons of bar iron, it is usual to say that the value of copper is ten times that of the iron, weight for weight. For our purpose, at least, this 
use of the word value is only an indirect mode of expressing a ratio. When we say that gold is more valuable than silver, we mean that, as commonly exchanged, the weight of silver exceeds that of the gold given for it. If the value of gold rises compared with that of silver, then still more silver is given for the same quantity of gold. But value like utility is no intrinsic quality of a thing; it is an extrinsic accident or relation.

(Jevons 1875: 10, emphasis in the original)

Jevons's portrayal of the act of exchange as a "ratio between two numbers" is quite peculiar. No previous economic thinker that we have looked at had viewed exchange as such. Also, defining "value" as a ratio of exchange and reducing it to the act of exchange is quite unusual in the history of economic thought. Why then does Jevons reduce both exchange and value to a ratio? The answer, as will be shown in this and the next sections, is found in Jevons's attempt to make economics and, in particular, the theory of exchange "scientific."

As it is now well known, the early generations of marginalist theorists had a fascination with models of mathematical physics and tried to give these models some economic interpretations. A perfect example is one of Jevons's earliest disciples, Phillip Henry Wicksteed. In his 1888 Alphabet of Economic Science, Wicksteed stated that his aim in the book is to help "illustrate and enforce" a "guiding principle" to Jevons's Theory of Political Economy (Wicksteed 1888: xii). The "guiding principle" starts with a long discussion of the path of a projectile, " $\mathrm{f}(\mathrm{x})$ " in his "Figure 1," and its time rate of change, " $\mathrm{f}(\mathrm{x})$ " in his "Figure 3" (Wicksteed 1888: 10-11). Wicksteed then passes on to the "economic interpretation of the curves" and writes:

In thus interpreting Figs. 1 and 3 we have substituted consumption of coal per month (measured in tons), for lapse of time (measured in seconds), as our variable; some of the advantages derived from consuming the coal, for space traversed by the projectile, as $\mathrm{f}(\mathrm{x})$, or the total effect of the variable; and rate per unit at which time is increasing comfort, or rate per unit at which time is increasing the space traversed, as $\mathrm{f}^{\prime}(\mathrm{x})$, or the marginal effectiveness of the variable.

If we call $f(x)$ the "total utility" of $x$ tons of coal per month, we might call $\mathrm{f}^{\prime}(\mathrm{x})$ the "marginal usefulness" of coal when the supply is $\mathrm{x}$ tons per month.

(Wicksteed 1888: 40-41)

The same economic interpretation of the path of a projectile and its time rate of change appears in the work of Wicksteed's master, Jevons. The only difference is that in Jevons's Theory of Political Economy, we do not see Wicksteed's "Fig. 1," even though we see a discussion of such a figure. However, we do see a "Fig. 4," which is the same as Wicksteed's "Figure 3" (Jevons 1879: 49). ${ }^{2}$

Jevons, however, is shrewder than asking "what is the economic interpretation of this curve?" Before presenting such a curve he goes through a series of steps that would make it appear as if he is actually deriving the curve based on some 
sound economic reasoning. The steps include (1) arguing that he will make political economy scientific by applying mathematics to some old and existing concepts, such as "utility," (2) completely confusing the reader as to what the term "utility" means, and (3) sneaking in, at the moment of complete confusion, a new concept of utility that fits perfectly well with the model of the projectile.

The first step appears in chapter 1 of The Theory of Political Economy, where Jevons produces a set of confusing and contradictory claims concerning the nature and status of political economy as a science, the nature of mathematics and its relation to political economy, and the relation between classical economics and Jevons's own work. One argument is that political economy of the past generation was a science in the sense that it dealt with quantities and used simple arithmetical operations. Here mathematics is viewed as essentially "a perfected system of language" or a set of "symbols" (Jevons 1879: 5). Adam Smith then becomes "thoroughly mathematical," since the "Wealth of Nations deals with 'quantities of labor,'... 'proportion,' 'equality,' etc." and "equality implies the existence of a mathematical equation" (1879: xxii-xxiii). Given this concept of science, Jevons sees certain continuity of thought between his own work and that of the past generation.

The second argument, which contradicts the first, is that political economy is not yet a science, since in order for it to become a science it must involve calculus, "as the complete theory of almost every other science involves the use of that calculus, so we cannot have a true theory of Economics without its aid" (Jevons 1879: 3). Here mathematics is more than a set of symbols, and political economy, as exemplified by the Wealth of Nations, turns into a non-science. Given this concept of science, Jevons's own Theory, as an attempt "to treat Economy as a calculus of pain and pleasure," turns into a science and there is a sharp discontinuity between his theory and that of the classical political economists (Jevons 1879: vi).

It should be noted that Jevons's confusing and contradictory arguments appear side by side. At the same time that he speaks of mathematics as being just a language or a set of symbols and simple operations, he holds that his "theory consists of applying the differential calculus to the familiar notions of wealth, utility, value," etc. (Jevons 1879: 3). It is difficult, of course, to imagine that Jevons, a professor of logic, does not realize the contradictory nature of his arguments and the fact that applying calculus to the classical concepts, which involved only finite quantities, is an impossible task. One might therefore conclude that his confusing contentions are the result of certain eagerness to get to his "Fig. 4" (Jevons 1879: 49).

Jevons's second step appears in chapter 2 of the Theory. The chapter begins with the discussion of Bentham's (1954) concept of utility and proceeds as if Jevons is going to apply mathematics to this concept. But as a few economists, including this writer, have observed this is an illusion (Robertson 1951; Fayazmanesh 1996, 1998a). Bentham's theory of utility is irrelevant to that of Jevons. The chapter is filled with definitions of utility according to various sources, including Say, Bastiat, Senior, and Jevons himself. But none of these definitions is identical. On one page alone Jevons produces five distinct definitions of "utility" and makes it appear as if they are identical. ${ }^{3}$ By the time Jevons is finished with this process of defining and 


\section{The "scientific" theory of exchange}

redefining utility, the reader is so confused that just about any vague concept would pass for the correct meaning of "utility."

Jevons's third step consists of pulling a rabbit out of the hat after creating massive confusion. Out of the blue, he states that utility "must be considered as measured by, or even as actually identical with, the addition made to a person's happiness" (Jevons 1879, 45, emphasis added). At this point the projectile model can take form. The range of the "utility function" is fixed, since "utility" is now turned into a continuous stuff, the set of real numbers. Of course, unlike the path of the projectile, this range does not have a unit. But that does not bother Jevons.

There is, however, a remaining hurdle, the domain of the function. Jevons writes: "Utility is a quantity of at least two dimensions, one dimension consisting in the quantity of commodity... Now, the quantity of the commodity is measured on the horizontal line $o x$ " (Jevons 1871: 56, emphasis in the original). But the "ox" axis is a major problem, since commodities in ordinary life, as well as in classical political economy, are only finitely divisible. The only way that this problem can be resolved is to change the nature of the commodities, and this is precisely what Jevons does. He puts on the "ox" axis "quantities of food" and then writes:

The notion of infinitely small quantities of food may seem absurd as regards the consumption of one individual; but, when we consider the consumption of a nation as a whole, the consumption may well be conceived to increase or diminish by quantities which are practically speaking, infinitely small compared with the whole consumption.

(Jevons 1871: 57)

Thus the absurdity of "infinitely small quantities of food" is seemingly resolved by an appeal to the consumption of a nation, rather than that of the individual.

But the attempt to change the nature of commodities is not confined to the distinction between the consumption of a nation and an individual. There are other efforts that are independent of this distinction. Two attempts, for example, are as follows. "By a commodity," Jevons writes, "we understand any object, or, it may be, any action or service, which can afford pleasure and pain. The name was originally abstract, and denoted the quality of anything by which it was capable of serving man" (Jevons 1871: 45, emphasis in the original). Apparently, including "action," "service," and, in the later edition, "substance" will make the commodity more and more continuous. But then Jevons tries a different argument. He states:

the dimensions of commodity, regarded merely as a physical quantity, will be the dimensions of mass. It is true that commodities are measured in various ways - thread by length, carpet by length, corn and liquids by cubic measure, eggs by number, metals and most other goods by weight. But it is obvious that, though the carpet be sold by length, the breadth and weight of the cloth are equally taken into account in fixing the terms of sale. There will generally be a tacit reference to weight, and through weight to mass of materials in all measurement of commodity.

(Jevons 1879: 63, emphasis in the original) 
Apparently, in Jevons's estimate, if one could measure all commodities by their respective masses, then the problem of "infinitesimally small unit" of commodities would be solved.

There are still other attempts by Jevons to define a commodity to suit his purpose. But the point has been made. Jevons goes through a series of steps before he gives economic meaning to the path of a projectile and its time rate of change. These steps include the claim concerning the application of mathematics to the existing concepts in political economy, creating a mass of confusion as to the meaning of old concepts and, in the midst of the confusion created, putting forward a new concept of utility. In the final analysis, what Jevons does is precisely what Wicksteed did, but Jevons does it more cleverly.

\section{Jevons's "scientific" theory of exchange}

It is in the process of making economics "scientific," that is, giving economic meaning to the path of a projectile and its time rate of change, that exchange and value are reduced to a ratio between two numbers. In this process the equation of exchange also changes drastically as will be shown later.

Jevons's concept of science compels him to squeeze old economic concepts, such as value, value in use, and value in exchange, into a mold of calculus. As such, he lambastes Mill for saying that "value of a thing means the quantity of some other thing, or things in general, which exchanges for it" and goes on to say that "value implies, in fact a relation; but if so, it cannot possibly be some other thing" (Jevons 1879: 77). It is, he contends, "scientifically incorrect to say that the value of a ton of iron is an ounce of gold" (Jevons 1879: 78). Instead, he argues that "value" of something is the "circumstance of its exchanging in a certain ratio for some other substance" (Jevons 1879: 77). A few sentences later, the word "circumstance" is dropped altogether, and we are told simply that "value in exchange expresses nothing but a ratio" (Jevons 1879: 78). Similarly, in interpreting Adam Smith's famous passage on the meaning of value, Jevons contends:

Smith evidently means by value in use, the total utility of the substance of which the degree of utility has sunk very low, because the want of such substance has been well nigh satisfied. By purchasing power he clearly means the ratio of exchange for other commodities.

(Jevons 1879: 79, emphasis added) ${ }^{4}$

He then suggests the following word substitutions:

(1) Value in use = total utility;

(2) Esteem = final degree of utility;

(3) Purchasing power $=$ ratio of exchange.

(Jevons 1879: 81)

A few lines later, Jevons writes that the third term, "purchasing power," for which he is substituting "ratio of exchange," is "often called by economists exchange or 


\section{The "scientific" theory of exchange}

exchangeable value" (Jevons 1879: 81, emphasis in the original). Finally, in his discussion of "dimension of value" in the second edition of the Theory, Jevons concludes that "the value in use of Adam Smith, or total utility, is the integral of U. dM, and has the dimension MU" (Jevons 1879: 84, emphasis in the original). Here, "M" stands for the "mass" of the commodity and "U" for the "dimension" of the "degree of utility" (Jevons 1879: 64-66). Following his claims concerning the meaning of Smith's "value," Jevons suggests, once again, the aforementioned word substitutions, but now the left side terms appear under "Popular Expressions of Meaning," and the right side terms under "Scientific Expression," all followed by their respective "Dimensions" (Jevons 1879: 84). Jevons further claims that the "ratio of exchange," which has "the dimension M divided by M," is inversely proportional to the "degree of utility of commodities exchanged" (Jevons 1879: 83, 99). ${ }^{6}$

Given what was said in the chapter on Adam Smith in this book, none of this makes any sense. Indeed, under no circumstance can one conclude that Smith's "value in use" is the same as Jevons's "total utility" or, what he also calls "whole utility" or "u" (Jevons 1879: 49). "Total utility" is a functional relation from some unclear set - which is nevertheless taken to be equivalent to the set of real numbers - to the set of units of "happiness" - which is again equivalent to the set of real numbers. ${ }^{7}$ This has absolutely nothing to do with Smith's "value in use," which refers to the set of uses of a class of objects. Similarly, it is strange to say that by "purchasing power" and "value in exchange" Smith meant "ratio of exchange." As was indicated earlier, Smith's "value in exchange" was technically a confused concept. However, setting aside the technical issues-which once dealt with will make the concept quite clear- "value in exchange" roughly translates into Mill's notion of the quantity of a good that exchanges for another. However, as was stated earlier, Jevons's unsubstantiated claims serve a purpose: they make some old economic concepts "scientific" by fitting them into a mold of calculus.

It is in this process of making economics "scientific" that the old Aristotelian equation of exchange, " 5 beds $=1$ house," also changes. The steps taken start with the following proposition (Jevons 1879: 94-95):

Suppose that two commodities are bartered in the ratio of $x$ for $y$; then every $m^{\text {th }}$ part of $x$ is given for the $m^{\text {th }}$ part of $y$, and it does not matter for which of the $m^{\text {th }}$ parts. No part of the commodity can be treated differently to any other part. We may carry this division to an indefinite extent by imagining $m$ to be constantly increased, so that, at the limit, even an infinitely small part of $x$ must be exchanged for an infinitely small part of $y$, in the same ratio as the whole quantities. This result we may express by stating that the increments concerned in the process of exchange must obey the equation

$$
\frac{d x}{d y}=\frac{x}{y}
$$

From the perspective of the real world, or even the Aristotelian fictitious world, the above view of barter is, of course, a complete mystery, since beds and houses 
cannot be divided into infinitesimally small units. Moreover, as we saw earlier, Jevons argues in Money and the Mechanism of Exchange that one reason for the development of money is the indivisibility of commodities. So if commodities can be divided into infinitesimal units, one of Jevons's major rationales for the existence of money disappears. Yet, none of these matters to Jevons since the task at hand is trying to fit concepts into a mold of calculus.

After the above equation, Jevons begins his "Theory of Exchange" by stating:

The keystone of the whole Theory of Exchange, and of the principal problems of Economics, lies in this proposition-The ratio of exchange of any two commodities will be the reciprocal of the ratio of the final degrees of utility of the quantities of commodity available for consumption after the exchange is completed. When the reader has reflected a little upon the meaning of this proposition, he will see, I think, that it is necessarily true, if the principles of human nature have been correctly represented in previous pages.

(Jevons 1879: 95, emphasis in the original)

Jevons presents this concept of exchange by assuming that two "trading bodies" A and B, respectively, hold "a" amount of corn and " $\mathrm{b}$ " amount of beef (Jevons 1879: 88, 95). The first body exchanges " $x$ " amount of corn for the second's " $y$ " amount of beef. The result of exchange between the first and second "trading bodies," or A and B, is (Jevons 1879: 99-100):

$$
\phi_{1}(a-x) \cdot \mathrm{d} x=\psi_{1} y \cdot \mathrm{d} y
$$

and

$$
\psi_{2}(b-y) \cdot \mathrm{d} y=\phi_{2}(x) \cdot \mathrm{d} x
$$

where $\phi$ and $\psi$ represent the "final degrees of utility" to A and B. But since $y / x=\mathrm{d} y / \mathrm{d} x$, according to Jevons (1879: 100), then

$$
\frac{\phi_{1}(a-x)}{\psi_{1}(y)}=\frac{y}{x}=\frac{\phi_{2}(x)}{\psi_{2}(b-y)}
$$

Subsequently, Jevons (1879: 105) expresses the most "general form" of his equation of exchange as

$$
\frac{\phi x}{\psi y}=\frac{y}{x}
$$

True to his economic "science," subsequently Jevons argues that the above equation resembles the equation of the lever in the classical mechanics or, more generally, his theory of exchange is analogous to the theory of the lever. ${ }^{8}$ 


\section{The "scientific" theory of exchange}

And, finally, in the most bizarre graphical presentation of exchange since Aristotle's lines or the scholastic's square, Jevons draws (Jevons 1879: 106) the following:

$\mathrm{d} y$

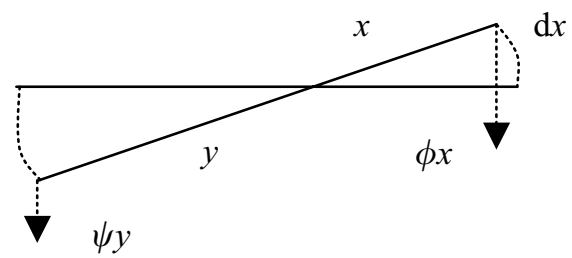

How this "lever" diagram explains exchange remains a mystery and Jevons does nothing to clarify it except to say that "several economic qualities are represented by the parts of the diagram to which they correspond or are proportional" (Jevons 1879: 105). But as unintelligible as Jevons's analogy is, the point of the whole story is quite clear: along with many other economic concepts, exchange is molded by Jevons into a certain prefabricated model of mathematical physics to become "scientific."

This constitutes Jevons's theory of exchange. The analysis has all the trappings of Jevons's confused notion of his relation with the classical political economists. On the one hand, he sees the analysis as an extension of what they had said earlier, albeit in a more correct form. On the other hand, he believes it to be a new, "scientific" theory, which resembles the theory of the lever. In the final analysis, however, Jevons's theory neither has anything to do with the old theories of exchange nor is an advancement upon them.

Because of the requirement of "science," Jevons's theory of exchange is, indeed, new. But it also contains all the confusions of the past theories and more. Similar to the old theories there is no trace of any distinction between the qualitative relations "barters for," "sells for," or "purchases." Nor is there any distinction between the quantitative counterparts of these relations. As far as the qualitative distinction between "purchases" and "barters for" is concerned, Jevons shows even more confusion than Adam Smith. This is evident when, in reference to Smith, he states: "By purchasing power he clearly means the ratio of exchange for other commodities" and "Purchasing power = ratio of exchange," or when, in the context of barter, he writes: "suppose that A, with the quantity of one commodity denoted by a, purchases another kind of commodity both from B" (Jevons 1879: 79, 81, 117, emphasis added). Indeed, when Jevons (1875: 8) defines "exchange" as the "the barter of the comparatively superfluous for the comparatively necessary," he shows how little he distinguishes between barter and monetary relations.

Similarly, and expectedly, there is no distinction whatsoever in Jevons's theory of exchange between money commodity and other commodities. This is, of course, quite strange for one who will later try to write a historical compendium on the difficulties of barter leading to the development of money commodity.

Not distinguishing between the properties of barter and monetary relations, combined with an attempt to make exchange "scientific," would also result in the 
most unusual "equation of exchange" in Jevons (1879: 118). As we saw in the previous chapters, when $x$ "barters for" $y$, or $x \beta y$, Aristotle, as well all those who followed him for nearly 2,000 years, would write

$$
x=y
$$

Jevons, on the other hand, would express the same act of barter as

$$
\frac{\phi x}{\psi y}=\frac{y}{x}
$$

Even though barter is still viewed by Jevons as an equation, the nature of the equation has changed fundamentally as the result of making economics "scientific." Aristotle's equation, as was argued in the previous chapters, is an impossible equation, since it makes no sense to equate two heterogonous commodities. Thus there was an attempt to find an underlying "substance" that would give the equation some semblance of rationality. But regardless of the exact nature of the substance, all those who saw exchange as having the form " $\mathrm{x}=\mathrm{y}$ " agreed that money can act as a proxy for the substance. It was as such that the equation of exchange served as the point of entry for introducing the concept of money.

With Jevons, however, all this changed. His equation is in fact not an impossible one. Technically speaking, the two sides of the equation are equal, and this holds even if we do not assume, as does Jevons, that commodities are measured by "mass." As such, the equation does not require looking for an underlying substance that would make it meaningful. Hence it is not at all necessary to have money act as a proxy for the equalizing substance. This being the case, Jevons does not need to introduce money as a solution to any equation. Furthermore, given the new "scientific" view of exchange, there is nothing unique about the money commodity; every commodity can act as such. Finally, even though the money commodity is useful it has no "utility" in the marginalist sense, so it cannot even enter the equation of exchange. Indeed, money is a nuisance as far as the "scientific" theory of exchange is concerned.

Jevons's world of exchange is therefore one of perpetual barter with no need for money. That is why in the entire Theory of Political Economy, particularly in the chapter on "The Theory of Exchange" there is not a single section devoted to money; and that is why none of the discussions about the difficulties of barter giving rise to the development of money appears in the Theory of Political Economy.

As we see in Chapter 7, however, the modern marginalist theorists are not so much concerned with Jevons's theory of exchange and its lack of money as they are with that of Léon Walras. Let us, therefore, devote the rest of this chapter to the examination of Walras's theory of exchange.

\section{Walras and the "scientific" theory of exchange}

Similar to Jevons, Walras's theory of exchange does not begin with the traditional starting points, such as the bartering barbarians, sons of Adam, savages, or the 
primitive communities. But unlike Jevons, Walras does not appear to start exactly with the "trading bodies" either. Instead, Walras commences his theory of exchange in lesson 3 of his Elements of Pure Economics with what he considers to be the everyday, modern Parisian exchange:

Consider for example, the wheat market. Let us suppose that, at a certain moment, five hectoliters of wheat are being exchanged for 20 francs, i.e. for 600 grams of silver 0.900 fine. We say then: "Wheat is worth 24 francs a hectoliter." This is how the phenomenon of value in exchange makes its appearance.

(Walras 1954: 68)

These lines are then followed by the statement that " 24 francs hectoliter" is a "particular value of wheat in terms of money, that is to say, this price of wheat" (Walras 1954: 69).

At first glance, Walras's starting point of exchange analysis appears quite remarkable, since it seems that, unlike all past theories of exchange, it has a direct reference to reality. But this is quite deceptive, and as we shall see soon, his point of departure has absolutely nothing to do with any modern market.

To begin with, given that in the classical writings the expression "value in exchange" mainly appears in the context of barter and "price" is used mostly in a monetary setting, Walras's interchangeable use of these expressions gives the impression that he is conflating direct and indirect exchange. This suspicion is confirmed in the arguments that come next. After the aforementioned exchange, Walras produces the classical equation of exchange but with certain twists of his own. He writes (Walras 1954: 70) that if

5 hectoliters of wheat are exchanged for 600 grams of silver, it means that " 5 hectoliters of wheat have the same value as 600 grams of silver," or that "the value in exchange of 5 hectoliters of wheat equals the value in exchange of 600 grams of silver," or finally, that " 5 times the value in exchange of 1 hectoliter of wheat equals 600 times the value in exchange of 1 gram of silver."

Accordingly, let $v_{b}$ be the value in exchange of 1 hectoliter of wheat and $v_{a}$ be the value in exchange of 1 gram of silver 0.900 fine. Using ordinary mathematical notations, we obtain the equation:

$$
5 v_{b}=600 v_{a}
$$

and, if we divide both sides of the equation by 5 , we obtain

$$
v_{b}=120 v_{a}
$$

If we agree to conform to the practice of this hypothetical market selected for our example, and choose as the unit of measure of value, not value in exchange of 1 gram of silver, but value in exchange of 5 grams of silver 0.900 fine, called a franc, that is to say, if we postulate that

$$
5 v_{a}=1 \text { franc, }
$$


it follows that

$$
v_{b}=24 \text { francs. }
$$

Let us analyze the above paragraphs. We can say that what Walras is looking at, using the quantitative relation "exchange(s) for" or $\xi$, which we used in the previous chapters, is simply this:

\section{5 hectoliters of wheat $\xi 600$ grams of silver}

As we also saw in the previous chapters, a classical writer would write this exchange as the impossible equation:

5 hectoliters of wheat $=600$ grams of silver

Walras, on the other hand, changes the classical equation to a seemingly possible equation:

The value in exchange of 5 hectoliters of wheat $=$ The value in exchange of 600 grams of silver

or

5 (The value in exchange of 1 hectoliter of wheat) $=600$ (The value in exchange of 1 gram of silver)

or

The value in exchange of 1 hectoliter of wheat/ The value in exchange of 1 gram of silver $=600 / 5$

In other words, Walras replaces the actual quantities of a class of objects in the old equation of exchange with "the value in exchange" of these quantities. In so doing, he makes apparently an impossible equation possible. But in the process he obliterates any meaningful notion of "value in exchange." That is, while by value in exchange of 5 hectoliters of wheat, a classical writer meant 600 grams of silver, in the case of Walras it is not at all clear what "value in exchange" means. All that one could say is that there is an undefined entity that appears on both sides of the equation of exchange, and when we divide this entity by one similar to it we get a pure number.

Walras's own explicit attempts to define "value in exchange" do not make the concept any clearer either. Right after the aforementioned analysis Walras states: "Value in exchange is thus a magnitude, which, as we now see is measurable" (Walras 1954: 70). A few pages later, in lesson 5, however, he seems to change his mind and redefines value in exchange by writing:

Value in exchange is a property, which certain things possess, of not being given or taken freely, but of being bought and sold, that is, of being conveyed 
in return for other things in definite quantitative proportions. The buyer of the thing is the seller of that which he gives in exchange. The seller of a thing is the buyer of that which he takes in exchange. In other words, every exchange of one thing for another is made up of a double purchase and a double sale.

(Walras 1954: 83, emphasis in the original)

It is hard to reconcile the two definitions. That is, it is not at all clear how "value in exchange" can be both a "magnitude" and at the same time a "property" that "certain things possess."

Walras's difficulty with defining "value in exchange" is, of course, not unique. As was pointed earlier, Jevons faced the same dilemma and defined and redefined the classical expression. In the process, he produced a number of definitions of value in exchange, including "terminal utility," "circumstance of its [a good] exchanging in a certain ratio for some other substance," and simply "a ratio" (Jevons 1871: 157, 1879: 77-78). None of Jevons's definitions matched, and, interestingly enough, none matches Walras's.

Other marginalist theorists also tried to redefine the term. Edgeworth (1926: 602), for example, saw value in exchange to correspond to the marginal utility "multiplied by the quantity." Wicksteed (1888: 79), on the other hand, following Jevons's first definition, defines "the value in exchange of a commodity" as the "differential coefficient of total utility" of the commodity. But he seems to realize that this definition does not square well with the classical expression "value in exchange," which involves two commodities. After all, when "I say that the exchange-value of a horse is $£ 31$," to use Wicksteed's own example, "I mean that a man could get $8 \mathrm{oz}$. of gold for the horse" (Wicksteed 1888: 80). Wicksteed tries to solve this incongruity in the most peculiar manner; "the exchange value of an article," he writes, "is simply its marginal utility measured in the marginal utility of the commodity selected as the standard of value" (Wicksteed 1888: 81).

Finally, some marginalist theorists, apparently feeling the inconsistencies, tried to exorcize "value in exchange" from economic theory altogether. One in particular was Pareto. In a footnote in the Elements of Pure Economics, Jaffe contends that Pareto assailed Walras's definition of value in exchange as "a property, which certain things possess" as "un-meaningful, because it defines an unknown "value in exchange,' in terms of an equally unknown 'property.' He finds it useless to refer to this metaphysical entity, when its concrete manifestation, price, i.e., ratio of exchange, is all that is needed in the theoretical development that follows" (Walras 1954: 498). ${ }^{9}$ Jaffe, however, does not find Pareto's criticism "altogether true" and thinks Walras's intended meaning of value in exchange was "a term in a ratio with no autonomous existence outside of that ratio" (Walras 1954: 498). This is, of course, yet another meaning of value in exchange, and Jaffe does not realize that Walras's definitions, as well as his own, are indeed nonsensical. Nor does Jaffe realize that there was a good reason for Walras's difficulty in defining the term.

Given what was said earlier in the chapter, we can easily see why Walras does what he does. Similar to Jevons, Walras has to twist and turn the old classical 
concept of value in exchange so that it becomes compatible with the utility theory. That is, ultimately, Walras would like to state: "Current prices or equilibrium prices are equal to the ratios of the raretés. In other words: Values in exchange are proportional to the raretés" (Walras 1954: 145, emphasis in the original). Jevons, as we saw, accomplished this in the most torturous way and, ultimately, turned the measure of all commodities into mass. Walras cuts to the chase by simply positing an undefined entity called "value in exchange of 1 unit of something" that if divided by "value in exchange of another unit of something" results in a pure number.

There are also other similarities between Jevons and Walras that explain the need to drastically change the equation of exchange and the meaning of value in exchange. Like Jevons, Walras feels obligated to make the theory of exchange "scientific." For example, right after the aforementioned formulation of exchange he writes: "In form (1), precisely as form (2), the equation is an exact translation of the following phrase, or as I should prefer to put it, the scientific representation of the following fact: 'Wheat is worth 24 francs a hectoliter' " (Walras 1954: 70, emphasis added). In this attempt to develop a "scientific" theory of exchange, Walras, similar to Jevons, obfuscates a kind of mathematics that could be applied to the classical theories of exchange - that is, a neutral system of notations - with a kind suitable to physics or mechanics. For example, in the same context of making exchange mathematical, he writes that the "pure theory of economics is a science which resembles the physico-mathematical sciences in every respect. This assertion is new and will seem strange; but I have just proved it to be true" (Walras 1954: 71). He then adds: "If the pure theory of economics or the theory of exchange and value in exchange... is a physico-mathematical science like mechanics or hydrodynamics, then economists should not be afraid to use the methods and language of mathematics" (Walras 1954: 71).

Also, given the confusion over the exact nature of mathematics applicable to the theory of exchange, Walras, similar to Jevons - and also the third fellow traveler, Marshall - does not appear to be able to decide on the exact relation between his own theories and that of his classical predecessors. ${ }^{10}$ For example, even though he believes that he is developing a new theory of exchange, which resembles physico-mathematical sciences, he still thinks that he is merely re-expressing, albeit in a corrected form, the classical ideas in a mathematical form:

As to mathematical language, why should we persist in using everyday language to explain things in the most cumbrous and incorrect way, as Ricardo has often done and as John Stuart Mill does repeatedly in his Principles of Political Economy, when these same things can be stated far more succinctly, precisely and clearly in the language of mathematics?

(Walras 1954: 72)

Given that Ricardo or Mill's theories of exchange had nothing to do with "mechanics or hydrodynamics" and were not calculus based, Walras's confusion 
with regard to the relation between his own theory of exchange and that of the classical political economists is made abundantly clear in the above passage.

In sum, like Jevons, Walras changes the equation of exchange and "value in exchange" because the new concept of science of economic - which is ultimately nothing but giving economic meanings to certain concepts in "physicomathematical sciences"-mandates it. The new "science" also obliterates any realistic and meaningful concept of price, distinction between barter and monetary relations, and uniqueness of money commodity.

\section{Buying and selling in a moneyless Walrasian world}

As we saw in the case of the "wheat market," Walras uses the terms value in exchange and price interchangeably. He then speaks of exchanging 5 hectoliters of wheat for 600 grams of silver and subsequently proposes to "choose" certain units of silver to be called francs (Walras 1954: 70). Thus silver appears to be just another good, rather than a unique commodity that since time immemorial has been used as money. Moreover, wheat appears to barter rather than to sell for silver. Similarly, as was noted in the case of defining "value in exchange," Walras speaks of "exchange of one thing for another"- that is, barter-"purchase" and "sale" in one stroke, as if there is no difference in the properties of direct and indirect exchange relations.

These problems are not unique to the discussion of the "wheat market." We see many of these same problems elsewhere in the Elements of Pure Economics. One of the most glaring cases appears in lesson 5, entitled "The Market and Competition: Problem of Exchange of Two Commodities for Each Other," which deals, once again, with the equation of exchange and "value in exchange" in a generalized form (Walras 1954: 83). The title of the lesson seems to indicate a barter relation, and yet, Walras starts his discussion by referring to the most advanced form of exchange, that is, "the stock exchange of large investment centers like Paris and London" (Walras 1954: 84). He justifies this beginning by saying: "Economists, generally speaking have fallen all too frequently into the error of studying value in exchange under unusual circumstances" (Walras 1954: 86). "They," he goes on to claim falsely, "are always talking about diamonds, Raphael's paintings, and concert recitals given by famous singers" (Walras 1954: 86, emphasis added). ${ }^{11}$ Instead, Walras writes:

I have cited the example of buying and selling securities for gold and silver on the stock market in order to give an introductory idea of the phenomenon of exchange and mechanism of competition. Securities, however, are a very special kind of commodities. Furthermore, the use of money in trading has peculiarities of its own, the study of which must be postponed until later, and not interwoven at the outset with the general phenomenon of exchange. Let us, therefore, retrace our steps and state our observations in scientific terms. We may take two commodities, say oats and wheat, or, more abstractly, (A) and (B).

(Walras 1954: 86-87) 
Once again the reference to the stock exchange is cosmetic. As the above statements make it quite clear, the setting is that of a barter situation, where money is cast aside. Here, there can be no meaningful concept of buying, selling, or price, since these concepts generally deal with money rather than a simple case of barter. Yet, the next two passages (Walras 1954: 87) read:

Let us imagine a market to which some people come holding commodity (A), ready to exchange part of it in order to procure commodity (B)... Since the biding will have to start at some point or other, we shall suppose that a broker offers to give up $n$ units of (B) for $m$ units of (A) in accordance, let us say, with the closing rate of exchange of the preceding day. This bid will conform to the equation of exchange

$$
m v_{b}=n v_{a}
$$

in which $v_{a}$ is the value in exchange of one unit of (A) and is $v_{b}$ is the value in exchange of one unit of (B).

Let us define prices in general as ratios between values in exchange or as relative values in exchange. In general, also, let us designate the price of (B) in terms of (A) by $p_{b}$ and price of (A) in terms of (B) by $p_{a}$. If, then, we denote, in the particular case we are dealing with, the quotients of the ratios $m / n$ and $n / m$ by $\mu$ and $1 / \mu$ respectively, it follows from the above that

$$
\begin{aligned}
& v_{b} / v_{a}=p_{b}=m / n=\mu, \\
& v_{a} / v_{b}=p_{a}=n / m=1 / \mu .
\end{aligned}
$$

These passages reconfirm what was said earlier: in Walras's moneyless world of exchange, not only is there buying and selling but also a fully functioning stock market where brokers offer bids. Moreover, in this same moneyless world of barter there is still a general notion of price. This "price" is not what one usually means by the term, that is, the expression of the worth of a commodity in terms of a unique commodity, money commodity. Instead, "price" here is just a number, a pure number with no dimensions attached to it. This is so because, as Walras had made it quite clear in his earlier discussion of the equation of exchange, the ratio " $\mathrm{v}_{\mathrm{b}} / \mathrm{v}_{\mathrm{a}}$ " is a dimensionless number.

What appears next is even more peculiar. Immediately after the aforementioned passage, Walras introduces (Walras 1954: 88) his "fundamental relationship" between the "quantities demanded, quantities offered and prices":

$$
O_{\mathrm{b}}=D_{\mathrm{a}} p_{\mathrm{a}}
$$

where $O_{\mathrm{b}}$ and $D_{\mathrm{a}}$ are, respectively, the quantities of (B) offered and quantities of (A) demanded. But given that $p_{\mathrm{a}}$ is a pure number, this new equation of exchange appears to be identical to the Aristotelian type of equation " 5 beds $=1$ house" after all.

In other words, we are back, full circle, to the old and impossible equation of exchange. But Walras does not seem to realize this fact, and, indeed, his "scientific" 


\section{The "scientific" theory of exchange}

theory of exchange, which is encumbered with too many vague concepts and notational substitutions, obscures the exact nature of the equation. As a result, we see no attempt on Walras's part - comparable to that of generations of economists before him - to find a substance that would make the two sides of the equation equal. Nor do we see any attempt to make money play the role of a proxy in the absence of such a substance.

Also, soon after, utility theory is introduced and the equation of exchange is transformed into the distinctive marginalist equation:

$$
r_{\mathrm{a}, 1} / r_{\mathrm{b}, 1}=p_{\mathrm{a}} \quad \text { and } \quad r_{\mathrm{b}, 1} / r_{\mathrm{a}, 1}=p_{\mathrm{b}}
$$

where $r_{\mathrm{a}, 1}$ and $r_{\mathrm{b}, 1}$ are the "raretés" or the "intensities of the last wants satisfied" for holder (1) of the commodities (A) and (B) (Walras 1954: 143). As argued in the case of Jevons, once these types of equations are posited any necessity for introducing money into the theory of exchange would vanish completely. Not only that, since money has no utility in the marginalist sense, logically it must be kept out of the equation of exchange.

It should be pointed out that there is no substantial change in the status of money as Walras's theory moves from the "Theory of Exchange of Two Commodities for Each Other" in part II of the Elements to the "Theory of Exchange of Several Commodities for One Another" in part III (Walras 1954: 81, 151). Toward the end of the latter part it is stated that in general the "commodity which serves as the numéraire serves also as money and acts as a medium of exchange" and that the "standard of measure of value thus becomes the monetary standard" (Walras 1954: 189, emphasis in the original). Subsequently, in a few terse passages, Walras finally lets one of the commodities act as a medium of exchange and then concludes that "just as we can pass from indirect to direct prices at will simply by abstracting from the numéraire, so we can pass from indirect to direct exchange, whenever it suits us, simply by abstracting from money" (Walras 1954: 191, emphasis in the original). This statement is indicative of how little Walras distinguishes between the properties of the relations "barters for," "purchases," and "sells for," discussed in the previous chapters.

One should also point out that ultimately Walras does, rather desperately, try to introduce money into his general equilibrium theory. But that happens more than halfway through the Elements, well after part IV on the "Theory of Production" and part V on the "Theory of Capital Formation." At last, in part VI, the "Theory of Circulation and Money," the assumption of the non-uniqueness of "money" is dropped when the "mechanism and equations of circulation and money" come under consideration (Walras 1954: 315). In this analysis money is perceived to be unique not because it buys goods and goods do not buy money, but because money is an "object without a utility of its own" and only its "services of availability" enter the utility functions of "consumers" and "producers" (Walras 1954: 316, 320).

In the final analysis, Walras's world of exchange, at least until "capital" comes into play, remains moneyless even though supposedly there is buying, selling, 
price, and even the hustle and bustle of the modern day stock exchange. This is, of course, a world similar to that of Jevons. But given the razzle-dazzle of the Walras's general equilibrium theory, it is the lackluster role of money in Walras's world of exchange that attracts most of the attention of the later generations of marginalist theorists, as we see in Chapter 7.

\section{Conclusion}

The folktale that Jevons recites concerning the difficulties of barter and emergence of money in his Money and Mechanism of Exchange is clearly superfluous to his theory of exchange. In the world of utility maximizing "homo economicus" there is no distinction between Mademoiselle Zélie and the inhabitants of the Society Islands. All "trading bodies," whenever and wherever they are, behave like a lever in bartering one good for another. In this exchange no one runs into any difficulties, since if anyone does, the analogy between the harmonious theory of exchange and that of the lever would fall apart. In short, Mademoiselle Zélie is completely irrelevant when it comes to Jevons's "scientific" utility theory of exchange. This irrelevance brings forth an interesting issue concerning the progress of making monetary theory realistic. Jevons's "scientific" theory not only does not increase the element of realism in the theories of exchange and money, but it actually does the opposite by creating more obstacles.

For more than 2,000 years economic thinkers had tried to answer what is the nature of exchange and money. The narratives that Aristotle, the scholastics, classicals, and Marx weaved concerning the bartering barbarians, sons of Adam, savages, and the primitive communities served such a purpose. As markets developed, however, it became increasingly necessary to elucidate the functioning of a monetized, market-dominated economy. Thus Smith's story of the "savage" running into the difficulties of barter and developing money was ultimately intended to explain how the economy of a "civilized society" works. Similarly, Marx's "primitive communities" bartering on the margins, the gradual extension of barter, the growing number of exchange transactions, and the increasing variety of commodities bartered leading to the further development of the commodity as exchange-value and stimulating the formation of money were all intended to reconstruct in thought a capitalist economy.

Explaining the working of a monetized, capitalist economy, however, was not the aim of Jevons's Theory of Political Economy. The intent was to make economics "scientific," on par with mathematical physics. Given this aim, the question became "what is the economic interpretation of the path of a trajectory and its time rate of change?" or "what is the economic counterpart of the theory of the lever?"

Answering the aforementioned questions does not require any historical perspective. Thus the Theory of Political Economy becomes devoid of any concept of history. Here, even the imaginary historical characters that appeared in the earlier economic writings would vanish. All that is required is an abstract pair of "trading bodies" who could appear anywhere in the universe at any time. But 
there is more to this fictitious exchange: the straightjacket of the new "science" mandated the removal of many vestiges of reality. Hence, for example, a "commodity," which for over 2,000 years had been viewed as a useful object that would exchange, becomes for Jevons "any object, substance, action, or service, which can afford pleasure or ward off pain" (1879: 38). This was, of course, done to make the commodity infinitely divisible so that the domain of the utility function becomes identical to the set of real numbers.

Moreover, because of the requirement of "science," the same commodity, which had always been measured in terms of its usual units of exchange, was now measured by Jevons in terms of "mass." Similarly, the ordinary expression "utility," which simply means "usefulness," was twisted and turned in the hands of Jevons until it became a functional relation from the set of real numbers to the same set. Furthermore, "value" and "value in exchange," which for the classical political economists meant the quantity of some object that will exchange for another, became for Jevons an abstract number, and the simple equation of exchange was transformed into the ratio of "degrees of utility." Above all, however, in this highly unreal ahistorical narrative of The Theory of Political Economy, money vanished altogether in the interest of "science."

The disappearance of the historical narrative and money, however, was not unique to Jevons. His fellow marginalist traveler, Léon Walras, also had no need for history or individuals. Indeed, when it comes to the issue of money and exchange there is a great deal of similarity between Walras's Elements and Jevons's Theory. Walras, too, must twist and turn the old classical concepts to make the theory of exchange "scientific," in tune with "mechanics or hydrodynamics." He, too, must create an exchange equation which is ultimately reflective of raretés. He, too, must actually avoid money because money does not exactly figure into this equation. The result is that Walras's world of exchange remains, similar to that of Jevons, moneyless.

Yet, Walras is more concerned than Jevons with methodological issues. ${ }^{12}$ Suddenly throwing the "trading body" into the picture, as is the case in Jevons, appears not quite palatable to Walras. He would like to have a realistic point of departure. Hence, he pretends to start his theory of exchange with the stock market in Paris or London. But as soon as he begins, he discards this point of departure by arguing that securities are a special kind of commodities and money has peculiarities of its own. Thus, instead of dealing with the analysis of the stock market and money, he posits an equation of exchange, which is similar to that of Jevons.

At the end, there is no substantive difference between Walras's theory of exchange and that of Jevons. Neither one has any use for the notion of the difficulties of barter leading to the development of money. Worse yet, neither has any use for money in the "scientific" theory of exchange to begin with. Yet, given the flamboyancy of Walras's mathematical notations, equations, and the eleventh hour introduction of money, it is Walras's general equilibrium theory and the role of money in it that attracts the eyes of the orthodox economists, as we see in Chapter 7. 
Before leaving this chapter, however, let me note briefly that the third of the marginalist pioneers, Alfred Marshall, also had no need for money. ${ }^{13}$ Marshall, who continuously touts the thesis of continuity of thought between himself and the classical political economists, not only has no analysis of money in his Principles of Economics but he also has no customary analysis of exchange. ${ }^{14}$ Actually, the only time that Marshall brings up the issue of the "Equation of Exchange" is in a note in his mathematical appendix with reference to Jevons's concept of exchange and Edgeworth's contract curve (Marshall 1890: 845). ${ }^{15}$ In another appendix entitled "Barter," Marshall makes his only distinction between barter and monetary relations by stating:

The real distinction then between the theory of buying and selling and that of barter is that in the former it generally is, and in the latter it generally is not, right to assume that the stock of one of the things which is in the market and ready to be exchanged for the other is very large and in many hands; and that therefore its marginal utility is practically constant.

(Marshall 1890: 793)

In other words, barter and monetary relations differ in the assumption that the marginal utility of money, as opposed to nuts and apples, is constant. Such remarks show how the new "science" of economics was itself becoming a barrier to any meaningful and realistic analysis of exchange and money. 


\section{Neo-Walrasianism, the matrix of exchange, and beyond}

In discussing the difficulties of barter and origin of money, most books, particularly textbooks, almost invariably refer the reader to William Stanley Jevons. However, as stated in Chapter 6, there is no room in Jevons's utility theory for the notion of the difficulties of barter or even money itself. Thus, when it comes to monetary theory, Jevons's utility theory is of very little use. Also, compared to Walras's ostentatious general equilibrium theory Jevons's exchange theory appears quite dull. Most orthodox economists, therefore, have historically shown a preference for Walras's theory as opposed to that of Jevons. Yet, even in Walras's general equilibrium theory one cannot find the notion of difficulties of barter and the necessity of money, as shown in Chapter 6. But could the Walrasian system be amended to include money, particularly fiat money?

Given what was said in Chapter 6, the answer to the above question appears to be negative, since "scientific exchange" and its affiliated equation of exchange rule out the existence of money from the very beginning. But the answer of many orthodox economists is not so definitive and depends partly on their theoretical perspectives. If one is inclined more toward Keynesianism than marginalism, the answer is also negative. For example, after asking "how can money have positive value in exchange?" James Tobin writes:

Economists have long regarded the theory of value as the central question of their discipline... Money, however, is an embarrassment to value theory. According to standard theory, something can have positive value only if it generates positive marginal utility in individuals' consumption or positive marginal productivity in the making of goods and services that do generate marginal utility. The embarrassing puzzle is the sharpest for fiat money. All of its value comes from the fiat that makes it money. Fiat money has no intrinsic non-monetary source of value. It cannot be eaten or worn or used in any way that generates utility for the consumers, except a few numismatists... Formal general equilibrium theory, which describes the imaginary world of frictionless barter, does of course express the prices of goods and services in a numéraire. It is tempting to identify numéraire prices as money prices. But the numéraire is just a mathematical normalization.

(Tobin 1992: 774, emphasis in the original) 
This view of the money - as being an embarrassment to the utility theory in general, and Walrasian theory in particular-however, is not shared by all orthodox economists, particularly those sympathetic to Walras. Actually, a few historians of economic thought are still searching for a robust theory of money in Walras's different editions of the Elements of Pure Economics. Others, mostly monetary theorists, find such a search to be in vain, but believe that the problem could be remedied and the theory, or at least some aspects of it, might be salvageable.

The diverse views about money, or lack of it, in Walras's general equilibrium theory have produced an enduring debate between various orthodox economists. In this debate the issue of "realism" of economic theory stands prominent. ${ }^{1}$ It is generally agreed that any theory of price that does not include money is not realistic. Thus, whether Walras's theory is realistic, or could be made realistic by adding certain assumptions, is an important feature of this debate.

Examining the controversy surrounding the status of money in the general equilibrium theory and the outcome of this controversy are the focal points of this chapter. In the first section, I briefly look at the debate over whether Walras's theory is or is not realistic, a debate that starts in the first half of the twentieth century and continues to this day among the historians of monetary theory. The second section deals with the neo-Walrasian attempts to incorporate money in the general equilibrium theory and Clower's response to these attempts in his 1967 seminal essay, "A Reconsideration of the Microfoundations of Monetary Theory." It is argued that the most revolutionary aspect of this article was the so-called matrix of exchange - a matrix intended to distinguish between barter and monetary relations and money and non-money commodities. Yet this revolutionary aspect got lost mostly in the shuffle of the marginalist discussions concerning such things as the adequacy of Clower's budget constraint. The third section examines the gap between Clower's matrix of exchange and the matrices of exchange that could be constructed based on the medieval economy. It will be shown in this section that such a real economy could provide much richer and more interesting matrices than that put forward by Clower. The fourth section looks at the direction that monetary theory took after the introduction of the matrix of exchange. In this section two theoretical perspectives are briefly examined, the decentralized exchange and, on a very different note, a unique attempt to revive Marx's theory of value form and money. It is concluded that while such attempts meant to increase the realistic content of monetary theory, they accomplished very little in that direction. The result was the destruction of the neo-Walrasian foundation of the modern monetary theory, but very little to replace it with.

\section{Realistic or unrealistic?}

The extent to which money plays a role in Walras's general equilibrium theory and, therefore, whether the theory has any semblance of, or relevance to, reality have been debated by marginalist theorists for a very long time. In two famous papers published in the 1930s, Arthur Marget gives us a flavor of the controversy up until 


\section{The matrix of exchange and beyond}

that period. In the first paper Marget attempts to show the importance of money in the Elements and establish Walras as a great monetary theorist who anticipated the Fisherian type of the "equation of exchange" and the real "cash-balance approach," particularly that of "Keynes's famous equation $n=p k$ " (Marget 1931: $573,600)$. In the second, Marget tries single-handedly to defend Walras against many critics who argued that his general equilibrium theory "rests at its crucial point upon some assumption which is contrary either to the facts of the world about us or to certain of the fundamental assumptions underlying Walras's general system of economic equilibrium" (Marget 1935: 154). One individual who came under Marget's intense criticism for misinterpreting Walras was John Hicks. According to Marget, Hicks contended that Walras's attempt to "discuss money as a medium of payment or exchange was a failure because it forgot one of the fundamental assumptions upon which his system of equation is constructed, namely the assumption of perfect foresight" (Marget 1935: 158). "In a world in which there is perfect foresight," Marget went on to state Hicks's position, "there would be no use for money at all. It would be a mistake, therefore, to attempt to introduce a 'demand for money' into his [Walras's] equations, since such a demand for money would be zero" (Marget 1935: 158).

Marget's defense of Walras had, at times, a broader dimension: it tried to ward off those who held that any utility-based theory, and not just Walras's, is unrealistic. For example, at one point Marget goes after

the mathematician Bertrand, who, in his much-discussed critique of Walras, had the arrogance to chide the latter for having failed to see any attempt to explain the actions of men in the market in terms of raretés "loses all significance when it is applied to business men," who, Bertrand insisted, think only in terms of costs, selling prices, and profits.

(Marget 1935: 171-172)

Earlier in the essay, Marget also writes of the "great disservice" done by those "who argue that the great bulk of received economic theory is perfectly inapplicable to the world as we know it because the theory is based upon a set of 'abstract' premises" (Marget 1935: 162).

Against all such individuals, and specifically those who saw Walras's general equilibrium theory as unrealistic, Marget waged a theoretical battle. In particular, he tried "to demonstrate, once and for all, that the Walrasian system of general equilibrium is not constructed upon barter assumptions" (Marget 1935: 169, emphasis in the original). Yet, Marget's "demonstration," which for the most part was nothing more than a Whiggish historiography and apologetic defense of Walras, was not convincing, particularly against Hicks's logical argument. Hicks himself appeared undaunted by Marget's counterarguments, since many years later in reference to Walras's "numéraire," he would still write:

The numéraire is not money; it is not even partial money; it is not even assumed that it is used by the traders themselves as a unit of account. It is no 
more than a unit of account which the observing economist is using for his own purposes of explaining to himself what the traders are doing.

(Hicks 1967: 3)

"Money is money," Hicks goes on to state, "because it can be spent in the shops" (Hicks 1967: 5).

Yet, even though Marget's attempt to show the realistic nature of Walras's general equilibrium theory - and the role that money plays in it - did not convince too many monetary theorists, the controversy did not die out and continues to this day, mostly in the realm of the history of economic thought. Perfect examples are two relatively recent books by Bridel (1997) and Walker (1996), one dismissing the Walrasian general equilibrium theory as essentially unrealistic and inherently incapable of including money and the other arguing the opposite.

Bridel attempts to drive the final nail in the coffin of the controversy by stating, from the very beginning, that despite "more than a century of theoretical efforts, the best developed modern Walrasian general equilibrium models cannot find room for money" (Bridel 1997: vii). As such, his aim is to demonstrate that "from its inception as a model of exchange between commodities, the very logic of general equilibrium theory barred money to play an essential role as a social institution allowing monetary exchanges among individuals" (Bridel 1997: vii). Given this aim, Bridel surveys Walras's "lifelong deliberate attempt to include money in the utility function" in different editions of the Elements (Bridel 1997: 2). He agrees with many economists — such as Hahn (1973, 1983), Howitt (1973), and Ostroy (1992) - that all such endeavors were "contrived" and money was merely an "add-on" to what was essentially a moneyless theory (Bridel 1997: viii, $9,92,141)$. Subsequently, Bridel looks at the post-Walras attempts to rectify the original failure. He also finds these to be contrived and, therefore, bound to fail. In reference to the Marget controversy Bridel writes that Hicks had made a "perfectly sound argument" in 1933 that

money can have no positive value, therefore it is a mistake to attempt to introduce demand for money functions into general equilibrium equations: Walras's model is one of barter... it took the profession nearly six decades to come to terms with such a severe limitation to Walras model.

(Bridel 1997: 42)

Walker does not agree that the controversy is over. He tries to distinguish between the different versions of Walras's general equilibrium model, particularly what Walker believes to be the preferred "mature comprehensive model," written by Walras in his "mature phase" of life as opposed to the final version written in the "phase of decline" (Walker 1996: 5-13). In this sense, Walker's analysis is somewhat different from that of Marget. Yet, the aim of the project and the mode of reasoning remain basically the same. Walker, too, attempts to show that Walras was a realist and his model is not that of an imaginary barter economy. He writes that the "current view of Walras's work is that he did not pay attention to market 


\section{The matrix of exchange and beyond}

institutions" (Walker 1996: 76). Against this widespread view, Walker tries, single-handedly, to demonstrate the contrary (Walker 1996: 76). To Walker, Walras's "market models are rich in details drawn from real markets and real economy generally" (Walker 1996: 76). Indeed, Walker contends, Walras "drew the structural properties of his model from economic reality, basing the model on the institutions of organized markets of his day" (Walker 1996: 92). This, Walker contends, makes Walras's model "remarkably complete and realistic" (Walker 1996: 92).

The claim concerning the realistic nature of Walras's monetary model can be found throughout Walker's work. Such claims, however, appear to be based on a few references that Walras makes to the modern market. For example, Walker refers to passages in the Elements, that were examined in Chapter 6, concerning the Parisian "stock market" and contends that "Walras drew on the features of the organized exchanges of his time for theoretical purposes" (Walker 1996: 78). But, as I argued in Chapter 6, these references are nothing more than some crude embellishments designed to hide what is essentially a fictitious barter model. The stock market is not the true starting point of Walras's equation of exchange. The point of departure is the exchange between two imaginary and atomistic entities meeting one another in a moneyless world. For this type of theory one does not need any reference to the modern day stock market. All that is needed is some old-fashioned bartering barbarians, à la Aristotle, or sons of Adam, à la Oresme, or savage natives, à la Smith, or Mademoiselle Zélie and Society Islanders, à la Jevons. Better yet, since utility theory requires no history, Walras could have accomplished the task by just starting with Jevons's "trading bodies." The reference to the stock exchange was merely part of the Walrasian show or, to use an expression from Bridel, a "sheer exercise in pyrotechnics" (Bridel 1997: 112).

In the end, Walker's claim that Walras was a realist and a great monetary theorist engaged in "scientific pursuit" does not appear to be any more convincing than similar claims by Marget six decades earlier (Walker 1996: 420). ${ }^{3}$ Indeed, it is hard to imagine how an ahistorical theory of exchange emulating "physico-mathematical science like mechanics or hydrodynamics" can ever be made realistic (Walras 1954: 71). It is even harder to conceive how such emulations can still be called "scientific" after a century of intense debates about the nature of science by philosophers of science and decades of discussion concerning the nature of the "marginal revolution" by methodologists of economic theory. ${ }^{4}$

\section{Neo-Walrasianism and the "matrix of exchange"}

If the controversy over Walras's inclusion of money in his general equilibrium theory and the realistic nature of the theory still continues in the realm of the history of economic thought, in the domain of monetary theory the controversy seems to have ended a long time ago. Following Walras, monetary theorists, 
working mostly within the straitjacket of marginal analysis, became increasingly concerned with developing a more realistic theory of money. The most important outcome of this development, I believe, was the emergence of the concept of the matrix of exchange. But before discussing this concept, let me briefly review the context in which the matrix of exchange was developed.

As was pointed out earlier, Hicks was among those early theorists who argued that Walras's general equilibrium theory had no room for money and the numéraire was not real money, since it does not buy anything in the shops. As such, Hicks proposed considering the great fairs of the Middle Ages as a possible source for modeling exchange. Yet, as pointed out in the introduction to this book, Hicks did not exactly practice what he preached. Instead of developing a model of exchange based on a real economy, he attempted to rescue the "marginal revolution" by trying to incorporate money into the utility theory, believing all along that "marginal utility analysis is nothing else than a general theory of choice" and people do choose to hold money (Hicks 1967: $62-63)^{5}$

The unrealistic marginalist theory of money also brought forth the neo-Walrasian critique of the theory and various attempts to rectify the problem. One of the most prominent members of the group is Don Patinkin, who writes:

The basic postulate of the classical monetary theory is that people do not drive utility from holding money, and consequently it does not enter the utility function. But this postulate stands in complete contradiction to the avowed purposes of formulating a monetary theory. For if money does not enter the utility function, people will certainly not hold money. Hence we could not possibly have any realistic monetary theory.

(Patinkin 1948: 135, emphasis added)

Similar to Hicks, Patinkin holds that in the "classical theory" money is no more than a unit of account and that "there is no more treatment of its far more important functions as a medium of exchange and or store of value" (Patinkin 1948: 135). ${ }^{6}$ In the real world, however, Patinkin argues, people do choose to hold money, and therefore money must enter the utility function to represent "the satisfaction derived by individuals from holding money as a means of dealing with uncertainty" (Patinkin 1948: 136). ${ }^{7}$ As such, Patinkin attempts in various essays to incorporate formally "real cash balances," or money as a "medium of exchange," into the usual utility function, assuming that individuals "derive satisfaction from holding money for transactions, precautionary and speculative purposes" (Patinkin 1950-1951: 44-45).

The result of this attempt to include money in the general equilibrium theory ultimately appears in Patinkin's Money, Interest, and Prices: An Integration of Monetary and Value Theory, the introduction of which starts with these terse statements: "Money buys goods, and goods do not buy money. The natural place, then, to study the workings of monetary forces is in the markets for goods" 


\section{The matrix of exchange and beyond}

(Patinkin 1965: xxiii, emphasis added). The aphorism is, of course, directed against the Keynesian "monetary theories which shift the center of emphasis from markets for goods to the market for money" (Patinkin 1965: xxiii).

This neo-Walrasian attempt to integrate monetary theory with value theory came under attack from within the ranks of the marginalist school, as well as Keynesian economists. ${ }^{8}$ One such attack, with perhaps the most devastating consequence, is that of Robert Clower, who raised serious questions in his 1967 essay, "A Reconsideration of the Microfoundations of Monetary Theory," about the unrealistic nature of exchange in both the Walrasian and neo-Walrasian models (Clower 1970: 202). ${ }^{9}$

Similar to the economists mentioned earlier in this work, Clower considers the analytical structure of Walras's general equilibrium theory as one that "precluded assignment of a specialized role to money as a means of payment" (Clower 1970: 19). The continuation of such an analysis, Clower argues, despite Keynes "raising doubts about the theoretical generality of the traditional value theory and its relevance for describing on going as contrasted with virtual economic process," leads to the development of "neo-Walrasian models" (Clower 1970: 20, emphasis in the original). But here again

money appears as just one among many analytically indistinguishable commodities in a world where trading activities are costlessly coordinated by a central market authority in such a manner that all feasible trades ultimately can be carried out directly, without the use of exchange intermediaries.

(Clower 1970: 20)

This "neo-Walrasian monetary model," Clower contends, is best exemplified by a

Patinkinesque community of self-interested individuals each of whom receives "like manna from heaven" a predetermined quantity per time unit of one or more durable goods that may be consumed directly, traded for other commodities, or held for future consumption or trade. ${ }^{10}$

(Clower 1977: 206)

The model, Clower goes on to say, consists of the usual utility maximization of "n goods" and some real cash balance, that is,

Maximize $U_{j}\left(d_{l j}, \ldots, d_{n j}, M_{j} / P\right)$

subject to

$$
\sum_{i=1}^{n} p_{i}\left(d_{i j}-s_{i j}\right)+M_{j}-M_{j}^{\prime}=0
$$


where $U_{j}$ satisfies familiar continuity and curvature conditions, $s_{i j}$ and $d_{i j}$ represent initial and desired commodities of goods, $M_{j}^{\prime}$ and $M_{j}$ represent initial and desired quantities of fiat money, and $P$ is a fixed-weight index of money prices $p_{1}, \ldots, p_{n}$ (Clower 1970: 203).

Does such a budget "constraint constitute an 'appropriate definition of choice alternative in a money economy?" "Clower asks. He then answers the question negatively by arguing that in such an equation "any commodity, whether good or money, can be offered directly in trade for every other commodity" (1970: 203-204). "But an economy that admits of this possibility," Clower goes on to argue, "clearly constitutes what any classical economists would regard as barter rather than a money economy," and the inclusion of fiat money makes no difference (Clower 1970: 204-205).

It is in this context of the "world where "money matters" "that Clower conceives of exchange in a novel way and puts forward the idea of the matrix of exchange (Clower 1970: 205). He does so by asking two interrelated questions: What is the distinction between money and other commodities, and how is monetary relation distinct from barter relation? These simple and most basic questions are indeed profound, since in the long history of the development of monetary theory no one seems to have bothered to raise them. The answers given, however, as we shall see, were not as profound as the questions themselves.

In answering the aforementioned questions, Clower attempts to define a set of basic concepts and relations. Thus, on what he calls the set of commodities, " $C=\left(C_{1}, \ldots, C_{n}\right)$," Clower defines an exchange relation, " $E$," which is a subset of the Cartesian product $C \times C$ (Clower 1970: 205). Trade is feasible, according to Clower, if and only if $C_{i} E C_{j}$, for all $i, j=1, \ldots, n$. This relation, Clower contends, is "non-empty and reflexive," since "any commodity available for trade can be held by the individual who possesses it" (Clower 1970: 205, emphasis added). Moreover, Clower argues, since by the nature of trade $C_{i} E C_{j}$ implies $C_{j} E$ $C_{i}$, then the relation $E$ is symmetric. Finally, according to Clower, the relation $E$ may or may not be transitive, since $C_{i} E C_{j}$ and $C_{j} E C_{k}$ may or may not imply $C_{i}$ $E C_{k}$. "Transitivity of exchange relation," Clower goes on to say, "is, in fact characteristic of just one class of economies, namely barter economies" (Clower 1970: 206). With this in mind, Clower defines money commodity as "any element $C_{i}$ of $C$ for which $C_{i} E C_{j}$ is true for all values of $j$ " (Clower 1970: 206). That is, a "commodity is regarded as money if it can be traded directly for all other commodities in the economy" (Clower 1970: 207).

Given the aforementioned definition, "a barter economy is one in which all commodities are money commodities," according to Clower (1970: 206). By contrast, Clower goes on to argue, "some commodities in a money economy cannot be traded directly for all other commodities; i.e., some exchanges necessarily involve intermediate monetary transactions" (Clower 1970: 206). This leads Clower to define a "money economy as a system involving at least one money commodity but a non-transitive exchange relation" or "a system in which not all commodities are money" (Clower 1970: 206-207). Given these definitions, 


\section{The matrix of exchange and beyond}

Clower develops the matrices of exchange for barter, pure money, and non-pure money economies:

$$
\begin{array}{|l|l|l|}
\cline { 2 - 3 } \multicolumn{1}{c|}{} & C_{1} & C_{2} \\
\hline C_{1} & \mathrm{x} & \mathrm{x} \\
\hline C_{2} & \mathrm{x} & \mathrm{x} \\
\hline
\end{array}
$$

Barter economy

\begin{tabular}{|c|c|c|c|}
\cline { 2 - 4 } \multicolumn{1}{c|}{} & $C_{1}$ & $C_{2}$ & $C_{3}$ \\
\hline$C_{1}$ & $\mathrm{x}$ & $\mathrm{x}$ & $\mathrm{x}$ \\
\hline$C_{2}$ & $\mathrm{x}$ & $\mathrm{x}$ & $\mathrm{o}$ \\
\hline$C_{3}$ & $\mathrm{x}$ & $\mathrm{o}$ & $\mathrm{x}$ \\
\hline
\end{tabular}

Pure money economy

\begin{tabular}{|c|c|c|c|c|}
\cline { 2 - 5 } \multicolumn{1}{c|}{} & $C_{1}$ & $C_{2}$ & $C_{3}$ & $C_{4}$ \\
\hline$C_{1}$ & $\mathrm{x}$ & $\mathrm{x}$ & $\mathrm{x}$ & $\mathrm{x}$ \\
\hline$C_{2}$ & $\mathrm{x}$ & $\mathrm{x}$ & $\mathrm{o}$ & $\mathrm{o}$ \\
\hline$C_{3}$ & $\mathrm{x}$ & $\mathrm{o}$ & $\mathrm{x}$ & $\mathrm{x}$ \\
\hline$C_{4}$ & $\mathrm{x}$ & $\mathrm{o}$ & $\mathrm{x}$ & $\mathrm{x}$ \\
\hline
\end{tabular}

Non-pure money economy

where "x" indicates $C_{i} E C_{j}$ and "o" indicates $C_{i} \not E C_{j}$. In the first case, all commodities are directly exchanged for one another. In the second, "one and only one commodity [i.e., $\mathrm{C}_{1}$ ] can be traded directly for any other commodity." And in the third, in addition to the exchange of money commodity for all commodities, some but not all non-money commodities are exchanged for each other.

Given these distinctions, Clower refers to Patinkin's aphorism, "money buys goods, but goods don't buy money," as nonsense. For Clower the statement should become: "Money buys goods and goods buy money; but goods do not buy goods" (Clower 1970: 207-208, emphasis in the original). This restriction, Clower contends, "is - or ought to be - the central theme of the theory of money economy" (Clower 1970: 208).

In sum, Clower contends that his aphorism "rules out the standard budget constraints of neo-Walrasian equilibrium analysis as an accurate description of planning alternatives open to transactors in a money economy" (Clower 1970: 208). He then suggests revising the budget constraint in such a way that it rules out as "feasible trades all pairwise combination of commodities" and would allow "money to be offered and demanded as one of the commodities entering into every trade" (Clower 1970: 208). This is done, Clower argues, by "dichotomizing the budget constraint into two branches," where, in the first case, all purchases are backed by money in hand, and, in the second case, all sales mean demand for money commodity:

$$
\sum_{i=1}^{n} p_{i} x_{i j}+M_{j}-M^{\prime} \quad j=0, x_{i j}=d_{i j}-s_{i j}, \text { where } x_{i j} \geq 0
$$

and

$$
\sum_{i=1}^{n} p_{i} x_{i j}+m_{j}=0, \quad \text { where } x_{i j}<0
$$

and $m_{j}$ is the "demand for transaction balances" (Clower 1970: 208-209). 
In its attempt to distinguish between money and non-money commodities, on the one hand, and barter and monetary economy, on the other, Clower's "A Reconsideration of the Microfoundation of Monetary Theory" is, indeed, a ground-breaking essay. By putting forward new concepts, such as the exchange relation, " $E$," and the matrix of exchange, the essay presents a great challenge not only to the "neoclassical" but also to the classical and pre-classical theories of exchange and money.

Yet, as will be shown shortly, Clower's innovative insights and concepts failed to change the direction of the development of monetary theory. A major reason for this failure is the usual resistance of economic theory to novel ideas. But the failure is also partly due to some of the shortcomings of the essay itself. Clower's work appears to be halfhearted in re-examining old concepts and proposing new ones. Moreover, the essay concentrates solely on the qualitative aspect of exchange, ignoring its quantitative aspect. Above all, however, if the main objective of the essay is to show the unrealistic nature of the neo-Walrasian theory and to propose a realistic substitute, the attempt does not succeed for two reasons. First, Clower's innovative concepts and insights are still confined to the "Patinkinesque" world of the community of self-interested individuals who receive manna from heaven. The result, therefore, appears to be no more than dichotomizing the marginalist budget constraint. Second, and more importantly, insofar as Clower's analysis of exchange has no direct reference to any real market, past or present, his matrices of exchange pose certain difficulties and ultimately do not make monetary theory significantly more realistic.

\section{The "matrix of exchange" and the real economy}

The unrealistic and problematic nature of Clower's matrices of exchange becomes apparent once we return to the medieval economy discussed in Chapter 3, an economy in which both barter and monetary exchange take place side by side. This would also allow us to develop a more realistic version of these matrices.

Consider the qualitative relation "barter(s) for," $B \subset U \times U$, defined in Chapter 2 on the set of classes of useful objects, $U$. The relation is not reflexive, since no good is exchanged for itself. But the relation is symmetric, since $U_{i} B U_{j}$ implies $U_{j} B U_{i}$, for all $i, j=1, \ldots, n$. As noted in Chapter 3 , it is difficult to say whether the relation is transitive in the medieval exchange. However, since the abacus manuscripts seem to suggest that anytime a useful object is offered for sale, it is simultaneously offered for direct exchange, one could assume, without any loss of generality, that the relation is transitive.

Let us maintain the simplicity of Clower's analysis by assuming that there are only three classes of useful objects that barter for one another, that is, $B=\left\{\left(U_{i}\right.\right.$, $U_{j}$ ), for all $i, j=1-3$, and $\left.i \neq j\right\}$. This assumption does no harm, since, as we saw in Chapter 3, the number of classes of objects entering exchange in the medieval era appears to have been quite limited anyway. Also, let us set aside Clower's notations and use, as in Chapter 2, "+" for the occurrence of direct exchange and "-" for no such occurrence. ${ }^{11}$ The quantitative "matrix of barter" 


\section{The matrix of exchange and beyond}

would appear as

\begin{tabular}{|c|c|c|c|c|}
\cline { 2 - 5 } \multicolumn{1}{c|}{$B$} & $U_{1}$ & $U_{2}$ & $U_{3}$ & $U_{4}$ \\
\hline$U_{1}$ & - & + & + & - \\
\hline$U_{2}$ & + & - & + & - \\
\hline$U_{3}$ & + & + & - & - \\
\hline$U_{4}$ & - & - & - & - \\
\hline
\end{tabular}

In this matrix of barter $U_{4}$ is assumed to be the class of money commodities and will not enter direct exchange. As mentioned in Chapter 3, in the medieval economy the class of money commodities consists of coins that have a specific use, they circulate other useful objects.

The qualitative relation "purchase(s)" or $P$, as we saw in earlier chapters, is very different from "barter(s) for." It consists of the binary relation $P \subset U_{\mathrm{m}} \times U$, where $U_{\mathrm{m}}$ is the class of money commodities. The relation $P$ is not reflexive, since no class of useful objects "purchases itself." It is not symmetric, since $U_{\mathrm{m}} P U_{i}$ does not imply $U_{i} P U_{\mathrm{m}}$. And since the relation is not symmetric, it is also not transitive.

Given the properties of $P$, the qualitative "matrix of purchase(s)" would appear as

\begin{tabular}{|c|c|c|c|c|}
\cline { 2 - 5 } \multicolumn{1}{c|}{$P$} & $U_{1}$ & $U_{2}$ & $U_{3}$ & $U_{4}$ \\
\hline$U_{1}$ & - & - & - & - \\
\hline$U_{2}$ & - & - & - & - \\
\hline$U_{3}$ & - & - & - & - \\
\hline$U_{4}$ & + & + & + & - \\
\hline
\end{tabular}

The qualitative relation "sell(s) for" was viewed as $S \subset U \times U_{\mathrm{m}}$. Similar to $P, S$ was neither reflexive nor symmetric nor transitive. Therefore, given $U=\left\{U_{i}\right.$, $i=1, \ldots, 4\}$, where $U_{4}$ is the class of money commodities, the qualitative "matrix of sell(s) for" consists of

\begin{tabular}{|c|c|c|c|c|}
\cline { 2 - 5 } \multicolumn{1}{c|}{$S$} & $U_{1}$ & $U_{2}$ & $U_{3}$ & $U_{4}$ \\
\hline$U_{1}$ & - & - & - & + \\
\hline$U_{2}$ & - & - & - & + \\
\hline$U_{3}$ & - & - & - & + \\
\hline$U_{4}$ & - & - & - & - \\
\hline
\end{tabular}

The qualitative monetary relation, $M \subset U \times U$, was viewed as the union of the two relations, "purchase(s)" and "sell(s) for," that is, $M=P \cup S . M$ is not reflexive. But since $U_{i} M U_{\mathrm{m}}$ implies that $U_{\mathrm{m}} M U_{i}$, it is symmetric. Moreover, since $U_{i} M U_{\mathrm{m}}, U_{\mathrm{m}} M U_{j}$ does not imply $U_{i} M U_{j}$, it is also not transitive. 
In terms of our previous example, the qualitative "matrix of monetary relation" consists of

\begin{tabular}{|c|c|c|c|c|}
\cline { 2 - 5 } \multicolumn{1}{c|}{$M$} & $U_{1}$ & $U_{2}$ & $U_{3}$ & $U_{4}$ \\
\hline$U_{1}$ & - & - & - & + \\
\hline$U_{2}$ & - & - & - & + \\
\hline$U_{3}$ & - & - & - & + \\
\hline$U_{4}$ & + & + & + & - \\
\hline
\end{tabular}

But as we saw in Chapter 3, the medieval exchange embraces both barter and monetary relation. Thus the qualitative relation "exchange(s) for," $E$, can be viewed as $E=B \cup M$. $E \subset U \times U$ is not reflexive. But since $U_{i} E U_{j}$ implies that $U_{j} E U_{i}$, it is symmetric. Also, if we assume that barter relation is transitive, $E$ is also transitive, that is, $U_{i} E U_{j}, U_{j} E U_{k}$ implies $U_{i} E U_{k}$.

The qualitative "matrix of exchange" in the medieval economy would therefore become

\begin{tabular}{|c|c|c|c|c|}
\cline { 2 - 5 } \multicolumn{1}{c|}{} & $U_{1}$ & $U_{2}$ & $U_{3}$ & $U_{4}$ \\
\hline$U_{1}$ & - & + & + & + \\
\hline$U_{2}$ & + & - & + & + \\
\hline$U_{3}$ & + & + & - & + \\
\hline$U_{4}$ & + & + & + & - \\
\hline
\end{tabular}

Before returning to Clower, let us also examine the concept of matrix of exchange from the quantitative perspective, a perspective that is completely missing in Clower's analysis. We can start by returning to the medieval economy and our quantitative relation of "barter(s) for," $\beta$, defined on the set of units of a class of useful objects, $U$. Let $b_{i j} u_{j}$ stand, as in Chapter 3 , for certain quantity of $U_{j}$ that barters for a unit of $U_{i}$. Once again, we can say $b_{i j} u_{j}$ is the $U_{j}$-barter-value of $u_{i}$. Now, if a class of useful objects $U_{i}$ does not barter for $U_{j}$, we can assume that it has no $U_{j}$-barter-value. In that case, we let $b_{i j}=0$.

As was argued earlier, $\beta$, similar to the qualitative relation $B$, is symmetric, but non-reflexive. Also, $\beta$ is transitive only if cheating does not occur, that is, the condition of simple barter prevails. In the case of complex or compound barter $\beta$ is intransitive, or barter is inconsistent, if arithmetical knowledge is imperfect. Thus, one might say that if the medieval economy is the model of exchange, $\beta$ is for the most part non-transitive.

Given these properties, and assuming that only three classes of useful objects barter for one another, the quantitative matrix of barter will consist of

$$
\beta=\left|\begin{array}{llll}
0 & b_{12} & b_{13} & 0 \\
b_{21} & 0 & b_{23} & 0 \\
b_{31} & b_{32} & 0 & 0 \\
0 & 0 & 0 & 0
\end{array}\right|
$$


We can say that $b_{i j}=1 / b_{j i}$, if and only if $U_{i} B U_{j}$, for all $i, j=1, \ldots, n$. Moreover, even if $U_{i} B U_{j}, \beta$ is consistent, that is, $b_{i k} \times b_{k j}=b_{i j}$, if and only if the condition of simple barter prevails.

What can be said of the matrices related to the quantitative monetary relation, $\mu$, and the quantitative relation of exchange, $\xi$ ? In Chapter 3 we saw that when

$$
u_{i} \lambda p_{i \mathrm{~m}} u_{\mathrm{m}}
$$

where $\lambda$ stands for the quantitative relation "sell(s) for," $p_{i \mathrm{~m}} u_{\mathrm{m}}$ constitutes the concept of price of a unit of $U_{i}$ in terms of money commodity. We can also think of $p_{\mathrm{m} i} u_{i}$ as certain units of $U_{i}$ that sell for a unit of $U_{\mathrm{m}}$. If money does not buy a useful object, we can assume that the object has no price and simply let $p_{i \mathrm{~m}}=0$. Similarly, if a useful object does not sell for money, then $p_{\mathrm{m} i}=0$. Assuming once again that $U_{4}$ is the class of money commodities, then the quantitative matrix of monetary relation, $\mu$, appears as

$$
\mu=\left|\begin{array}{llll}
0 & 0 & 0 & p_{14} \\
0 & 0 & 0 & p_{24} \\
0 & 0 & 0 & p_{34} \\
p_{41} & p_{42} & p_{43} & 0
\end{array}\right|
$$

Clearly, $p_{i \mathrm{~m}}=1 / p_{\mathrm{m} i}$ if and only if $U_{i} M U_{\mathrm{m}}$.

Finally, if $\xi$ is the quantitative counterpart of the relation $E$, then

$$
\xi=\left|\begin{array}{llll}
0 & b_{12} & b_{13} & p_{14} \\
b_{21} & 0 & b_{23} & p_{24} \\
b_{31} & b_{32} & 0 & p_{34} \\
p_{41} & p_{42} & p_{43} & 0
\end{array}\right|
$$

Clearly, $b_{i j}=1 / b_{j i}$ and $p_{i j}=1 / p_{j i}$, if and only if $U_{i} E U_{j}$, for all $i, j=1, \ldots, n$ and $i \neq j$. Moreover, in the case of simple barter that was mentioned in Chapter 3, where there is no cheating, $b_{i k} \times b_{k j}=p_{i j}$ and $p_{i k} \times p_{k j}=b_{i j}$. However, if there is cheating, as in the case of complex or compound barter, then $b_{i k} \times b_{k j} \neq p_{i j}$ and $p_{i k} \times p_{k j} \neq b_{i j}$.

We can now return to Clower's concepts and compare them with the aforementioned matrices of medieval exchange. As noted earlier, Clower defines on the set of "commodities" an "exchange relation." But Clower's "commodities" have no specific use associated with them; thus any good can become a "money commodity," something that is contrary to the facts of the real world, including the medieval world. Given the real world economy, Clower's definition of the exchange relation also lacks precision. In particular, unlike what was discussed earlier, there is no analysis of the properties of the direct and indirect exchange relations. This leads him to argue that the "exchange relation" is reflexive because "any commodity in trade can be held by the individual who possesses it." But it is not the issue of "holding" a commodity that determines the properties of 
exchange relation, but whether a class of useful objects "barter(s) for," "buy(s)," or "sell(s) for" another. Since a class of useful objects does none of these with respect to itself, the exchange relation actually is not reflexive.

Similarly, Clower contends that the exchange relation is symmetric. But in this contention he pays no attention to the fact that the relations "purchase(s)" and "sell(s) for," unlike "barter(s) for," are actually not symmetric. Not paying attention to the properties of "purchases" also leads Clower to say that "money buys goods and goods buy money, but goods do not buy goods." However, while it is true that money buys goods and goods do not buy goods, it is equally true that goods do not buy money either. Thus, ironically, Patinkin's aphorism, "money buys goods, but goods don't buy money," appears to be correct after all.

Clower's contention concerning the transitivity of the relation of exchange also does not appear to stand the test of reality. As we saw, he argues that the relation of exchange is transitive only if we have a pure "barter economy." But if the exchange relation is understood as the union of both barter and monetary relation, then, as in the case of the medieval economy, the relation could actually be transitive even if we have a "non-pure money economy," where both direct and indirect transactions take place.

The imprecision in defining such concepts as "commodity" and "exchange relation," ultimately results in Clower defining "money commodity" as "any element $C_{\mathrm{i}}$ of $C$ for which $C_{\mathrm{i}} E C_{\mathrm{j}}$ is true for all values $j$," as opposed to saying that "money commodity" is any class of useful objects $U_{i}$ of $U$ for which $U_{i} P U_{j}$ or $U_{j} S U_{i}$ for all values of $j$. This problem, combined with the long-held belief in the existence of a mythical pure "barter economy," then leads Clower to define such an economy as "one in which all commodities are money commodities." But since this society does not seem to have ever existed, it is basically pointless to define it. The same can be said about the matrix of a pure "barter economy."

Clower's notion of "money economy" also becomes problematic, since it is defined with reference to a mythical barter economy. If there is no such thing as a pure "barter economy," then it makes little sense to define a "money economy as a system involving at least one money commodity but a non-transitive exchange relation" or "a system in which not all commodities are money" (Clower 1970: 206-207). Given this analysis, we can see that a money economy may involve barter and, indeed, the latter cannot function without the former. The issue is to what degree one dominates the other. Here, Clower's distinction between "pure" and "non-pure money economy" becomes relevant. The medieval society is a "non-pure money economy" in the sense that both barter and monetary mechanisms coexist and are used simultaneously. But the medieval economy ultimately gave rise to an economy in which barter became a minor feature. The result could be called a "pure money economy."

\section{Post-Clower matrices of exchange}

As hinted earlier, much of the orthodox work that followed Clower's essay became concerned not with his novel concepts but with such things as the 


\section{The matrix of exchange and beyond}

appropriateness of his budget constraint. A case in point is the work of the "decentralized exchange" theorists, Ostroy and Starr.

These writers are also critical of the Walrasian tradition on the grounds that in this tradition, contrary to the facts of the real world, the transaction role of money is basically missing (Ostroy and Starr 1992, 1996). Ostroy, for example, argues that "it is not clear if what we know as Walrasian general equilibrium is compatible with a model in which money as a medium of exchange plays an essential role" (Ostroy 1992: 784). Similarly, with reference to the entire "Walras-Hicks-Patinkin tradition," he contends that the "Walrasian model of exchange is not much concerned with how commodities are exchanged" (Ostroy 1992: 785).

However, from the perspective of these writers Clower's constraint actually "narrows the set of permissible exchanges compared to its barter counterpart," and, moreover, the "constraint makes no sense in the Walrasian model of exchange," since it "does no good to append what is a trading constraint on a model which ignores trade" (Ostroy 1973: 597). Instead, in a series of essays, Ostroy and Starr try to incorporate in their exchange models Jevons's notion of the difficulties of barter to show that a monetary economy is "superior" to a barter economy and that money allows the decentralization of exchange (Starr 1972: 290; Ostroy and Starr 1974: 1111).

Starr, for example, criticizes the Walrasian general equilibrium for ignoring direct exchange between the "households" and sets out, using Jevons's concept of double coincidence of wants, to develop a "framework with general equilibrium viewpoint in which transactions and money enter essentially" (Starr 1972: 290). This is done through a series of definitions, theorems, and lemmas, which lead to the following conclusion. Double coincidence holds at equilibrium prices if exchange is (1) "price consistent," that is, goods "delivered to trader i from trader $\mathrm{j}$ are paid with goods of equal value sent from i to $\mathrm{j}$ "; (2) "monotone excess demand diminishing," that is, only "goods for which trader $i$ has an excess demand and of which trader $j$ has excess supply are sent from $j$ to $i$," a prescription that eliminates indirect or middleman trade; and (3) "excess demand fulfilling," that is, as trade "proceeds to equilibrium," all "excess demands are satisfied" (Starr 1972: 297). Starr goes on to conclude that a monetary economy satisfies all these three conditions. However, he argues, a barter economy will do the same only if there is double coincidence of wants. Thus monetary exchange is superior, according to Starr, that is, "any thing a barter economy can do a monetary economy can do better" (Starr 1972: 302).

Even though from the perspective of the neo-Walrasian monetary theory the decentralized exchange theories are significant, they do very little in bringing monetary theory closer to reality. Actually, by incorporating in their models of exchange different versions of Jevons's bartering Society Islanders and Mademoiselle Zélie, the decentralized models compound the problem of lack of realism. For example, one essay, which intends to show the usefulness of money in a decentralized exchange, starts with "an eminent scholar," who tells the authors of the essay about the "inconvenience of barter" when trying to exchange his textbook for lodging (Ostroy and Starr 1974: 1093). The moral of the story is 
that barter requires central coordination of trade. But as we have seen, in the medieval economy barter was carried out quite regularly and successfully without any central coordination.

Modeling monetary exchange based on old folktales is actually a major feature of the decentralized exchange literature. Ostroy and Starr seem to see no problem with the tradition of starting with folktales and formalizing them as theories. One of their major works, "The Transactions Role of Money," starts directly with some "parables of monetary exchange" or "simple stories of exchange relations," such as a "pair of Robinson Crusoes" (Ostroy and Starr 1996: 8). These stories are designed, according to the authors, as "introduction to the more formal models" of transaction scenarios (Ostroy and Starr 1996: 8).

Another feature of the decentralized exchange models, which makes these theories even more removed from reality, is the extreme infatuation with mathematical elegance and sophistication. The models often degenerate into an exercise in pure mathematics, a series of axioms, lemmas, and propositions that "prove," for example, that monetary exchange is superior to barter economy. This is as if the development of money is only a matter of pure mathematics and logic rather than a historical evolution.

In the final analysis, the decentralized exchange theories do very little for the development of a realistic monetary theory. Indeed, as far as such a development is concerned, these offshoots of Clower's critique of neo-Walrasianism seem to lead to another dead end in the evolution of monetary theories.

There is, however, an unorthodox line of work that attempts to carry Clower's monetary analysis forward. The work belongs to the mathematician Ulrich Krause. Krause's book, Money and Abstract Labor, which is mostly neglected by economists, is a unique and innovative analysis that tries to integrate certain insights of Clower with that of Marx. ${ }^{12}$ Given Marx's monetary theory, Krause becomes concerned with the missing dimension in Clower's analysis, that is, the quantitative rather than qualitative aspect of exchange. ${ }^{13}$ In particular, he focuses on the issue of "consistency" of exchange, that is, the condition under which the exchange of $b$ amount of commodity B for a unit of commodity A, $c$ amount of commodity $\mathrm{C}$ for a unit of commodity $\mathrm{B}$, and $a$ amount of $\mathrm{C}$ for a unit of commodity A imply that $a=b \cdot c$ (Krause 1982: 28-30). If exchange is consistent, then no augmentation of value in exchange is possible. But exchange, according to Krause, need not be consistent.

Since the so-called impossible equation of the type $\mathrm{A}=b \mathrm{~B}$, which is usually used by classical economists and Marx to depict exchange, implies consistency, Krause attempts to replace "=" with a "neutral sign," which denotes "the specific process of equating products in an act of exchange" (Krause 1982: 30, emphasis added). As such, he defines a relation of exchange $\tau$ on the set of "commodities," $C=\left\{x C_{i} \mid x>0,1 \leq i \leq n\right\}$, where $x$ stands for a certain quantity of commodity $C$. As a "direct exchange," $\tau$ is conceived to be

1 "complete" in the sense that for any two commodities $C_{i}$ and $C_{j}$, there are positive $x$ and $y$ such that $x C_{i} \tau y C_{j}$. 


\section{The matrix of exchange and beyond}

2 "one-one," that is, if $x C_{i} \tau 1 C_{j}$ and $y C_{j} \tau 1 C_{j}$, then $x=y$,

3 "homogenous," that is, if $x C_{i} \tau y C_{j}$, then $(a x) C_{i} \tau(a y) C_{j}$, for $a>0$, and

4 "reflexive," that is, $1 C_{i} \tau 1 C_{i}$, for every $i$ (Krause 1982: 35 ).

The last property, according to Krause, holds by "convention" (Krause 1982: 46). That is, "since no commodity $C_{\mathrm{i}}$ exchanges for itself," the exchange value of $C_{i}$ relative to itself, or $e_{i i}$, "is not defined," but we can "stipulate that $e_{i i}=1$ for every $i$ " (Krause 1982: 31). This assumption of reflexivity of exchange relation is similar to that of Clower, except for the fact that Krause points out that in reality such an assumption cannot hold.

Furthermore, as a direct exchange relation, $\tau$ is viewed by Krause to be "symmetric," that is, $x C_{i} \tau y C_{j}$ implies $y C_{j} \tau x C_{i}$, but not necessarily "transitive," that is, $x C_{i} \tau y C_{j}$ and $y C_{j} \tau z C_{k}$ do not imply $x C_{j} \tau z C_{k}$, since exchange, if accidental, need not be consistent (Krause 1982: 36). In this case one can conceptualize an $n \times n$ "exchange matrix" $E=\left(e_{i j}\right), 1 \leq i, j \leq n$, where $e_{i j}$ is the "exchange value of commodity $C_{i}$ relative to $C_{j}$ " (Krause 1982: 31 and 33). Given the symmetry of direct exchange, $e_{i j}=1 / e_{j i}$ (Krause 1982: 31 ).

But Krause argues that "in a society based on exchange, direct exchange is not an adequate principle of social intercourse, because the required double coincidence of wants occurs so rarely; indirect exchange is therefore a necessity" (Krause 1982: 38, emphasis added). "Indirect exchange" is seen by Krause as a "series of direct acts of exchange" (Krause 1982: 35). For example, the indirect exchange $x C_{i} \tau y C_{j}$ might consist of two separate direct exchanges: $x C_{j} \tau z C_{k}$ and $z C_{k} \tau y C_{j}$. As an indirect exchange, $\tau$ has the properties 1-4 mentioned earlier. But not only $\tau$ might not be transitive, but it might also not be symmetric, according to Krause. For example, if the owner of $C_{j}$ has no use for $C_{i}$, then $e_{j i}=0$.

According to Krause, a relation such as $\tau$ that satisfies the above properties 1-4 and is also transitive defines a "barter economy" (Krause 1982: 51-52) ${ }^{14}$ But what is a monetary economy? The answer is found in Krause's concepts of the "money commodity," $C_{k}$, and "money relation," $\tau_{k}$, which are constructed as follows (Krause 1982: 46-47).

Define a relation $\tau_{k}$ "induced by the commodity $C_{k}: x C_{i} \tau_{\mathrm{k}} y C_{j}$ if and only if there exits a $v>0$ such that $x C_{i} \tau v C_{k}$ and $y C_{i} \tau v C_{k}^{\prime \prime}$ (Krause 1982: 46). The commodity $C_{k}$ is called a "money-commodity (in relation to $\tau$ ) if it is both an equivalent and a means of circulation," and, if this is the case, " $\tau_{\mathrm{k}}$ is money relation" (Krause 1982: 46, emphasis in the original). By an "equivalent" Krause means a commodity that is used to express the worth of the other commodities "completely and consistently" (Krause 1982: 46). By a "means of circulation" he means a commodity $C_{k}$ (in relation to $\tau$ ) if it is the case that " $x C_{i} \tau_{\mathrm{k}} y C_{j}$ if and only if there exits a $u>0$ such that $x C_{i} \tau u C_{k}$ and $u C_{k} \tau y C_{j}$," or any commodity $C_{k}$, in relation to $\tau$, such that $\tau$ is symmetric (Krause 1982: 46). Another way of conceptualizing this is that $C_{k}$ is money commodity "if and only if direct exchange is possible between $C_{k}$ and every other commodity," a definition that resembles Clower's concept of "money commodity" (Krause 1982: 48, 166). In fact, similar to Clower, Krause argues that a "barter economy" is "characterized 
by the fact that all commodities are money commodities" or that " $\tau$ " and " $\tau_{k}$ " are identical if " $\tau$ " is transitive (Krause 1982: 52). On the other hand, an "economy is designated a money economy if (at least) one commodity plays a special role as a money commodity (relative to $\tau$ ), but not all commodities are money commodities" (Krause 1982: 52-53). Similar to Clower, Krause argues, a "pure money economy is a money economy with exactly one money commodity" (Krause 1982: 53).

Krause's quantitative analysis of exchange is quite unique and innovative. It also points out some of the shortcomings of Clower's matrix of exchange analysis. Yet, much of Krause's work suffers from the flaws of earlier writers and ultimately cannot stand up to reality. For example, to the extent that Krause's analysis is concerned with the same mythical "barter economy" it is also unrealistic, and what was said about Clower's analysis holds equally true for that of Krause.

Indeed, much of Krause's work seems to be an exercise in pure mathematics with no relevance to reality. This is, for example, true of the attempt to distinguish between the general notions of "direct exchange," in the sense of accidental trade, and "indirect exchange" in the sense of a "series of direct acts of exchange." The distinction, as mentioned earlier, is prompted by Krause's contention that "direct exchange is not an adequate principle of social intercourse, because the required double coincidence of wants occurs so rarely; indirect exchange is therefore a necessity." Yet none of these contentions have any support in reality. The double coincidence of wants, as mentioned earlier, is not a problem in the medieval exchange, and direct exchange, combined with monetary exchange, is indeed an adequate means of social intercourse. We also do not know of any non-monetary society in which indirect exchange, in the sense of a series of direct exchanges, existed. Thus, much of Krause's analysis appears to be irrelevant to a realistic theory of exchange. The only aspect of this analysis that has some bearing in reality is that associated with direct exchange in the sense of barter relation and indirect exchange in the sense of monetary relation, which are dealt with below.

Krause, of course, recognizes that Clower's analysis has "no mention of quantities of commodities" (Krause 1982: 166). But if Clower leaves out the quantitative aspect of exchange, Krause himself leaves out the qualitative aspect altogether, apparently assuming that the two are identical. But as we have seen, this assumption is not true. Furthermore, while Krause correctly sets aside "="as the relation of exchange, it is not clear what is the meaning of the "neutral" sign " $\tau$ " that replaces it. If " $\tau$ " stands for the quantitative relation of "barters for," then it cannot possibly stand for "the specific process of equating products in an act of exchange," especially after one has dismissed the concept of equality of exchange.

The properties of Krause's " $\tau$ " are also not without problems. Some properties, such as being a "one to one" relation, appear to have no significance beyond the realm of pure mathematics. Others do not seem to stand the test of reality. If " $\tau$," for example, is the quantitative relation of barter, then contrary to Krause's contention it cannot, even by convention, be a reflexive relation, since no quantities of a class of useful objects will ever barter for itself. Therefore, it is 


\section{The matrix of exchange and beyond}

misleading to assume that " $e_{i i}=1$ " in the "exchange matrix," as Krause does. Furthermore, the relation of barter cannot be "complete" since not all useful objects barter for one another in a real economy. ${ }^{15}$ Also, such a relation need not be transitive, since barter may involve deceit. ${ }^{16}$ It is this deceitfulness, and not Krause's concept of accidental exchange, that explains why direct exchange may be inconsistent or why the "impossible equation" is indeed impossible. Moreover, the assumption of homogeneity of the barter relation appears to be farfetched. Setting aside the fact that some items of medieval barter, such as hats, could never have been traded in fractions, it is hard to see what useful role such an assumption plays in modeling an exchange economy where rudimentary knowledge of arithmetic is lacking.

Krause's "money relation" is also problematic. The relation is defined relative to money commodity. The latter, as was pointed out, is perceived to be both an "equivalent" and a "means of circulation." However, given the medieval separation of these two functions, it is unnecessary to assume that "money commodity" must fulfill both functions in order to define the monetary relation. Furthermore, as it was argued earlier, as a means of circulation, the commodity money is unique in the sense that it "purchases" other commodities or other commodities "sell for" it. Yet, Krause does not seem to notice this unique property of money, and, therefore, in his work any "commodity" can play the role of the means of exchange. Similarly, Krause's "money relation," or " $\tau_{k}$ " does not involve any concept of buying or selling. Indeed, since " $\tau$ " and " $\tau_{k}$ " are assumed to be identical if " $\tau$ " is transitive, and since it is not clear what the meaning of " $\tau$ " is in the first place, it is even less clear what " $\tau_{k}$ " is all about. The results of these ambiguities are the usual definitions of "barter economy," that is, an economy in which "all commodities are money commodities," and the "money economy," that is, an economy in which "not all commodities are money-commodities" (Krause 1982: 52-53).

In sum, Krause's analysis of exchange is more detailed than that of Clower. It also adds a quantitative dimension to Clower's work. Yet, similar to the decentralized exchange models, this analysis does very little to narrow the gap between theory and reality. Actually, in some ways the work increases the distance between the two by combining Marx's enigmatic analysis of value form with Jevons's notion of difficulties of barter. The problem is further exacerbated by Krause's extreme concern with mathematical elegance and sophistication, a concern that seems to have beleaguered most models of exchange from Walras to the decentralized school.

\section{Conclusion}

The razzle-dazzle of the Walrasian general equilibrium theory seems to have prevented economists from probing deeply into Walras's problematic "equation of exchange" and exploring the confusions that surround the theory from the very beginning. But the very fact that exchange takes place in this theory without the use of money - at least until "capital" comes into play — did not escape the attention of twentieth-century economic thinkers. Among the historians of 
economic thought there might still be a lingering controversy over whether the theory is realistic in the sense of being able to incorporate money as a means of exchange, but the controversy ended a long time ago among monetary theorists. As Bridel quotes numerous "brilliant modern theorists," including Clower, the consensus is that in the Walrasian general equilibrium theory money does not play an essential role (Bridel 1997: xiii).

Clower, of course, played a key role in demolishing the neo-Walrasian monetary model, best exemplified by a "Patinkinesque community of self-interested individuals each of whom receives "like manna from heaven" " a certain quantity of goods (Clower 1977: 207). In the process, he put forward a number of groundbreaking concepts that challenged the notion of exchange as a relation of equality. This was done by posing some basic questions: what are the properties of the barter relation as opposed to monetary relation and how is the money commodity different from non-money commodities? In answering these questions, Clower introduced a very valuable concept: the matrix of exchange. Such a concept, as has been shown in this chapter, could be quite useful in dissecting the medieval exchange and distinguishing between the qualitative and the quantitative aspects of barter and monetary relations. Indeed, such a concept could be used to ask a fundamental question: why did an economy in which barter played a prominent role and was actually preferred to monetary exchange eventually give rise to a monetary economy? In other words, how did what Clower calls "pure money economy"which, as opposed to the "pure barter economy," is not fictitious - come into being?

Answering such a question is beyond the scope of this book. But by looking back at our analysis we can say that as soon as a number of classes of useful objects, previously immune to exchange, entered the market, the relation of exchange changed in the direction of virtual disappearance of barter and the domination of monetary relation. That is, in terms of the matrix of exchange, if new items, such as $U_{5}$, enter the matrix of exchange, then the evolutionary direction of the qualitative matrix of exchange will change from

\begin{tabular}{|c|c|c|c|c|}
\cline { 2 - 5 } \multicolumn{1}{l|}{$E$} & $U_{1}$ & $U_{2}$ & $U_{3}$ & $U_{4}$ \\
\hline$U_{1}$ & - & + & + & + \\
\hline$U_{2}$ & + & - & + & + \\
\hline$U_{3}$ & + & + & - & + \\
\hline$U_{4}$ & + & + & + & - \\
\hline
\end{tabular}

to

\begin{tabular}{|c|c|c|c|c|c|}
\cline { 2 - 6 } \multicolumn{1}{c|}{$M$} & $U_{1}$ & $U_{2}$ & $U_{3}$ & $U_{4}$ & $U_{5}$ \\
\hline$U_{1}$ & - & - & - & + & - \\
\hline$U_{2}$ & - & - & - & + & - \\
\hline$U_{3}$ & - & - & - & + & - \\
\hline$U_{4}$ & + & + & + & - & + \\
\hline$U_{5}$ & - & - & - & + & - \\
\hline
\end{tabular}




\section{The matrix of exchange and beyond}

In other words, it seems that certain quantitative changes would precede a qualitative change in the matrix of exchange.

But what was the reason for this evolutionary trend? What role did the formation of productive capital, as opposed to merchant's capital, play in this process? Did the growth of the market economy actually bring about the proverbial difficulties of barter, turning a mixed barter and monetary economy into a mostly "pure money economy"? These are the kinds of questions that monetary theory should have raised following Clower's concept of matrix of exchange.

Unfortunately, this was not the direction that the development of monetary theory took. As was stated earlier, the old ideas and theories overpowered the novel aspects of Clower's contribution. Instead of pursuing further the matrix of exchange and its relevance to analyzing money and exchange in a real economy, the major issue among the orthodox economists became the appropriateness of the budget constraint. The result was attempts to include money in the general equilibrium theory or work toward a decentralized model of exchange. In the latter case, the "barbarians," "sons of Adam," "savage nations," or Society Islanders and Mademoiselle Zélie made a come back as the "eminent scholar" running into the difficulties of barter in exchanging his textbook for lodging.

On the heterodox side, the response to Clower's "matrix of exchange" and the analysis of barter and monetary relations became a combination of Marx's value form and Jevons's alleged difficulties of barter. Even though the ideas put forward were quite novel and required further scrutiny, they received almost no attention, mostly because of the ideological resistance to anything associated with Marx.

In either direction, what started as rethinking of the old ideas concerning exchange soon became a futile exercise in displaying mathematical prowess rather than developing a theory of exchange whose point of departure is a real economy and not folktales. The result was a hodgepodge of mostly old ideas appearing in new mathematical forms.

Almost a decade after his essay on the matrix of exchange, Clower himself drew this bleak picture of the state of affairs:

Modern discussions of monetary theory have fairly well demolished its traditional foundation without so far putting anything definite in their place. To be sure, some progress towards reconstruction has been made. In particular, contributions by John R. Hicks (1967), F.H. Hahn (1971), Karl Brunner and Allan Meltzer, Jack Hirschleifer and a host of other writers have shown that set-up costs of engaging in trade must play a central role in any acceptable formal theory of monetary exchange. Other contributions by Clower (1969), Morris Perlman, Joel Fried, Joseph Ostroy and R.M. Starr, and Peter Howitt have suggested that individual holdings of commodity inventories must also be taken into accounts. Finally, many writers have argued that certain physical characteristics of commodities are vital. Thus some of the ingredients for a reconstruction of the foundations are not seriously in doubt. What remains to be settled is the manner in which these and possibly other ingredients might best be combined. 
This problem is not likely to be resolved in the near future; at best we might hope for an early professional consensus about the way in which the problem should be approached.

(Clower 1977: 206)

Unfortunately, decades later not much has happened in resolving the problem, and nothing much should be expected to happen as long as monetary theories have very little reference to reality. 


\section{Conclusion}

In his Monetary Theory before Adam Smith Monroe writes with reference to Aristotle:

In his crabbed and often obscure paragraphs are developed many important ideas on money-important not only because of the great insight which they reveal, but because of the profound influence which they had on modern monetary theory through his devoted disciples, the Schoolmen.

(Monroe 1966: 3)

This book has provided ample evidence for Monroe's claim, as well as similar contentions made by other historians of economic thought, concerning the profound influence of Aristotle on monetary thinking. The evidence provided, however, does not support the view that Aristotle showed "great insight" on monetary matters. On the contrary, I hope I have shown that Aristotle's teachings on money and exchange, similar to his teachings on the natural world, were actually an impediment to the growth of knowledge. The conjectures that he put forward concerning the origin of money were not insightful at all. The first community or family, its lack of exchange, its division into parts, the subsequent barter of goods, the difficulties associated with carrying the necessities of life, the agreement among individuals to employ useful objects, the stamping of these objects, etc. were all a beautifully constructed history of the origin of money, but this was no real history, it was a fantasy. Once this fabricated history is contrasted with the real history, such as that of the medieval economy, it completely falls apart.

When it comes to the concept of exchange, Aristotle shows no insight either. $\mathrm{He}$ is not trying to figure out the mechanism of exchange in the real world. He does not use the markets of his own time as the point of departure for observation and theorizing. Instead, he refers to a fictitious market in which exchange takes on the form of an equation, the relation of exchange is reduced to the relation of equality and a common substance, such as money, brings about that equality. None of these help us in understanding money and exchange. But while in a mostly non-monetized economy such storytelling and abstract theorizing were of little consequence, they had a profoundly negative impact when it came to understanding a monetized economy. 
In a world dominated by capital, economic thinkers had to grapple with many fundamental questions concerning monetary matters. How should one deal with money in a comprehensive discourse on the capitalist economy? Where should money enter the analysis? What should be the point of departure of monetary theory itself? How is one to distinguish between barter and monetary exchange? What is the distinction between money commodity and non-money commodities? Any meaningful and generalized treatise on the working of the capitalist economy must inevitably address these questions, and in many ways the works of the classical political economists attempted to do that, either consciously or unconsciously. Yet, once again, the real economy did not serve as the point of departure for abstraction and model building.

Adam Smith, as we saw, answered many of the aforementioned questions by resorting to some fictitious rude state of the society, which he modeled after the prevailing images of the North American Indians. In such a society, he conceptualized, the division of labor begins and the savages barter regularly. But the bartering savages, the story goes, will soon run into difficulties of exchanging goods for one another and subsequently designate some good or goods as money.

The aforementioned narrative became the starting point for Smith's theory of direct and indirect exchange. In this theory, once again, the savage plays a crucial role. One beaver, Smith reasons, should naturally exchange for, or be worth, two deer in the rude state because it is only natural that the produce of two days' labor should be worth double the produce of one day's labor. Or, alternatively, Smith contends, the beaver and deer should exchange according to how much labor one can command for them.

Smith's narrative concerning the origin of money and the nature of exchange is essentially nothing more than Aristotle's. The North American Indians replace the first community or the barbarians. Beds and houses are replaced by deer and beaver. "Is equal" is replaced by "exchanges for" or "is worth." The essential difference between the two narratives is in the solution offered to the equation of exchange. While Aristotle does not seem to be able to come up with anything but money as the substance that solves the equation, Smith postulates labor substance as the solution in the first stage of history and money substance in the last stage. In all this theorizing, Smith's method of analysis is in essence the same as that of Aristotle's: a rational reconstruction of money and exchange with no reference to any actual market. This was the best that classical economists could offer. But the critics of political economy did not do much better either, and this includes Karl Marx.

Marx's 1857 Introduction, a methodological commentary on the classical political economy, begins by saying:

The object before us, to begin with, material production.

Individuals producing in society-hence socially determined individual production - is, of course, the point of departure. The individual and isolated hunter and fisherman, with whom Smith and Ricardo begin, belongs among the unimaginative conceits of the eighteenth-century Robinsonades.

(Marx 1973: 83) 


\section{Conclusion}

Marx's condemnation of the classical economists' analytical entry point, his subsequent search for a proper point of departure, and his numerous plans drawn up for a comprehensive treatise on the capitalist economy would make one to expect that in dealing with money and exchange he would avoid the pitfalls of the classicals and ground his analysis thoroughly in some real economy. This is particularly expected since some sections of Marx's Capital, such as the transformation of money into capital and the takeover of the merchant's capital by productive capital, are reflective of the history. Yet this does not appear to be the case and in the initial phase of dealing with money and exchange Marx ultimately follows in the footsteps of Aristotle and the classical political economists.

Marx asserts that exchange begins on the margins of the primitive communities. But the only support that he provides for this assertion is a reference to some nebulous ancient Indian commune or Inca state. Worse yet, he believes that his concept of the origin of exchange is similar to that of Aristotle's. This belief in some primordial bartering communities plays a crucial role in starting the third section of the first chapter of Volume 1 of Capital. The concept of the simple, isolated, or accidental form of value appears to be based on nothing more than the image of the bartering savage that one encounters in eighteenth-century Robinsonades. Indeed, the entire transition from this early form of value to the money form seems to follow along the old and mythical narrative concerning the development of money.

Even when it comes to the point of departure of the first section of the first chapter of Volume 1 of Capital, the contention that Marx envisions some fictitious simple commodity producing economy cannot be easily dismissed. True, he does begin Capital with the commodity, the simplest social form of the product of labor in contemporary society, but he asserts that this is a simple commodity and not the same commodity that emerges from the capitalist production process. This simple commodity, Marx argues, could exist in isolation in pre-capitalist economies as well. Such an argument is in perfect accord with the belief, attributed by Marx to Aristotle, that exchange begins on the boundaries of primitive communities and then spreads inward.

The strong influence of Aristotle on Marx was not, of course, confined to how exchange and money emerged. Aristotle's equation of exchange, which Marx admires, became the backbone of Marx's analysis of exchange. Marx perfected the Aristotelian analysis by replacing the relation of exchange with the mathematical relation of equality and then reasoned why the equation of exchange, as so stated, is meaningless unless one assumes that it is merely the form of appearance of another type of equation, one that equates quantities of congealed abstract labor. Thus, in the end, when it came to money and exchange, not even Marx could completely escape the stranglehold of Aristotle's historiography. Nor could he fully escape the shackle of the Aristotelian method of abstract analysis.

The classicals and Marx, however, were not the last of the monetary writers who were under the spell of Aristotle's historiography and method of analysis. Modern monetary theorists suffer the same fate, even though they might not be fully aware of it. Besides some Whiggish historians who see the roots of the 
marginal utility analysis in many ancient economic writings, particularly those of Aristotle, not too many modern economists seem to know or care about what Aristotle had to say on monetary matters. Yet, when in their writings they quote Jevons on the theory of the difficulties of barter they are paying homage to Aristotle, since Jevons's theory is essentially a systematic version of the ancient folktale. The major difference between the two versions is that in the latter the exchange between the civilized Mademoiselle Zélie and the savages of the Society Island replaces that between the divided first community or the barbarians.

What, however, distinguishes the classicals and Marx from the modern "neoclassical" economists is that while in the former there was a clear link between the theory of exchange and what was perceived to be the history of exchange, in the latter there is no such link. For the most part, the marginalist theorists do not know how to incorporate the Aristotelian-Smithian-Jevonsian story of the origin of money in their theories. This is a problem that goes back to their pioneers.

Both Jevons and Walras continued to see exchange as an equation. But given their unique concept of science, they transformed the old Aristotelian equation of exchange into one involving the ratio of the final degrees of utility or raretés. In this transformation neither Jevons nor Walras could reconcile the new "scientific" theory of exchange with the notion of the difficulties of barter. After all, a theory of exchange mimicking the theory of the lever or the physico-mathematical sciences leaves no room for history, even a fictitious one. It also leaves no room for the notion of the difficulties of barter and emergence of money, since the entire theory is based on barter after all, and money, which has no utility of its own, is actually a nuisance. Thus the marginalist theory of exchange, particularly the flamboyant Walrasian general equilibrium version, remains essentially moneyless. This fact, of course, did not escape the attention of the best of the marginalist theorists, particularly Hicks.

In his criticism of the Walrasian general equilibrium theory, Hicks, indeed, made significant contributions to the monetary theory. He reasoned that any money that cannot be spent in the shops is not money and that any exchange theory which does not include money in an essential way cannot be considered realistic. He further reasoned that since money evolves, any theory of it must reflect its evolution. Given this, he argued that monetary theory is, or should be, realistic in the sense of being less abstract than other economic theories.

Whatever the merit of Hicks's reasoning, his line of argument suggested that the starting point of monetary theory should be grounded in some real economy. Thus he hinted that the great fairs of Europe in the Middle Ages could be used to visualize the distinction between barter and monetary exchange and money and non-money commodities. Unfortunately, this insightful suggestion was followed neither by Hicks himself nor by any other economist. The result was continued neo-Walrasian efforts to foist money on an essentially moneyless theory of exchange and, subsequently, Clower's seminal critique of these efforts in his "A Reconsideration of the Microfoundations of Monetary Theory."

What made Clower's criticism unique was not his attempt to show that the neo-Walrasian model was unreal and that dichotomizing the budget constraint in 


\section{Conclusion}

the model would make it real, but the attempt to conceptualize exchange relation in a unique fashion by putting forward the concept of the matrix of exchange. This appears to be the first time that exchange is viewed not as an equation but as a relation whose properties must be analyzed concretely. This is also the first time that a serious formal distinction between the relation of barter and monetary relation is being contemplated and the unique role of money commodity is being analyzed. Yet, given that the analysis was still taking place within the bounds of thinkable thought, Clower's brief exploration into the properties of exchange relation got lost in the marginalist discussions.

More importantly, Clower's analysis, similar to that of many generations of monetary thinkers who preceded him, showed no sign of direct reference to any economy, past or present. As a result, an analysis that was meant to increase the realistic content of monetary theory, by asking questions about the distinction between money and other commodities and between barter and monetary relations, still remained at a high level of abstraction. Had the questions been posed in the context of a real economy, such as Hicks's envisioned market fairs in the medieval era, the answers could have been very different and monetary theory might have become more realistic.

The medieval economy of the thirteenth and fourteenth centuries, indeed, provides a unique opportunity to test persistent theories concerning barter and monetary exchange. As opposed to the fictitious economies put forward by many generations of monetary thinkers to conceptualize exchange, this economy is real. There is also plenty of information about it. The best sources of information are not the writings of the scholastics - who ignored the reality of the market practices - but the "abacus manuscripts" written by the medieval and renaissance merchants. These manuscripts offer a window to an earlier time when the economy was in the process of being monetized. In such an economy barter and monetary transactions exist side by side. This indicates that barter not only is not difficult but also that, since it could result in making more profit in exchange, it is often preferred to monetary transactions. If anthropological studies of modern communities engaged in barter, or studies of monetary historians, do not put an end to the myth of the difficulties of barter as the origin of money, the reality of the medieval exchange should draw it to a close.

Furthermore, the economy of the age of commercial revolution provides a unique opportunity to answer certain lingering questions concerning the nature of exchange and the exact properties of barter and monetary relations. It dismisses the concept of exchange as an equation. It makes it clear that neither the relation of barter nor the monetary relation should be treated as a mathematical relation of equality. It tells us what barters for what and what buys what. It gives us a better understanding of the aphorism "money buys goods, and goods do not buy money." It advises us that the natural place to study the workings of monetary forces is not in the markets for goods alone, but in the markets where money matters from the very beginning. It describes the conditions under which exchange could actually be consistent. It informs us of the significant role that knowledge, particularly knowledge of arithmetic, plays in market practices. 
The monetized medieval economy is that primordial, and yet real economy, which could serve as the point of departure for visualizing the workings of a market. It could also serve as the starting point for the reconstruction of monetary theory along an evolutionary path. If such an economy became the basis for overthrowing the Aristotelian image of nature, it should also serve as the foundation for dispensing with the Aristotelian image of money and exchange, an image which for so long has stifled monetary thinking. 


\section{Notes}

\section{Introduction}

1 See, for example, Davidson $(1972,1978)$.

2 This argument is repeated elsewhere. For example, in his essay " 'Revolutions' in Economics," Hicks discusses Keynes and Keynesianism and contends that where the General Theory "belongs is in monetary economics; and since monetary statistics have long been abundant (much more abundant than most other statistics until the present century) monetary economics has always been topical; it has always had a close relation to the circumstances of the time in which it has been written; it has had to change as they have changed" (Hicks 1976: 216).

3 There are a number of fine books that deal with the history of monetary theory in general, some of which will be encountered in this book. See, for example, Monroe $(1965,1966)$.

4 On the ambiguity of the expressions "exists" or "is real," see Mäki (1998a: 405-406).

5 On the loose way that economists use the word "theory," see Nagel (1963: 211-212). On the ambiguous use of the terms "real" and "realism," see Mäki $(1989,1998 b)$. Mäki suggests that economists should talk about "the realisticness or unrealisticness of theories and assumptions rather than their 'realism' " and "should keep 'realism' and 'realisticness' separate" (Mäki 1989: 179, 1998b: 409).

6 Mäki (1998b) tries to go beyond this classification by suggesting further divisions within the categories.

\section{The first community and the equation of exchange}

1 There are, of course, some exceptions. Monroe, for example, mentions in passing the "semi-mythological accounts of inventors of money, which have no scientific value" (Monroe 1966: 6). However, Monroe deals with this issue as one of many aspects of monetary theory prior to Adam Smith.

2 Meikle writes with reference Soudek's type of interpretation that "the wonderful mathematical stories that have been woven around the proportion are fantasies" (Meikle 1995: 144).

3 On Marx's "equation of exchange" and derivation of value, see Fayazmanesh (1994).

4 For a discussion of some of these writings, particularly that of Gordon (1964), see Miekle (1995: 133).

5 As noted earlier, this absence of statistics is admitted by more recent modernists such as Cohen (1992: 26) as well who believes that he can overcome the problem by a close reading of some texts. Unfortunately, much of Cohen's argument is unconvincing, peppered with many "might have been" scenarios. For example, he writes that settlement of "overseas commercial obligations by transporting monies from Athens might have significantly reduced the supply of silver circulating in Attica," or that commissions 
"were negotiable, often seemingly exorbitant; yet competition might be substantial" (Cohen 1992: 15, 19, emphasis added).

6 The quotation comes from Berry (1967: 39).

7 The graphic presentation follows John Casti's (1989: 411) depiction of binary systems.

8 This issue, explained in Chapter 7, is usually referred to as the "consistency of exchange," that is, the exchange of $b$ amount of commodity B for a unit of commodity A, $c$ amount of commodity $\mathrm{C}$ for a unit of commodity B, and $a$ amount of $\mathrm{C}$ for a unit of commodity A implies that $a=b c$. See Krause (1982: 28-30).

9 In a more recent translation, the passage reads "the kind of men who set aside a space in the middle of their town and where they can meet and make false promises to one another" (Herodotus 1998: 68).

10 As explained in Chapter 7, Clower responded to this aphorism by saying "money buys goods and goods buy money, but goods do not buy goods" (Clower 1970: 208).

11 Marx, as we shall see, would argue that five beds and a house cannot be equal to each other as physical objects and, therefore, they must be equal as something else. That something, Marx contends, is congealed abstract labor (see Fayazmanesh 1994).

12 In his highly interesting study of the scholastics, which we look at in Chapter 3, Joel Kaye argues that what distinguishes Aristotle's concept of equality from that of fourteenth-century writers is that in "Aristotle's Ethics it was the judge who was given the primary task of 'reducing' things to equality," whereas in the scholastics it is "money" that does the job (Kaye 1998: 133). But as the above quoted passage shows, Aristotle himself clearly argues that money establishes equality in exchanges. The scholastics, it seems, had to sort out among Aristotle's many confusing and contradictory arguments and choose one over the other.

\section{The sons of Adam, justice in exchange, and} the medieval economy

1 Deuteronomy, 32:8.

2 As Wood (2002: 5) points out, exactly "what triggered this is difficult to say" and is a subject of controversy.

3 Aquinas tries to reduce the confusion by adding that for Aristotle "measuring things by need" is "according to nature" and measuring them by "currency" is "according to human convention" (Aquinas 1964: 426). On this issue of "natural" and "artificial measure," see Kaye (1998: 66).

4 It is interesting to note that Aquinas here appears to be trying to quantify work by referring to its "number."

5 Quoted in Kaye (1998: 74).

6 The term "value" appears only once in Book V of Ethica Nicomachea when Aristotle speaks of "money value of five beds" (Aristotle 1949, Book V, Part V: 1133'25). "Money value" seems to be used in the sense of price.

7 A recent example is Wood (2002), particularly chapter 6. For a textbook analysis "which follows very closely the excellent study of Odd Langholm," see Ekelund and Hebert (1997: 25).

8 The scholastics themselves were quite unclear when it came to the distinction between "value" and "price." For example, Aquinas writes that "the balance of justice is upset if either the price exceeds the value of the goods in question or the thing exceeds the price" (Aquinas 1975: 215). But Aquinas does not explain what value means as opposed to price. Similarly, Oresme speaks of "value and price" without any attempt to define the two and differentiate between them (Oresme1956: 15). The problem, of course, would persist in the writings of the early classical economists as well.

9 An exception is Poitras (2000). See also my own 2001 essay, "Barter, Money and Commercial Arithmetic," Journal of the History of Economic Thought. The next three sections draw largely from this earlier work. 


\section{Notes}

10 On the possible date of publication and structure of Al-Khwarizmi's Algebra, see G. J. Toomer (1973). For the contribution of medieval Islamic civilization to the development of mathematics, see J. L. Berggren (1986).

11 For a discussion of the structure of Fibonacci's Liber Abaci, see Kurt Vogel (1971).

12 For the importance of the "rule of three" in renaissance trade, see Judy Klein (1997: 25-34). On the use of this rule in art, as well as commerce, see Michael Baxandall (1988: 94-102).

13 For a discussion of problem situations in abacus manuscripts, see Van Egmond (1976: 164-228).

14 Van Egmond (1976: 12-18) points out that the abaci manuscripts may also deal with more esoteric and theoretical subjects, such as geometry and algebra, insofar as the immediate usefulness of these subjects for solving everyday problems is concerned. The term abaco in this context should not be confused with the medieval reckoning board. The expression stands for a tradition in mathematical computation that is borrowed by the Italian merchants and scholars from the works of the Moslem mathematicians. For a detailed discussion of the distinctive features of different kinds of mathematical manuscripts written between the years 1300 and 1500 and, in particular, the distinction between abaci and algorism, see Van Egmond (1976, chapters I and VI).

15 Van Egmond (1976: 185) also points out that for the medieval and renaissance merchants, barter is "one of the major forms of commerce."

16 Van Egmond (1976: 186) notes that the "majority of barter problems" in the abacus manuscripts is of this nature.

17 As Spufford points out, the term "imaginary money," which is often used in this context, is a misnomer since "on closer inspection an historical explanation may be found for the existence of each money of account, and that such an historical explanation will indicate to which real coin the system continued to be attached" (Spufford 1988: 413-414).

18 Swetz, for example, argues that the

reason for preferring barter to direct monetary payment were twofold: there was a shortage of currency (not until the discovery of gold in the New World and its import into Europe did a large scale money economy function), and the existence of trade fairs... [where] in the absence of trusted "international" currency, it was easier and safer to barter goods.

(Swetz 1987: 239)

There are, however, some problems with this explanation. Even though it is true that barter is preferred to monetary payment, the higher barter value per se does not indicate this preference. Moreover, the money stock in Europe increased in the late thirteenth and early fourteenth centuries before it started to decrease. On the estimate of European money stock in the late Middle Ages, see Peter Spufford (1988, table 2: 420).

19 As we saw, Baker also refers to "just price." But his phrase has no moral connotation.

20 Some examples in the abaci manuscripts actually show how much profit is gained in barter when the opponent does not set the "overprice" correctly:

Two men want to barter wool and cloth. A canna of cloth is worth 6 lire and in barter it is valued at 8 lire. The hundredweight of wool is worth 25 lire and in barter it is offered at such a price that the man with the cloth finds he has earned 10 per cent. At what price was the hundredweight of wool offered in barter?

(Van Egmond 1976: 187)

Similar examples are found in the Well-Spring of Science. 
21 Such scenarios could lend themselves to the construction of game theoretical models.

22 The acceptance of the new science, if not its development, surely must be related to the development of capitalism. But what made the capitalist development itself possible has, of course, been the subject of numerous controversies. Among many, one well-known thesis is that of Paul Sweezy (1976), which emphasizes exchange as the cause of the breakdown of feudalism and the rise of capitalism. Another which de-emphasizes exchange and stresses the changing property relations belongs to Murice Dobb (1947), Hilton (1976), and Robert Brenner (1977). For a summary of the controversy, see Hilton (1983); for a critical review of the so-called Brenner Debate, see Duchesne (2001).

\section{The bartering savage and the equation of exchange}

1 With a few exceptions, such as Clower (1999), there is hardly any mention of Smith's concept of barter in the literature dealing with Smith's writings. For a survey of such literature, see Brown (1997).

2 This section draws from an earlier essay of mine, Fayazmanesh (1998a).

3 On the relation between Smith's concepts of objects, goods, and commodities, see also Murray Milgate's "goods and commodities" in The New Palgrave (1987).

4 Later generation of economists, particularly Marx, would use the term "commodity" in a more technical manner, as we shall see in Chapter 5.

5 See also Smith (1976: 189-190). For a comparison of iron and the precious metals, see Smith (1978: 496).

6 On how the "paradox of value" was actually concocted, see Fayazmanesh (1998a).

7 The concept of equality was re-employed in the latter part of the age of classical political economy. For example, as we shall see, Samuel Bailey expressed the exchange of one "A" for two "B" as "one A is in our estimation equal to two B" (Bailey 1967: $2-3)$. But even during Smith's time one can find a close association between "is worth" and "is equal" in the writings of some monetary thinkers. Galiani, for example, writes: "If we say that ten bushels of grain are worth as much as a cask of wine, we are expressing a proportion of equality between possession of one thing and the other" (Galiani 1751: 21).

8 This definition of labor appears when Smith writes: "The real price of everything, what everything really costs to the man who wants to acquire it, is the toil and trouble of acquiring it" (Smith 1976: 47). A few pages later Smith recasts the concept of labor by arguing that the worker "must always lay down the same portion of his ease, his liberty, and his happiness" (Smith 1976: 50).

9 In the case of the bartering savage, Ricardo, for example, writes that "the exchangeable value of commodities produced would be in proportion to the labor bestowed on their production; not their immediate production only, but on all those implements or machines required" (Ricardo 1817: 24). The term "bestowed" is, of course, used by Smith himself on a number of occasions. For example, in the discussion of productive and unproductive labor, Smith writes: "There is one sort of labor which adds to the value of the subject upon which it is bestowed: there is another which has no such effect" (Smith 1976: 330)

10 As explained in Chapter 3, "labor and expense" was the closest that scholastics came to solving the equation of exchange. But Smith goes one step further, even though in chapter 1 of the Wealth of Nations, and in the context of the discussion of agriculture, he still refers to "labor and expense bestowed upon" land (Smith 1976: 16).

11 See Ricardo (1817, chapter 1), particularly the opening lines: 11. See also Dobb (1973: 49).

12 For a discussion of the "truck system" and its longevity in the British economy, see Hilton (1957). 


\section{Notes}

13 Before Smith posits money as the regulator of "exchangeable value," he discusses some difficulties with the concept of labor as a measure of "exchangeable value":

But though labor be the real measure of the exchangeable value of all commodities, it is not that by which their value is commonly estimated. It is often difficult to ascertain the proportion between two different quantities of labor. The time spent in two different sorts of work will not always alone determine this proportion. The different degrees of hardship endured, and of ingenuity exercised, must likewise be taken into account...

Every commodity, besides, is more frequently exchanged for, and thereby compared with, other commodities than with labor. It is more natural, therefore, to estimate its exchangeable value by the quantity of some other commodity than by that of the labor which it can purchase. The greater part of people, too, understand better what is meant by a quantity of a particular commodity than by a quantity of labor. The one is a plain palpable object; the other an abstract notion, which, though it can be made sufficiently intelligible, is not altogether so natural and obvious.

(Smith 1976: 48-49)

14 See, for example, Marx (1969: 97) and Sraffa (1953: xxxv). Also see Dobb (1973: 46). 15 As the editors of "The History of Astronomy" point out, since Smith refers to the impending return of Halley's Comet in 1758, the piece must have been written prior to this date.

16 At one point, with reference to the Copernican system, Smith writes that "the learned give up the evidence of their senses to preserve the coherence of the ideas of imagination" (Smith 1980: 77). The same line appears in Galileo's Dialogue when, again with reference to Copernicans, he writes that "they have through sheer force of intellect done such violence to their senses as to prefer what reason told them over that which sensible experience plainly showed them to the contrary" (Galileo 1632: 327).

17 In the aforementioned symposium on haggling, Margaret Schabas argues at the beginning of her "Market Contracts in the Age of Hume" that "Hume heralded the time when bartering and, I will suggest, haggling becomes a thing of the past," a contention that is mostly based on the fact that Hume makes "no explicit references to higgling" (Schabas 1994: 118, 127). Similar to Smith's declaration of the death of barter, Schabas's contention appears to be a bit premature. The original Palgrave's Dictionary of Political Economy, published in 1925, had still an entry on higgling written by Edgeworth (1925: 304-305). In discussing "higgling," Edgeworth correctly makes references to the works of such late comers as Jenkin (1887), Walras (1954), and Marshall (1890). This indicates that "higgling" was a surviving feature of the market even in the late nineteenth and early twentieth centuries. Schabas moderates her position elsewhere in the essay by stating that such things as barter and higgling were merely on the decline in the age of Hume. For example, she writes at one point that "David Hume (1711-1776) was alive at a time when haggling may have peaked but then declined" (Schabas 1994: 124). As other papers in the same symposium made it clear, such things as higgling survived way beyond the age of Hume and Smith. See, for example, Michael White's paper on William Thornton's 1866 dismissal of the "laws of supply and demand" by appealing to the process of "haggling" (White 1994: 150).

18 Such questions, as we shall see soon, were only asked in the twentieth century, and even then for a brief period, by writers such as Patinkin (1965) and Clower (1970).

19 On responses of early marginalist to Thornton, see White (1994).

\section{Primitive communities, the equation of exchange, and proper point of departure}

1 After evaluating what Marx and Engels had to say on primitive communities, Hobsbawm (1977: 25) notes: "At the time the Formen were written, Marx's and Engels's 
knowledge of primitive society was therefore only sketchy. It was not based on any serious knowledge of tribal societies." Similar views are expressed by others. See, for example, Lekas (1988).

2 As we see shortly, in the postface to the second edition of the first volume of Capital, Marx refers to his own "derivation of value by the analysis of the equations in which every exchange-value is expressed" (Marx 1977: 94, emphasis added). Subsequently, he refers frequently to the exchange relation as an "equation" (Marx 1977: 127). It should also be noted that what is translated in one version of Capital as "value-relation" is translated in another version as "equation of value" (Marx 1974: 51, 1977: 142).

3 See respectively, Marx (1976: 9, 1977: 127, 1970: 28, 1971: 139, 144).

4 A number of writers have referred to Marx's equation of exchange as an impossible or nonsensical equation, since it makes no sense to say a given quantity of a useful object is equal to some quantities of another useful object. See, for example, Krause (1982: 28-29); Carling (1984-1985: 409, or 1986: 60). But as I have argued, Marx himself was fully aware of the fact that the equation is nonsensical. It was for this reason that he looks for a substance that would make the equation possible and meaningful.

5 For a more detailed discussion, see Fayazmanesh (1994).

6 Let us note that in the aforementioned passage Marx, once again, portrays barter as some primitive act, where "exchange takes place only for the reciprocal use of the commodity." But the medieval barter shows that this is not necessarily the case.

7 This is an important distinction that has gone unnoticed by various commentators on Marx

8 As mentioned in the introduction to this book, Marx believes that "all science would be superfluous if the form of appearance of things directly coincided with their essence" (Marx 1981: 956).

9 Such arguments are often shrouded in the mystical Hegelian "dialectics."

10 See Fayazmanesh (1984).

11 The second point of departure is not exactly "value," as some have argued, but the simplest form of value, as we shall see. "Value" is actually the end product of the first section.

12 In other translations of Capital the term "exchange" in the first sentence actually reads "barter" (Marx 1974: 87).

13 Some arguments concerning Marx's method pertain mainly to this second point of departure. For example, Martha Campbell's defense of Marx's theory of money and her contention that "simple value form is completely different from barter" is primarily related to the section on the form of value (Campbell 1997: 92). Unfortunately Campbell's defense is not at all convincing. Indeed, some of her comments, such as from "Marx's perspective, a 'barter economy' is a chimera," or that "according to Marx, barter is always external to society," are plainly false when compared to Marx's actual writings on barter (Campbell 1997: 99-100).

14 Arthur argues that Marx let Engels's review of $A$ Contribution pass "because he was still undecided about the relevance of his logical arrangement of categories for historical research" (Arthur 1997: 11). One might, of course, argue that Marx was himself unclear and confused as to what his analysis of money-form meant in terms of history. But it makes no sense to argue that he was undecided about this issue. Nine years later, in Capital, he repeated the same method of presentation even more strongly.

15 In such arguments whereas the nature of the second commodity is relatively clear that of the first is not.

16 It is interesting to note that Arthur quotes the first paragraph of this passage but not the second, where the circular method is said to be historical as well (Arthur 1997: 30).

17 Marx's concern with the issue of the proper beginning point sometimes appears to be on the verge of obsession (see Fayazmanesh 1984, 1994).

18 At one point in the 1857 Introduction Marx argues that even though the category of "money" is quite old, one should first deal with it in its most modern form, since the 


\section{Notes}

"anatomy of the ape" can be understood fully only after the "human anatomy" has been revealed (Marx 1973: 102-105).

19 It should be noted that when Marx began "The Chapter on Money" in Grundrisse he actually put "II" in front of it, indicating that some other section had to come before it. For a discussion of what he had in mind for the first section, see Fayazmanesh (1984).

20 See letter to Lassalle in Padover (1979: 425). Also see Marx (1975b: 98-100).

\section{Mademoiselle Zélie and the "scientific" theory of exchange}

1 In chapter XV of his Money and Mechanism of Exchange Jevons returns to the issue of barter and writes:

No sooner have a people fully experienced the usefulness of a good system of money, than they begin to discover that they can dispense with it as a medium of exchange, and return to a method of traffic closely resembling barter. With barter they begin and with barter they end; but the second form of barter, as we shall see, is very different from the first. Purchases and sales continue to be made in terms of gold and silver coin, but equivalent quantities of goods thus estimated are made to pay for each other. If ownership in gold or silver intervenes at all, it is in the shape of warrants or representative documents with which gold can be procured, if desired, but which are seldom used to procure it.

(Jevons 1875: 189, emphasis in the original)

In other words, if representative money exists, then inconveniences of barter are not experienced, an issue that will be discussed shortly. But here there is an element of confusion in Jevons's argument. The use of paper money, he seems to argue, turns exchange into barter. This confused argument is based on Jevons's peculiar assumption that if money is not a useful commodity, then it is not actually money.

2 In the first edition of the Theory the same graph appears as "Fig. II" (Jevons 1871: 37).

3 See Jevons (1879: 38) and Fayazmanesh (1996, 1998a)

4 This is, of course, the beginning of the creation of the mythical "paradox of value" (see Fayazmanesh 1998a; White 2002).

5 "Degree of utility" is defined by Jevons as "the differential coefficient of u considered as a function of $\mathrm{x}$ " (Jevons 1879: 51).

6 The first edition of the Theory of Political Economy contradicts this assertion. In that work Jevons claims that "value in exchange" means "terminal utility" (Jevons 1871: 157).

7 As indicated earlier, Jevons squeezes the first set to become equivalent to the set of "quantity of food" or "quantity of commodity" (Jevons 1871: 55, 59).

8 To be more specific, Jevons argues that if " $A B$ " is a "lever turning freely about $C$," " $P$ " is the "force applied at $A$ " and " $W$ " the "force exerted ... at $B$ ", then $\phi x / \psi y=y / x$ is analogous to $W / P=A C / B C$ (Jevons 1879: 102-105).

9 It appears to this writer that Pareto's attack was more against Marx than Walras. In the paragraph that Jaffe cites, concerning "value in exchange," Pareto refers to Marx and then writes in a footnote: "In a recently published work, it is said that "price is the concrete manifestation of value.' We have had incarnations of Buddha, here we have incarnations of value!" (Pareto 1971: 177, emphasis in the original). There is no mention of Walras in this footnote or the related paragraph. Walras's name appears two paragraphs later.

10 On Marshall's contradictory positions on this issue, see Fayazmanesh (1998b).

11 Contrary to Walras's claim, classical political economists were mostly concerned with reproducible commodities. Thus, Ricardo argues that such things as "rare statutes and pictures, scarce books and coins, wines of peculiar quality" are not the subject 
of his study (Ricardo 1817: 12). Instead, he is concerned with goods that can be "multiplied":

In speaking then of commodities, of their exchangeable value, and of the laws which regulate their prices, we mean always such commodities only as can be increased in quantity by the exertion of human industry, and on the production of which competition operates without restraint.

(Ricardo 1817: 12)

12 Pascal Bridel (1997: 142) argues that from the "outset of his scientific career, Walras has always drawn a clear-cut distinction between the 'ideal type' of pure economics and the 'real types' of applied and social economics." He further adds: "In opposition to most modern economic theorists who consider that the realism of a model is judged on its ability to reflect essential characteristics of the reality, Walras adopts a firmly rationalistic 'anti-realistic' epistemology."

13 I am not including Carl Menger among the marginalist pioneers, since I believe his concept of science and his economic theories set him apart from the other three. It is interesting to note that he admonishes the concept of "regarding the quantities of goods in an exchange as equivalents," which he rightly traces back to Aristotle (Menger 1981: 192, 305). However, when it comes to "The Nature and the Origin of Money," he basically follows the Aristotelian line with some minor differences (Menger 1981: 257-262, 317).

14 On Marshall's continuity of thought thesis, see Fayazmanesh (1998b).

15 For a discussion of this note and the controversy between Marshall and Edgeworth over "barter" of apples and nuts, see Newman (1990).

\section{Neo-Walrasianism, the matrix of exchange, and beyond}

1 See the caveat concerning "realism" in the introduction to this book.

2 Here, Marget was referring to Hicks's 1933 essay.

3 For some critical reviews of Walker's claims, see De Vroey (1999) and Bridel (1998). For a reply, see Walker (1999).

4 For a sample of divergent views concerning the status of the "marginal revolution" as a scientific revolution, see Blaug (1973, 1992, 1997), Coats (1973), and Mirowski (1984, 1988, 1989a,b)

5 This view is expressed in his 1935 essay, "A Suggestion for Simplifying the Theory of Money." Similar views are also expressed in Hicks's later writings. For example, with reference to Don Patinkin's attempt in Money, Interest, and Prices to incorporate the demand for real balances into the Walrasian general equilibrium theory, Hicks contends that he would like to proceed more slowly than Patinkin and that he shall construct a model to which "Walras' theory ought to apply exactly" (Hick 1967: 3).

6 On the confusing use of the terms "classical" and "neoclassical," see Fayazmanesh (1998b).

7 Similar arguments appear elsewhere. See, for example, Patinkin (1950-1951: 42).

8 For a list of such criticisms, see Brunner (1951).

9 Clower's 1967 essay reappears as "Foundations of Monetary Theory" in his Monetary Theory (1970) and in Money and Markets (1984). I use the 1970 version.

10 Patinkin himself presents a lively picture of this world when, in modeling a barter economy, he writes: "Each individual begins Monday morning of any given week with an initial collection of goods which, like manna of the Children of Israel, has descended upon him 'from heaven' during the preceding night" (Patinkin 1965: 4).

11 See the graphical presentations in Chapter 2.

12 Beside a few scattered citations, such as those of Mirowski (1989a: 351-353), this work has received almost no attention from the orthodox economists and very little 


\section{Notes}

attention from heterodox economists. This neglect is, of course, partially due to the usual treatment of "Marxist" oriented works. But it is also partially due to the structure of Krause's work itself. The book lacks clarity and organization and, at times, it is reduced to an exercise in pure mathematics.

13 Krause writes that Clower's discussion of direct exchange relation "contains no mention of quantities of commodities" (Krause 1982: 166, emphasis in the original).

14 "An interchange relation $\tau$ is said to define a barter economy; more precisely, $\tau$ itself constitute barter if $\tau$ is a transitive value relation" (Krause 1982: 51). "Value relation," in turn, is defined as any binary relation that possesses the properties 1-4 (Krause 1982: 38-39).

15 Even though Krause uses the expressions "use-value," "exchange-value," and "commodity," he does not attempt to define and sort out these highly ambiguous concepts (see, for example, Krause 1982: 20-21, 31,33). Thus there is no distinction between a class of useful objects and a commodity in his work.

16 It should be recalled that Krause also argues that the direct relation of exchange, " $\tau$," need not be transitive. But in so saying, he has in mind an accidental and not a regular exchange. The dismissal of the "impossible equation" is also based on this notion of accidental versus regular exchange. 


\section{References}

Al-Khwarizmi, M. Ibn Musa (1831) al-Kitab al-mukhtasar fi hisab al-jabar wal-Muqabala, in F. Rosen (ed.) The Algebra of Mohammad ben Musa, reprint, 1986, Hildesheim: Georg Olms Verlag.

Aquinas, T. (1964) St. Thomas Aquinas: Commentary on the Nicomachean Ethics, C. I. Litzinger (trans.) vol. 1, Chicago, IL : Henry Regnery Company.

(1975) Summa Theologice, vol. 38, New York: Blackfriars.

Aristotle (1946) Politica, in M. D. Ross (ed.) The Works of Aristotle, vol. X, Oxford: Oxford University Press.

(1949) Ethica Nicomachea, in M. D. Ross (ed.) The Works of Aristotle, vol. IX, Oxford: Oxford University Press.

Arthur, C. J. (1997) "Against the Logical-Historical Method: Dialectical Derivation versus Linear Logic," in F. Moseley and M. Campbell (eds) New Investigations of Marx's Method, Atlantic Highlands, NJ: Humanities Press.

Bailey, S. (1967) A Critical Dissertation on the Nature, Measure and Causes of Value, New York: Augustus. M. Kelley.

Baker, H. (1568) The Well-Spring of Science, London: Printed by J. Flesher for Christopher Meredith, 1650.

Baldwin, J. W. (1959) The Medieval Theories of the Just Price: Romanists, Canonist, and Theologians in the Twelfth and Thirteenth Centuries, reprinted in L. Silk (ed.) Pre-Capitalist Economic Thought: Three Modern Interpretations, 1972, New York: Arno Press.

Banaji, J. (1979) "From the Commodity to Capital: Hegel's Dialectic in Marx's Capital," in D. Elson (ed.) Value: The Representation of Labor in Capitalism, Atlantic Highlands, NJ: Humanities Press.

Baxandall, M. (1988) Painting and Experience in Fifteenth Century Italy, New York: Oxford University Press.

Bentham, J. (1954) Jeremy Bentham's Economic Writings, W. Stark (ed.) London: George Allen \& Unwin.

Berggren, J. L. (1986) Episodes in the Mathematics of Medieval Islam, New York: Springer-Verlag.

Berry, B. J. L. (1967) Geography of Market Centers and Retail Distribution, Englewood Cliffs, NJ: Prentice Hall.

Bhaskar, R. (1978) A Realist Theory of Science, Atlantic Highlands, NJ: Humanities Press.

- (1983) "Realism," in T. Bottomore (ed.) A Dictionary of Marxist Thought, Cambridge, MA: Harvard University Press. 


\section{References}

Blaug, M. (1973) "Was There a Marginal Revolution?," in R. D. Collison Black, A. W. Coats, and C. D. W. Goodwin (eds) The Marginal Revolution in Economics, Durham, NC: Duke University Press.

— (1992) The Methodology of Economics, Cambridge: Cambridge University Press (1997) "The Marginal Revolution," Economic Theory in Retrospect, 5th edition, Cambridge: Cambridge University Press.

Bowley, M. (1973) Studies in the History of Economic Theory before 1870, London: Macmillan.

Brenner, R. (1977) "The Origins of Capitalist Development: A Critique of Neo-Smithian Marxism," New Left Review, 104: 25-93.

Bridbury, A. R. (1992) The English Economy from Bede to the Reformation, New York: The Boydell Press.

Bridel, P. (1997) Money and General Equilibrium Theory: From Walras to Pareto (1870-1923), Cheltenham: Edward Elgar.

- (1998) "Review: Walras's Market Models," Journal of Economic Literature, 36, 1: 231-233.

Brown, V. (1994) "Higgling: The Language of Markets in Economic Discourse," in N. De Marchi and M. Morgan (eds) Higgling: Transactors and Their Markets in the History of Economics, HOPE 26 (supplement): 66-93.

- (1997) “ 'Mere Inventions of the Imagination': A Survey of Recent Literature on Adam Smith," Economics and Philosophy, 13, 2: 281-312.

Brunner, K. (1951) "Inconsistency and Indeterminacy in Classical Economics," Econometrica, 19, 2: 152-173.

Campbell, M. (1997) "Marx's Theory of Money: A Defense," in F. Moseley and M. Campbell (eds) New Investigations of Marx's Method, Atlantic Highlands, NJ: Humanities Press.

Carling, A. (1984) “Observation on the Labor Theory of Value," Science \& Society, 48, 4: $407-418$

_ (1986) "Forms of Value and the Logic of Capital," Science \& Society, 50, 1: 52-80.

Casti, J. L. (1989) Alternative Realities: Mathematical Models of Nature and Man, New York: John Wiley \& Son.

Chown, J. F. (1994) A History of Money, London: Routledge.

Clower, R. W. (1967) "A Reconsideration of the Microfoundations of Monetary Theory," Western Economic Journal, 6: 1-9.

— (1970) Monetary Theory: Selected Readings, Harmondsworth: Penguin Books.

_ (1977) “The Anatomy of Monetary Theory," The American Economic Review, 67, 1: 206-212.

_ (1984) Money and Markets: Essays by Roberts W. Clower, D. A. Walker (ed.), Cambridge: Cambridge University Press.

_ (1999) "From Markets to Money," Ekonomia: The Journal of Cyprus Economic Society, 3, 1: 1-13.

Coats, A. W. (1973) "Retrospect and Prospect," in R. D. Collison Black, A. W. Coats, and C. D. W. Goodwin (eds) The Marginal Revolution in Economics, Durham, NC: Duke University Press.

Cohen, E. E. (1992) Athenian Economy and Society: A Banking Perspective, Princeton, NJ: Princeton University Press.

Davidson, P. (1972) "Money and the Real World," The Economic Journal, 82, 325: 101-115. (1978) Money and the Real World, London: Macmillan.

Davies, G. (1994) A History of Money: From Ancient Times to the Present Day, Cardiff: University of Wales Press. 
Davis, Natalie Zemon (1960) "Sixteenth-Century French Arithmetics on the Business Life," Journal of the History of Ideas, 12 (January-March): 18-48.

de Roover, R. (1953) "The Commercial Revolution," in A. Molho (ed.) Social and Economic Foundations of Italian Renaissance, 1969, New York: John Wiley \& Sons.

_ (1955) "Scholastic Economics: Survival and Lasting Influence from the Sixteenth Century to Adam Smith," The Quarterly Journal of Economics, 69, 2: 161-190.

- (1958) "The Concept of the Just Price: Theory and Economics Policy," The Journal of Economic History, 18, 4: 418-434.

De Vroey, M. (1999) "Transforming Walras into a Marshallian Economist: A Critical Review of Donald Walker's Walras's Market Models," Journal of the History of Economic Thought, 21, 4: 413-435.

Dobb, M. (1947) Studies in the Development of Capitalism, New York: International Publishers.

_ (1973) Theories of Value and Distribution since Adam Smith: Ideology and Economic Theory, Cambridge: Cambridge University Press.

Duchesne, R. (2001) "Robert Brenner on Political Accumulation and Transition to Capitalism," Review of Radical Political Economics, 33, 1: 79-98.

Edgeworth, F. Y. (1925) "Higgling," in H. Higgs (ed.) Palgrave's Dictionary of Political Economy, London: Macmillan.

— (1926) "Utility," in H. Higgs (ed.) Palgrave's Dictionary of Political Economy, London: Macmillan.

Einzig, P. (1966) Primitive Money in Its Ethnological, Historical and Economic Aspects, Oxford: Pergamon Press.

Ekelund, R. B. and Hébert, R. F. (1997) A History of Economic Theory and Method, New York: McGraw-Hill.

Fayazmanesh, S. (1984) The Commodity as the Point of Departure of Capital: A Methodological Inquiry, $\mathrm{PhD}$ dissertation, University of California, Riverside.

_ (1994) "Marx's Semantics and the Logic of the Derivation of Value," Research in the History of Economic Thought and Methodology, 12: 65-91.

— (1996) "On the Application of Mathematics to Economics: A Case Study of Jevons's Reading of Smith," paper presented at the Annual Meeting of the History of Economics Society, Vancouver, BC. Canada, June 29.

(1998a) "The Magical, Mystical Paradox of Value," Research in the History of Economic Thought and Methodology, 16: 123-153.

- (1998b). "On Veblen's Coining of the Term 'Neoclassical' ," in S. Fayazmanesh and M. R. Tool (eds), Institutionalist Method and Value: Essays in Honor of Paul D. Bush, vol. 1, London: Edward Elgar, reprinted in R. Tilman (ed.) The Legacy of Thorstein Veblen, 2003, London: Edward Elgar.

- (2001) "Barter, Money and Commercial Arithmetic," Journal of the History of Economic Thought, 23, 1: 77-98.

Fibonacci, L. (1202). Fibonacci's Liber Abaci: A Translation into Modern English of Leonardo Pisano's Book of Calculation, L. Sigler (trans.) 2002, New York: Springer.

Finley, M. I. (1973) The Ancient Economy, London: Chatto \& Windus.

_ (1977) "Aristotle and Economic Analysis," in J. Barnes (ed.) Articles on Aristotle: Ethics and Politics, London: Duckworth.

Galbraith, J. K. and Darity, W. J. (1994) Macroeconomics, Boston, MA: Houghton Mifflin. Galiani, F. (1751) On Money, P. Toscano (trans.) 1977, Ann Arbor, MI: University Microfilms International. 


\section{References}

Galilei, Galileo (1632) Dialogue Concerning the Two Chief World Systems, S. Drake (trans.), 1953, Berkeley, CA: University of California Press.

(1638) Two New Sciences, S. Drake (trans.) 1974, Madison, WI: University of Wisconsin Press.

Gordon, B. (1964) "Aristotle and the Development of Value Theory," Quarterly Journal of Economics, 78: 115-128, reprinted in M. Blaug, Aristotle (384-322 BC), 1991, London: Edward Elgar.

Hadden, R. W. (1994) On the Shoulder of Merchants: Exchange and the Mathematical Conception of Nature in Early Modern Europe, Albany, NJ: State University of New York Press.

Hahn, F. H. (1973) “On the Foundations of Monetary Theory,” in F. Hahn (ed.) Equilibrium and Macroeconomics, 1984, Cambridge, MA: MIT Press.

(1983) Money and Inflation, Cambridge, MA: MIT Press.

Harris, J. (1757) An Essay upon Money and Coins, reprint, 1970, New York: Johnson Reprint Corporation.

Heichelheim, F. M. (1964) An Ancient Economic History, Leyden: A. W. Sythoff.

Herodotus (1998) The Histories, R. Waterfield (trans.) Oxford: Oxford University Press.

Hicks, J. R. (1933) "Gleichgewicht und Konjonktut," Zeitschrift für Nationalökonomie, 4: 441-455.

- (1967) Critical Essays in Monetary Theory, London: Oxford University Press. (1976) “' 'Revolutions' in Economics,” in Spiro J. Latsis (ed.) Method and Appraisal in Economics, Cambridge: Cambridge University Press.

Hilton, G. W. (1957) "The British Truck System in the Nineteenth Century," The Journal of Political Economy, 65, 3: 237-256.

Hilton, R. (1976) “A Critique," in R. Hilton (ed.) The Transition from Feudalism to Capitalism, London: NLB.

- (1983) "Transition from Feudalism to Capitalism," in T. Bottomore (ed.) A Dictionary of Marxist Thought, Cambridge, MA: Harvard University Press.

Hobsbawm, E. J. (1977) Pre-Capitalist Economic Formations, New York: International Publishers.

Hollander, S. (1965) "On the Interpretation of the Just Price," Kyklos, 18: 615-634.

Howitt, P. W. (1973) "Walras and Monetary Theory," Western Economic Journal, 11, 4: 487-499.

Humphrey, C. (1985) "Barter and Economic Disintegration," Man, 20 (March): 48-72.

_ (1992) "Introduction," in C. Humphrey and S. Hugh-Jones (eds) Barter, Exchange and Value: An Anthropological Approach, Cambridge: Cambridge University Press.

Jenkin, H. C. F. (1887) “Time-labor System," in S. C. Colvin and J. A. Ewing (eds) Papers, Literary, Scientific, etc., London: Longmans, Green \& Company.

Jevons, W. S. (1871) The Theory of Political Economy, New York: Macmillan and Co.

- (1875) Money and Mechanism of Exchange, 1902, London: Kegan Paul.

- (1879) The Theory of Political Economy, 5th edition, 1957, New York: Kelley \& Millman Inc.

Kaye, J. (1998) Economy and Nature in the Fourteenth Century: Money, Market Exchange, and the Emergence of Scientific Thought, New York: Cambridge University Press.

Keynes, J. M. (1933) “A Monetary Theory of Production," The Collected Writings of John Maynard Keynes, vol. XIII, 1973, London: Macmillan.

Klein, J. L. (1997) Statistical Visions in Time: A History of Time Series Analysis 1662-1938, Cambridge: Cambridge University Press.

Krause, U. (1982) Money and Abstract Labor, London: Verso. 
Langholm, O. (1979) Price and Value in the Aristotelian Tradition: A Study in Scholastic Economic Sources, Bregen: Universitetsforlaget.

Lawson, T. (1997) Economics and Reality, London: Routledge.

— (1998) "Transcendental Realism," in J. B. Davis, D. W. Hands, and U. Mäki (eds) The Handbook of Economic Methodology, Cheltenham, UK: Edward Elgar.

Lekas, P. (1988) Marx on Classical Antiquity: Problems of Historical Methodology, New York: St. Martin's Press.

Levy, J. P. (1964) The Economic Life of the Ancient World, Chicago, IL: The University of Chicago Press.

Lowery, S. T. (1979) "Recent Literature on Ancient Greek Economic Thought," Journal of Economic Literature, vol. XVIII: 65-86, reprinted in M. Blaug, Aristotle (384-322 BC), 1991, London: Edward Elgar.

— (1987) The Archaeology of Economic Ideas: The Classical Greek Tradition, Durham, NC: Duke University Press.

Mäki, U. (1989) "On the Problem of Realism in Economics," Riceche Economiche, 43, 1-2: 176-198.

_ (1998a) "Realism," in J. B. Davis, D. W. Hands, and U. Mäki (eds) The Handbook of Economic Methodology, Cheltenham, UK: Edward Elgar.

_ (1998b) "Realisticness," in J. B. Davis, D. W. Hands, and U. Mäki (eds) The Handbook of Economic Methodology, Cheltenham, UK: Edward Elgar.

Marget, A. W. (1931) "Leon Walras and the 'Cash-Balance Approach' to the Problem of the Value of Money," The Journal of Political Economy, 39, 52: 569-600.

- (1935) "Monetary Aspects of the Walrasian System," The Journal of Political Economy, 43, 2: 145-186.

Marshall, A. (1890) Principles of Economics, reprint, 1936, London: Macmillan.

Marx, K. (1968) Theories of Surplus Value, part II, Moscow: Progress Publishers.

_ (1969) Theories of Surplus Value, part I, Moscow: Progress Publishers.

- (1970) A Contribution to the Critique of Political Economy, New York: International Publishers.

— (1971) Theories of Surplus Value, part III, Moscow: Progress Publishers.

- (1973) Grundrisse: Foundations of the Critique of Political Economy, New York: Vintage Books.

_ (1974) Capital, vol. 1, New York: International Publishers.

_ (1975a) "Notes on Adolph Wagner (1879-80)," in T. Carver (ed.) Karl Marx: Texts on Method, Oxford: Basil Blackwell.

- (1975b) Marx-Engels Selected Correspondence, Moscow: Progress Publishers.

_ (1976) Value: Studies by Karl Marx, A. Dragstedt (trans.) London: New Park Publication. (1977) Capital, vol. 1, New York: Vintage Book.

- (1981) Capital, vol. 3, New York: Vintage Books.

Meek, R. L. (1958) Studies in the Labor Theory of Value, London: Lawrence \& Wishart. Meikle, S. (1995) Aristotle's Economic Thought, Oxford: Clarendon Press.

Menger, C. (1981) Principles of Economics, New York: New York University Press.

Milgate, M. (1987) "Goods and Commodities," The New Palgrave, 2: 546-549.

Mirowski, P. (1984) "Physics and the Marginalist Revolution," Cambridge Journal of Economics, 8, 4: 361-379.

- (1988) Against Mechanism, Totowa: Rowman \& Littlefield. (1989a) More Heat Than Light, New York: Cambridge University Press.

_ (1989b) "On Hollander's 'Substantive Identity' of Classical and Neoclassical Economics: A Reply,” Cambridge Journal of Economics, 13, 3: 471-477. 


\section{References}

Monroe, A. E. (1965) Early Economic Thought: Selections from Economic Literature Prior to Adam Smith, Cambridge: Harvard University Press.

— (1966) Monetary Theory before Adam Smith, New York: Augustus M. Kelly.

Nagel, E. (1963) “Assumptions in Economic Theory," The American Economic Review, 53, 2: 211-219.

Newman, P. (1990) "The Great Barter Controversy,” in J. K. Whitaker (ed.) Centenary Essays on Alfred Marshall, Cambridge: Cambridge University Press.

Oresme, N. (1956) The De Moneta of Nicholas Oresme and English Mint Documents, C. Johnson (ed. and trans.) London: Thomas Nelson.

Ostroy, J. M. (1973) "The Informational Efficiency of Monetary Exchange," The American Economic Review, 63, 4: 597-610.

Ostroy, J. M. and Starr, R. M. (1974) "Money and the Decentralization of Exchange," Econometrica, 42, 1: 1093-11114.

- (1992) "Money and General Equilibrium Theory," in P. Newman, M. Milgate, and J. Eatwell (eds) The New Palgrave Dictionary of Money \& Finance, vol. 2, London: Macmillan.

_ (1996) "The Transactions Role of Money," in B. M. Friedman and F. H. Hahn (eds) Handbook of Monetary Economics, vol. 1, New York: Elsevier.

Padover, S. K. (1979) Letters of Karl Marx. Englewood Cliffs, NJ : Prentice-Hall.

Pareto, V. (1971) Manual of Political Economy, New York: A. M. Kelley.

Patinkin, D. (1948) "Relative Prices, Say's Law, and the Demand for Money," Econometrica, 16, 2: 135-154.

- (1950-1951) "A Reconsideration of the General Equilibrium Theory of Money," The Review of Economic Studies, 18, 1: 42-61.

- (1965) Money, Interest, and Price, New York: Harper \& Row.

Plato (2000) The Republic, Cambridge: Cambridge University Press.

Poitras, G. (2000) The Early History of Financial Economics, 1478-1776, Cheltenham: Edward Elgar.

Polanyi, K. (1957) The Great Transformation, Boston, MA: Beacon Press.

_ (1968) "Aristotle Discovers the Economy," in G. Dalton (ed.) Primitive, Archaic and Modern Economies, Essays of Karl Polanyi, New York: Anchor Books.

Recorde, R. (1557) The Whetsone of Witte, reprint, 1969, Amsterdam: Da Capo Press.

Ricardo, D. (1817) On the Principles of Political Economy and Taxation, in The Works and Correspondences of David Ricardo, vol. 1, 1953, Cambridge: Cambridge University Press.

Robertson, R. M. (1951) “Jevons and His Precursors,” Econometrica, 19, 3: 229-249.

Schabas, M. (1994) "Market Contracts in the Age of Hume," in N. De Marchi and M. Morgan (eds) Higgling: Transactors and Their Markets in the History of Economics, HOPE 26 (supplement): 117-134.

Schumpeter, J. (1954) History of Economic Analysis, New York: Oxford University Press. Smith, A. (1965) An Inquiry into the Nature and Causes of the Wealth of Nations, edited by E. Cannan, New York: The Modern Library.

(1976) An Inquiry into the Nature and Causes of the Wealth of Nations, 2 vols, edited by R. H. Campbell, A. S. Skinner, and W. B. Todd, The Glasgow Edition of the Works and Correspondence of Adam Smith, Oxford: Clarendon Press.

- (1978) Lectures on Jurisprudence, Oxford: Oxford University Press.

(1980) "The History of Astronomy," in W. P. D. Wightman and J. C. Bryce (eds) Essays on Philosophical Subjects, Oxford: Clarendon Press. 
(1983) Lectures on Rhetoric and Belles Lettres, Oxford: Clarendon Press.

Soudek, J. (1952) "Aristotle's Theory of Exchange: An Inquiry into the Origin of Economic Analysis," Proceedings of American Philosophical Society, 96, 1: 45-75, reprinted in M. Blaug, Aristotle (384-322 BC), 1991, London: Edward Elgar.

Spufford, P. (1988) Money and Its Uses in Medieval Europe, Cambridge: Cambridge University Press.

Sraffa, P. (1953) The Works and Correspondences of David Ricardo, vol. 1, Cambridge: Cambridge University Press.

Starr, R. M. (1972) "The Structure of Exchange in Barter and Monetary Economics," The Quarterly Journal of Economics, 86, 1: 290-302.

Sweezy, P. (1976) "A Critique," in R. Hilton (ed.) The Transition from Feudalism to Capitalism, London: NLB.

Swetz, F. J. (1987) Capitalism and Arithmetic: The New Math of the 15th Century, La Salle, IL: Open Court.

Thornton, W. T. (1869) On Labor: Its Wrongful Claims and Rightful Dues, London: Macmillan.

Tobin, J. (1992) "Money," in P. Newman, M. Milgate, and J. Eatwell (eds) The New Palgrave Dictionary of Money and Finance, London: Macmillan.

Toomer, G. J. (1973) "Al-Khwarizmi," Dictionary of Scientific Biography, New York: Scribner's Sons.

Van Der Wee, H. (1977) "Monetary, Credit and Banking Systems," in E. E. Rich and C. H. Wilson (eds) Cambridge Economic History of Europe, vol. V, Cambridge: Cambridge University Press.

Van Egmond, W. (1976) Commercial Revolution and the Beginning of Western Mathematics in Renaissance Florence, 1300-1500, $\mathrm{PhD}$ dissertation, Indiana University.

Vogel, K. (1971) "Fibonacci," Dictionary of Scientific Biography, New York: Scribner's Sons.

_ (1978) “Überholte kaufmännishe Praktik aus dem Mittelalter," Beiträge zur Geschichte der Arithmetik, München: Minerva.

Walker, D. A. (1996) Walras's Market Models, Cambridge: Cambridge University Press.

_ (1999) "Some Comments on Léon Walras's Health and Productivity," Journal of the History of Economic Thought, 21, 4: 437-448.

Walras, L. (1954) Elements of Pure Economics, London: George Allen \& Unwin.

White, M. V. (1994) “'That God-Forgotten Thornton': Exorcising Higgling After On Labor," in N. De Marchi and M. Morgan (eds) Higgling: Transactors and Their Markets in the History of Economics, HOPE 26 (supplement): 147-183.

— (2002) "Doctoring Adam Smith: The Fable of the Diamonds and Water Paradox," History of Political Economy, 34, 4: 659-683.

Wicksteed, P. H. (1888) The Alphabet of Economic Science, 1955, New York: Kelley \& Millman.

Wood, D. (2002) Medieval Economic Thought, Cambridge: Cambridge University Press. 



\section{Index}

abacus manuscripts 134,138 n.14, 138 n.20; monetary lessons 32; nature and structure 28, 31-32; "Rules of Barter" formalization 36-39; "Rules of Barter" section 32-36; Treviso Arithmetic 32, 33, 40; Well-Spring of Science 32, 33, 40, 41

Al-Khwarizmi, Muhammad Ibn Musa 31 ancient economy 4-5, 14; Finley's criticism 16; Heichelheim description 14-15 Aquinas, Thomas 4, 28-29, 30-31, 32, 45, 137 n.8

Aristotle: concept of exchange as relation of equality $4,10,17,20-22,24,28,70$, 74, 130, 137 n.12; criticism and interpretation of Aristotelian exchange theory 9, 12-14; enduring influence on monetary theory $4,9-10,25,44,130$, 132-133; equation of exchange 4,10 , 29, 60, 62, 94-95, 97, 130; exchange relation 17-23; exchange theory 10 , 11-12, 24, 51, 57; influence on Marx 5, $66,74,75,83,132$; Marx's perfection of Aristotelian equation of exchange 5 , $66,69-71,83,132$; monetary theory $3-4,9-10,23-25,47,130$; origin of money $10-11,17,24$

Arthur, Christopher 76, 141 n.14

Bailey, Samuel 62, 70, 73, 139 n.7

Baker, Humfrey 32, 34, 35, 36, 39, 40-41, 138 n.19

Baldwin, J. W. 30

Banaji, J. 76

banks and banking: ancient times 15

barter 7-8, 84; and arithmetical knowledge 28, 41-42, 45; complex barter 37; compound barter 34-36, 37-39; Jevons's theory 142 n.1; Marx's theory $66-67,68,77,78-79,83,105$,
141 n.6; in medieval ages 27-28, $32-33,85-86$; and monetary exchange distinction 1, 96, 107, 134; pervasiveness and significance 33 ; preference over monetary exchange 28 , $32,41,42,134,138$ n.18; pure barter economy $6,87-88,85,87-88,89$; simple barter 36-37; Smith's theory 47-49, 105, 139 n. 1; types 33-36

barter difficulties $4,5,26,27-28,39-41$, 48 ; "double coincidence of wants" 39-40, 85-86, 88, 122, 124, 125; Harris's theory 48; Jevons's theory 5, 85-89, 105, 128, 133; Marx's theory 67-68; means of subdivision 39 , 40-41; measure of value $49,86,87$; Smith's theory 48-49; unit of account $10,39,40$

bartering savage $5,46-47,78,85,86-87$, 105, 131, 139 n.9; and solution for equation of exchange 56-59

"barter price" 33-34

Bentham's theory of utility 91

Bertrand, J. L. F. 110

Bridbury, A. R. 27

Bridel, Pascal 111, 112, 127, 143 n.12

Brown, Vivienne 63

Brunner, Karl 128

Buridan, Jean 27

buying and selling: in moneyless

Walrasian world 102-105

capitalism: Marx's dating of 27

"cash price" 33-34

Chown, John F. 40

Clower, Robert: critique of neo-Walrasian model 6, 109, 114-115, 123, 127,

133-134; exchange relation 115,117 , 120-121; matrix of exchange 6,109 , $115-116,117,123,125,126,127,128$ 


\section{Index}

Cohen, E. E. 15,136 n. 5

commodity 79-82, 92-93, 121; simple 79-81, 132

complex barter 37

compound barter 34-36, 37-39

Copernicus, Nicholas 27, 44, 140 n.16

Darity, W. J. $88-89$

Davies, Glyn 88

Davis, Natalie Zemon 32, 41-42, 44

decentralized exchange theory 6,109 , 122-123

de Roover, R. 27, 29-30

direct exchange $3,5,84,102,122,124$, $125,131,144 \mathrm{n} .13$; in medieval economy $17,32-33$

division of labor $11,46,48-49,58,82$, 83,131

economics 14; Plato's 11, 48

Edgeworth, F. Y. 14, 100, 107, 140 n.17

Einzig, Paul 88

Engels, Frederick 75-76, 77, 79, 81,140 n. 1

equation of exchange 5, 47; Aristotelian 4, 10, 29, 60, 62, 94-95, 97, 130;

Jevons's 97; Marx's perfection of

Aristotelian equation 5, 66, 69-71, 83,

132; Smith's solution $56-61,131$;

Walras's 98-99, 101-102

exchange: Aristotelian 10, 123-126, 24, 51, 57; criticism and interpretation of Aristotelian 9, 12-14; fairness in 13-14, 17, 23, 28, 38, 42; Jevons's portrayal of 89-90; Krause's quantitative analysis of 123-126; origin 5, 65, 66-68; Smith's use of the term 50-51; visualization 3, 4, 133

exchange as relation of equality $4,10,17$, 20-22, 24, 28-29, 44, 62, 66, 70, 71-72, 73-74, 127, 130, 137 n.12

exchange relation $42-43,134,141 \mathrm{n} .2$; Aristotelian 17-23; Clower's 115, 117, 120-121; Smith's 51, 54

exchange-value $5,67,72-74,77$, $79,82,141 \mathrm{n} .2$; see also value in exchange

fairness in exchange $13-14,17,23,28$, 38,42

fairs of middle ages $3,7,46,113,133$

Fibonacci, L. 31

Finley, M. I. 13, 16

Fried, Joel 128
Galbraith, J. K. 88-89

Galileo Galilei 24, 27, 44

Hadden, R. W. 27, 42

Hahn, F. H. 111, 128

Harris, Joseph 48, 49

Hasebroek, Johannes 16

Heichelheim, F. M. 14-15

Herodotus 20

Hicks, John R. 4, 128, 136 n.2; critique of Walrasian general equilibrium theory $2-3,6,7,110-111,113,133$

higgling and haggling 63, $140 \mathrm{n} .17$

Hirschleifer, Jack 128

Hollander, S. 30

Howitt, Peter 111,128

Humphrey, C. 87-88

indirect exchange $3,5,17,19,20,23,44$, $98,102,104,120,121,124,125,131$

investment: in ancient times 16

Jaffe, W. 100, 142 n.9

Jevons, William Stanly 4, 5, 13, 84, 108, $142 \mathrm{n} .1$; origin of money $84-85$, 86-87; scientific theory of exchange 6 , $85,93-97,105-106,133$; theory of difficulties of barter 5-6, 85-89, 105, 128,133 ; utility theory $91-92,105$, 106,108 ; value in exchange 93-94, 100,106 ; value in use 93,94 ; view of value 93, 106

"just price" 34, 44-45, 138 n.19; and equality of exchange 41-43

just price theory $5,27,28,29-31,45$

Kaye, Joel 27, 30-31, 44, 137 n.12

Keynes, John Maynard 1, 2, 110, 114, 136 n. 2

Krause, Ulrich 82, 123-126, 144 n.13, 144 n. 15

labor: abstract concept 13, 27, 69-70, 139 n.8; Aquinas concept 29; exchange of labor for money/goods 26,27

labor theory of value $13,58-61,62$

Langholm, O. 27, 30

Leonardo of Pisa 31

Levy, Jean-Philippe 15

Lowery, S. T. 14

Magnus, Albertus 29, 30

Marget, Arthur 109-111, 112 
marginal utility theory 113

market economy: primitive-modernist controversy $14-17$

market price 41

markets: growth in medieval ages 27

market (supply-demand) theory 30

Marshall, Alfred 1, 2, 101, 107, 140 n.17

Marx, Karl 4, 13, 62, 142 n.9; dating of capitalism 27; first point of departure in Capital 77, 79-82, 132; influence of Aristotle 5, 66, 74, 75, 83, 132; knowledge of primitive communities 66,140 n.1; monetary theory $82-83$, 131-132; origin of money 65-66, 67-69, 75-76, 77, 83, 132; perfection of Aristotelian equation 5, 66, 69-71, 83, 132; reading of Aristotle 66, 67; second point of departure in Capital 75-79, $141 \mathrm{n} .13$; theory of barter $66-67,68$, $77,78-79,83,105,141$ n.6; value in exchange 73-74, 142 n.9

matrix of exchange: based on medieval economy 109, 117-120; Clower's 6, 109, 113-116, 117, 127; comparison of Clower's and matrices of medieval exchange 120-121; post-Clower 109 , 121-126

medieval economy $3,4-5,43-44$, 134-135; justice in exchange 28-31; see also abacus manuscripts

Meek, Ronald 76

Meikle, S. 9, 13, 14, 20, 22

Meltzer, Allan 128

Mill, John Stuart 93, 94, 101

monetary theory $1-2,4,7-8,130-131$;

Aristotelian 3-4, 9-10, 23-25, 47, 130;

Aristotelian influence 4, 5, 9-10, 25,

44, 66, 74, 85, 130, 132-133;

evolutionary path $2-3,7,135$;

Marx's 82-83, 131-132; in

medieval ages 26-28; Smith's

47, 131

money: importance of 110 ; as medium of exchange 10,39, 40; and non-money commodities distinction 3, 4, 96

money, origin of 4, 131, 133; Aristotelian 10-11, 17, 24; Jevons's theory 5-6, 84-85, 86-87; Marx's theory 65-66, 67-69, 75-76, 77, 83, 132; metallic money 49-50; Oresme's theory 26, 27-28, 39

Monroe, A. E. 39, 130, 136 n.1
Nagel, E. 7

neo-Walrasianism 6, 112-117, 127;

Clower's critique $6,109,114-115,123$, 127, 133-134

Oresme, Nicholas 4, 27, 28, 137 n.8

Ostroy, Joseph 111, 122-123, 128

"overprice" 34, 41-42, 138 n.20

Pacioli, Luca 42

Pareto, V. 100, 142 n.9

Patinkin, Don 2, 20, 113-114, 116, 121, 122,143 n. 5,143 n. 10

Perlman, Morris 128

Plato 11, 48

Polanyi, Karl 15, 16, 46

primitive communities: development of money form 68-69; exchange of commodities 66-67, 68, 82, 83, 84, 105, 132; Marx's knowledge of 66, 140 n. 1

primitivist-modernist controversy $4,9-10$, 14-17

production: cost of 29-30, 44-45

purchasing power (ratio of exchange) 93-94, 96

"real" 6,7

realism 6-7; economic theory 7, 109

Recorde, Robert 21

Ricardo, David 2, 58, 61, 62, 101, 131, 139 n.9, 142 n.11

Schumpeter, J. 9, 10, 13-14

science of economics $6,85,89-93$

scientific realism 7

scientific theory of exchange 108,133 ; Jevons's 6, 85, 93-97, 105-106; Walrasian 6, 97-102, 103-104, 106 simple barter $36-37$

simple commodity 79-81, 132

simple commodity production 5 , $76,79,81$; see also barter, Marx's theory

Smith, Adam 4, 46, 74, 91, 96; barter theory 47-49, 105, 139 n.1; critique of Smith's exchange theory $62-63$; exchange theory $47-49,50-52,105$, $139 \mathrm{n} .1$; solution to equation of exchange 59-61; value in exchange 51, $53,54-56,94,140$ n. 13 ; value in use $52-53,56,93,94$

Soudek, J. 13

Spufford, Peter 40, 138 n.18 


\section{Index}

Sraffa, P. 61

Starr, R. M. 122-123, 128

stock exchange 102-103, 112

substance of exchange: Aquinas's

28-29; Aristotelian 11, 13, 17,

22-23, 24, 28, 70; Marx's 70;

Smith's 47, 131

Swetz, F. J. 31, 32, 33, 138 n.18

theory of value 108

Thornton, William 63-64

Tobin, J. 108

"true price" see "cash price"

use-value $66-67,71,72-73,74,78,79$, 80, 82; see also value in use

utility theory of exchange 6; Aristotelian

13; Bentham's 91; Jevons's 91-92, 105, 106, 108; Walrasian 104

value 137 n.6, 137 n.8; Jevons's view 93, 106; as ratio of exchange 89-90

value form $77-78,109,128,132$, $141 \mathrm{n} .13$

value in exchange 18; Jevons's 93-94, 100, 106; Marx's 73-74, 142 n.9; other definitions 100; Smith's 51, 53, 54-56,
94; Walras's 98-101; see also exchange-value

value in use 18, 56; Jevons's (total utility)

93, 94; Smith's 51, 52-53, 56, 93, 94;

see also use-value

Van Der Wee, Herman 33

Van Egmond, W. 32, 33, 34, 40, 138 n.14

Vogel, Kurt 34, 35, 36, 39, 42

Walker, Donald 111-112, 143 n.3

Walrasian general equilibrium theory 6 , 104-105, 108-109, 126, 133; Hicks's critique $2-3,6,7,110-111,113,133$; incorporation of money in 109 ,

113-114, 128; realistic or unrealistic controversy 109-112, 126-127;

Starr's critique 122 ; see also neo-Walrasianism

Walras, Léon 4, 6, 85, 89, 106, 142 n.9, 143 n.12; buying and selling 102-105; price 102, 103; scientific theory of exchange 6,103-104, 103-104, 106, 133; value in exchange $98-101$

Weber, Max 16

Wicksteed, Philip Henry 90, 93, 100

Wood, Diana 27, 39, 137 nn.2, 7 



